Uso da técnica de teste estrutural para o teste e monitoração de serviços

\author{
Marcelo Medeiros Eler
}



SERVIÇO DE PÓS-GRADUAÇÃO DO ICMC-USP

Data de Depósito:

Assinatura:

\title{
Uso da técnica de teste estrutural para o teste e monitoração de serviços
}

\author{
Marcelo Medeiros Eler
}

Orientador: Prof. Dr. Paulo Cesar Masiero

Tese apresentada ao Instituto de Ciências Matemáticas e de Computação - ICMC-USP, como parte dos requisitos para obtenção do título de Doutor em Ciências - Ciências de Computação e Matemática Computacional. VERSÃO REVISADA

USP - São Carlos

Julho de 2012 
Ficha catalográfica elaborada pela Biblioteca Prof. Achille Bassi e Seção Técnica de Informática, ICMC/USP, com os dados fornecidos pelo(a) autor(a)

E37u $\begin{aligned} & \text { Eler, Marcelo Medeiros } \\ & \text { Uso da técnica de teste estrutural para o teste e } \\ & \text { monitoração de serviços / Marcelo Medeiros Eler; } \\ & \text { orientador Paulo Cesar Masiero. -- São Carlos, 2012. } \\ & \text { 132 p. } \\ & \text { Tese (Doutorado - Programa de Pós-Graduação em } \\ & \text { Ciências de Computação e Matemática Computacional) -- } \\ & \text { Instituto de Ciências Matemáticas e de Computação, } \\ & \text { Universidade de São Paulo, 2012. } \\ & \text { 1. Engenharia de Software. 2. Computação Orientada } \\ & \text { a Serviços. 3. Teste de Software. 4. Teste } \\ & \text { Estrutural. 5. Monitoração. I. Masiero, Paulo Cesar, } \\ & \text { orient. II. Título. }\end{aligned}$


Agradeço a Deus, em primeiro lugar, e a Jesus Cristo, seu filho, porque Dele por Ele e para Ele são todas as coisas (S. Paulo, Romanos 11:36). Agradeço aos meus pais, Rubens e Glória, pela educação que me deram, pelo incentivo e pelo apoio incondicional em todos os momentos. Agradeço a minha irmã Daniela e minha cunhada Juliana pela amizade e companherismo que sempre demonstraram. Agradeço em especial ao meu irmão Danilo, amigo e companheiro de jornada desde pequenos, passando pelo colégio, graduação, mestrado e doutorado. Agradeço especialmente à minha esposa Amanda que esteve ao meu lado em todos os momentos, pacientemente, acompanhando e apoiando meu trabalho tanto aqui quanto no exterior. Agradeço também a minha nova família, Samuel e Jane, meus sogros, e meu cunhado Anderson, pela amizade e incentivo.

Quero agradecer especialmente ao Prof. Paulo Cesar Masiero pela confiança em mim depositada e pela forma com que, pacientemente, conduziu esta orientação. Sua ética, profissionalismo, competência e dedicação em tudo o que faz serão sempre lembrados como virtudes a serem exercitadas e buscadas em minha carreira profissional. Agradeço também ao Prof. Márcio Eduardo Delamaro pelas sugestões de melhoria do trabaho ao longo desses anos. Quero também expressar minha gratidão especial à Antonia Bertolino, minha orientadora no período que estive na Itália para o doutorado sanduíche. Ao Prof Rogério Garcia, que foi quem me incentivou a ingressar no mestrado e trilhar este caminho.

Aos meus amigos Beltranos, que têm sido companheiros de uma vida toda; aos amigos da Igreja Batista Unida de Martinópolis e da Primeira Igreja Batista de São Carlos; aos novos e antigos amigos e professores do LabES, com os quais tive o prazer de compartilhar este tempo de formação, desde o meu mestrado; aos demais amigos e funcionários do ICMC e da USP de São Carlos, muito obrigado.

Quero agradecer especialmente ao André Endo, pelas conversas, discussões e pela parceria na criação do serviço JaBUTiWS.

Agradeço támbém especialmente à FAPESP pelo financiamento desta pesquisa. 

That day, for no particular reason, I decided to go for a little run. So I ran to the end of the road. And when I got there, I thought maybe I'd run to the end of town. And when I got there, I thought maybe I'd just run across Greenbow County. And I figured, since I run this far, maybe I'd just run across the great state of Alabama. And that's what I did. I ran clear across Alabama. For no particular reason I just kept on going. I ran clear to the ocean. And when I got there, I figured, since I'd gone this far, I might as well turn around, just keep on going. When I got to another ocean, I figured, since I'd gone this far, I might as well just turn back, keep right on going. (...) When I had to go... you know... I went. 

Lista de Figuras $\quad$ v

$\begin{array}{lll}\text { Lista de Tabelas } & \text { vii }\end{array}$

$\begin{array}{ll}\text { Lista de Listagens } & \text { ix }\end{array}$

Resumo $\quad$ xi

$\begin{array}{ll}\text { Abstract } & \text { xiii }\end{array}$

1 Introdução $\quad 1$

1.1 Contexto: engenharia de software e serviços . . . . . . . . . . . . . 1

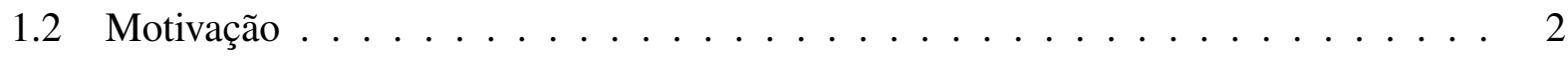

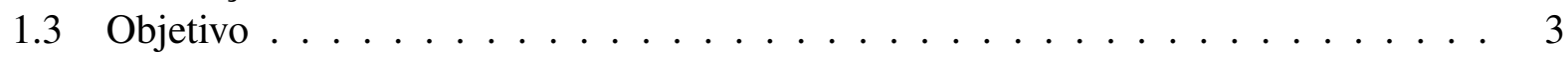

1.4 Organização . . . . . . . . . . . . . . . . . . . . 4

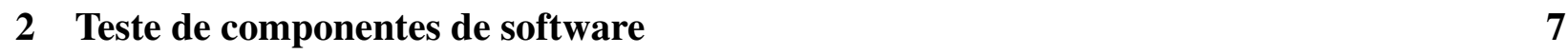

2.1 Considerações iniciais . . . . . . . . . . . . . . . . . . 7

2.2 Componentes de software . . . . . . . . . . . . . . . . 8

2.3 Fatores a serem considerados no teste de componentes . . . . . . . . . . . . . 9

2.4 Abordagens de teste de componentes . . . . . . . . . . . . . . . . . 11

2.4 .1 Teste embutido . . . . . . . . . . . . . . . . . 12

2.4 .2 Metadados . . . . . . . . . . . . . . . . 15

2.5 Considerações finais . . . . . . . . . . . . . . . . 17

3 Teste de serviços $\quad 19$

3.1 Considerações iniciais . . . . . . . . . . . . . . . . . . . . . . . . . . . . . . . . . . . .

3.2 Arquitetura Orientada a Serviços . . . . . . . . . . . . . . . . 20

3.3 Testabilidade de serviços . . . . . . . . . . . . . . . . 23

3.4 Técnicas e critérios de teste para serviços . . . . . . . . . . . . . . 24

3.4 .1 Teste de Unidade . . . . . . . . . . . . . . . . . . . . . 26

3.4 .2 Teste de Integração . . . . . . . . . . . . . . . . . . . . 28

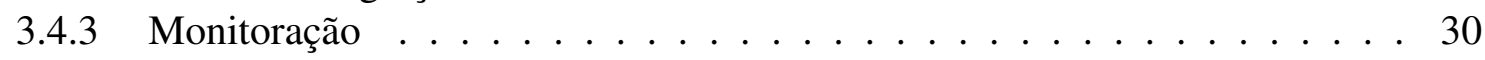

3.5 Considerações finais $\ldots \ldots \ldots \ldots \ldots$ 
4 Uma abordagem de teste estrutural de serviços $\quad 35$

4.1 Considerações Iniciais . . . . . . . . . . . . . . . . . . . 35

4.2 Desenvolvedor . . . . . . . . . . . . . . . . 37

4.2 .1 Instrumentação . . . . . . . . . . . . . . . . . . . . . . . . . . . . .

4.2.2 Especificar e implementar uma interface de teste . . . . . . . . . . . 38

4.2.3 Especificar metadados de teste . . . . . . . . . . . . . . . . . 40

4.3 Serviço de Teste . . . . . . . . . . . . . . . . . . . . . . 41

4.4 Integrador . . . . . . . . . . . . . . . . . . . . . . . . . . . . . .

4.4.1 Teste de um serviço testável isoladamente . . . . . . . . . . . . . . . . 43

4.4.2 Teste de um serviço testável no contexto de uma aplicação . . . . . . . . . . . 44

4.5 Governança . . . . . . . . . . . . . . . . . . . . . 46

4.6 Comparação da abordagem BISTWS com trabalhos relacionados . . . . . . . . . . 48

4.7 Considerações finais . . . . . . . . . . . . . . . . . 50

5 Uma instânciação da abordagem BISTWS

5.1 Considerações iniciais . . . . . . . . . . . . . . . . . 53

5.2 JaBUTiWS - um serviço para apoiar o teste estrutural de programas Java . . . . . . 54

5.2 .1 Uma visão geral do serviço de teste . . . . . . . . . . . . . . . . . 54

5.2 .2 Exemplo de uso . . . . . . . . . . . . . . . . . 58

5.2 .3 Aplicações ........................... 60

5.3 JaBUTiWS: uma instânciação do Serviço de Teste da abordagem BISTWS . . . . . 60

5.3 .1 Instrumentação . . . . . . . . . . . . . . . . . . 61

5.3.2 Cálculo de cobertura estrutural . . . . . . . . . . . . . . 63

5.3 .3 Metadados ........................ 64

5.3.4 Um exemplo de uso da abordagem BISTWS para testar um serviço isoladamente . . . . . . . . . . . . . . . . . . . 6 64

5.4 Um estudo de caso usando a abordagem BISTWS para testar um serviço no contexto de uma aplicação . . . . . . . . . . . . . . . . . . . . . . 68

5.4 .1 Primeira iteração . . . . . . . . . . . . . . . . . 72

5.4 .2 Segunda iteração . . . . . . . . . . . . . . . . . 73

5.4.3 Comparação com geração randômica de casos de teste . . . . . . . . . . . 74

5.4 .4 Resposta às questões de pesquisa . . . . . . . . . . . . . . . 75

5.4 .5 Ameaças à validade do estudo . . . . . . . . . . . . . . . . 76

5.4.6 Análise de overhead de código instrumentado . . . . . . . . . . . . . 76

5.5 Um experimento realizado para avaliar a abordagem BISTWS . . . . . . . . . 77

5.5 .1 Definição das hipóteses . . . . . . . . . . . . . . . . . 78

5.5 .2 Sujeitos e objetos experimentais . . . . . . . . . . . . . 79

5.5 .3 Preparação . . . . . . . . . . . . . . . . . . 79

5.5 .4 Operação . . . . . . . . . . . . . . . . . . . 79

5.5 .5 Resultados ........................... 80

5.5 .6 Ameaças à validade do experimento . . . . . . . . . . . . . 81

5.5 .7 Discussão . . . . . . . . . . . . . . . . 85

5.6 Considerações Finais . . . . . . . . . . . . . . . . . . . . 86

6 Uma abordagem de monitoração de serviços testáveis $\quad 89$

6.1 Considerações iniciais . . . . . . . . . . . . . . . . . . . . . 89

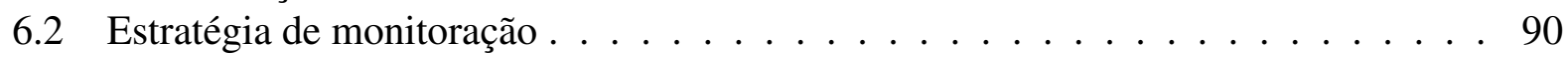

6.2.1 Configuração . . . . . . . . . . . . . . . . . 90 
6.2 .2 Monitoração . . . . . . . . . . . . . . . . . . . . . 99 91

6.2 .3 Implementação . . . . . . . . . . . . . . . . . . . . . . . . . . 94

6.3 Estudos de caso . . . . . . . . . . . . . . . . . . . . 96

6.3.1 Estudo exploratório 1: monitoração de um serviço simples . . . . . . . . . 97

6.3.2 Estudo exploratório 2: monitoração de um serviço testável no contexto de uma aplicação . . . . . . . . . . . . . . . . . . . . . 100

6.3.3 Estudo exploratório 3: monitoração em um contexto mais realístico . . . . 103

6.4 Comparação da abordagem de monitoração de serviços testáveis com uma abordagem funcional . . . . . . . . . . . . . . . . . . . . . . . 104

6.4.1 Definição das hipóteses . . . . . . . . . . . . . . . . . 105

6.4 .2 Sujeitos e objetos experimentais . . . . . . . . . . . . . 106

6.4 .3 Operação do experimento . . . . . . . . . . . . . . . . . 106

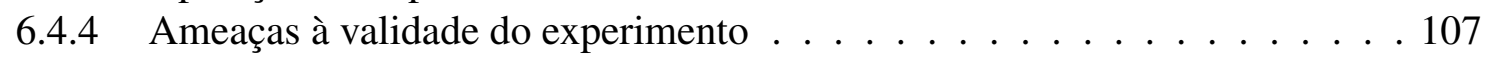

6.4.5 Análise dos dados do experimento . . . . . . . . . . . . . . . . 107

6.4 .6 Teste de hipóteses . . . . . . . . . . . . . . . . . . 110

6.5 Trabalhos relacionados . . . . . . . . . . . . . . . . 111

6.6 Considerações finais . . . . . . . . . . . . . . . . . . 113

7 Conclusão $\quad 115$

7.1 Considerações Finais . . . . . . . . . . . . . . . . . . . . 115

7.2 Contribuições . . . . . . . . . . . . . . . . . . 116

7.3 Trabalhos Futuros . . . . . . . . . . . . . . . 118

$\begin{array}{ll}\text { Referências } & 121\end{array}$ 



\section{Lista de Figuras}

2.1 Um componente testável. . . . . . . . . . . . . . . . . . . . . . 13

2.2 Uma arquitetura genérica de componentes testáveis e testadores. . . . . . . . . . 13

3.1 Arquitetura Orientada a Serviços. . . . . . . . . . . . . . . . . . . . 22

3.2 Uma ilustração da abordagem SOCT . . . . . . . . . . . . . . . . . . . . . 28

4.1 Uma ilustração da abordagem BISTWS . . . . . . . . . . . . . . . . . 37

4.2 Diagrama de sequência de uma sessão de teste de um serviço testável . . . . . . . . 44

4.3 Diagrama de sequência de uma sessão de teste de um serviço testável usado no contexto de uma aplicação . . . . . . . . . . . . . . . . . . . . . . . 45

5.1 Arquitetura do JaBUTiWS. . . . . . . . . . . . . . . . . . . . 56

5.2 Máquina de estado de um projeto de teste criado com o JaBUTiWS . . . . . . . . . 57

5.3 Diagrama de classes de ShippingWS. . . . . . . . . . . . . . . . 65

5.4 Interface gráfica usada para gerar um serviço testável . . . . . . . . . . . . . 66

5.5 Diagrama de sequência usado pelo integrador para testar ShippingWS . . . . . . 68

5.6 Ilustração da composição RegisterService . . . . . . . . . . . . . . . . . . . 69

5.7 Diferenças entre os sujeitos que usam a abordagem funcional e os que usam a abordagem BISTWS . . . . . . . . . . . . . . 78

5.8 Boxplots feitos para os resultados do experimento . . . . . . . . . . . . . 82

5.9 Boxplots da cobertura estrutural considerando cada nível de experiênciao dos sujeitos 83

5.10 Boxplots do número de falhas encontradas considerando cada nível de experiênciao dos sujeitos . . . . . . . . . . . . . . . . 83

5.11 Boxplots da cobertura alcançada pelos sujeitos usando a abordagem BISTWS considerando cada nível de experiência . . . . . . . . . . . . . . 84

5.12 Boxplots da cobertura alcançada pelos sujeitos usando a abordagem Funcional considerando cada nível de experiência . . . . . . . . . . . . . 85

5.13 Boxplots do número de falhas encontradas com a abordagem BISTWS considerando a experiência dos sujeitos . . . . . . . . . . . . . . 85

5.14 Boxplots do número de falhas encontradas com a abordagem funcional considerando a experiência dos sujeitos . . . . . . . . . . . . . 86

6.1 Ilustração de uma estratégia de monitoração de um serviço testável . . . . . . . . . 91

6.2 Diagrama de classes do framework de monitoração . . . . . . . . . . . . . . . 95

6.3 Código fonte e grafo de fluxo de controle da operação calcFactorial . . . . . 97

6.4 As quatro alterações sofridas por WSFactorial . . . . . . . . . . . . . 98 
6.5 Ilustração da aplicação ShoppingService . . . . . . . . . . . . . . . . . . . . 100

6.6 Boxplots dos resultados do experimento . . . . . . . . . . . . . . . . . . 109

6.7 Boxplot dos resultados do experimento considerando a monitoração de BankWS . 109

6.8 Boxplot dos resultados do experimento considerando a monitoração de BankWS IRWS . . . . . . . . . . . . . . . . . . . 110 


\section{Lista de Tabelas}

2.1 Abordagens de teste orientado a objetos aplicadas a componentes. . . . . . . . . 11

3.1 Abordagens de teste de unidade . . . . . . . . . . . . . . . . . . 27

3.2 Abordagens de teste de integração . . . . . . . . . . . . . . . . . . . . . . 29

3.3 Abordagens de monitoração . . . . . . . . . . . . . . . . . 31

5.1 Operações da interface do serviço JaBUTiWS . . . . . . . . . . . . . . . 56

5.2 Cobertura estrutural obtida com a execução dos casos de teste da biblioteca ApacheCommons-BeanUtils usando o JaBUTiWS . . . . . . . . . . . . . . . . . . 59

5.3 Interface de ShippingWS com as operações de teste . . . . . . . . . . . . . . 66

5.4 Casos de teste fornecidos como metadado do tipo a priori de ShippingWS . . . . 67

5.5 Casos de teste criados pelo integrador para testar ShippingWS isoladamente . . . 67

5.6 Análise de cobertura estrutural dos casos de teste do integrador . . . . . . . . . . 69

5.7 Casos de teste de CustomerService . . . . . . . . . . . . . . . 70

5.8 Cobertura alcançada pela execução dos metadados de teste de CustomerService 70

5.9 Cobertura estrutural obtida pelo integrador ao testar Cust omerServi ce no contexto da composição RegisterService . . . . . . . . . . . . . 71

5.10 Perfil de uso criado pelo integrador para usar CustomerService . . . . . . . 72

5.11 Cobertura estrutural de CustomerServi ce na primeira iteração de uso dos metadados gerados sob demanda . . . . . . . . . . . . . . . . . 73

5.12 Cobertura estrutural obtida para CustomerService na segunda iteração . . . . 74

5.13 Cobertura obtida pelos casos de teste gerados randomicamente . . . . . . . . 75

5.14 Análise de overhead . . . . . . . . . . . . . . . . . . . 77

5.15 Projeto do experimento . . . . . . . . . . . . . . . . . . 80

5.16 Resultados do experimento . . . . . . . . . . . . . . 81

6.1 Tipos de mudanças sofridas por um serviço e as reações sugeridas . . . . . . . . . 93

6.2 Requisitos de teste de calcFactorial . . . . . . . . . . . . . . . 97

6.3 Conjunto de regressão para monitorar WSFactorial . . . . . . . . . . . . 97

6.4 Mudanças sofridas por WSF actorial detectadas pelo framework de monitoração 99

6.5 Cobertura estrutural obtida para cada versão de WSFactorial . . . . . . . . . . . . 99

6.6 Casos de teste criados para ShoppingService . . . . . . . . . . . . . . . . . 102

6.7 Resultados da monitoração dos mutantes de ShippingService . . . . . . . . 103

6.8 Projeto do experimento . . . . . . . . . . . . . . . . . . 106

6.9 Pontuação de cada monitorador com base nos resultados do experimento . . . . . . 108 



\section{Lista de Listagens}

5.1 Trecho do script usado para invocar o JaBUTiWS . . . . . . . . . . . . . . . 59

5.2 Arquivo de propriedades de um serviço testável criado com o JaBUTiWS . . . . . 62

5.3 Estrutura XML dos metadados do tipo a priori . . . . . . . . . . . . . . . 64

6.1 Trecho de código usado para instanciar o framework de monitoração . . . . . . . . . 101 

A computação orientada a serviços propõe o desenvolvimento de software por meio da composição de serviços com os objetivos de aumentar o reúso de software e facilitar a criação de aplicações dinâmicas, flexíveis e com baixo acoplamento. O uso de serviços no desenvolvimento de software só é possível se os desenvolvedores de aplicações (integradores) confiarem na qualidade dos serviços oferecidos por terceiros. Uma forma de aumentar a confiança sobre serviços adquirido de terceiros é a realização de testes. Entretanto, o teste de serviços é difícil porque os testadores ficam limitados a usar técnicas de teste baseadas em especificação por causa da indisponibilidade do código fonte. Nesse contexto, os testadores não podem usufruir dos benefícios de combiná-las com técnicas baseadas em implementação, como a técnica estrutural, por exemplo. Uma abordagem para viabilizar o uso da técnica de teste estrutural no contexto de aplicações baseadas em serviços sem expor o código fonte dos serviços é apresentada. Ela propõe a criação de serviços testáveis, que são serviços com alta testabilidade e que possuem uma interface de teste cujas operações apoiam o teste estrutural. Integradores podem realizar o teste de um serviço testável e obter, sem acessar o código fonte, uma análise de cobertura. Metadados de teste também são fornecidos pelos serviços testáveis para auxiliar integradores na obtenção de uma cobertura estrutural maior. A abordagem também apoia atividades de monitoração ativa de serviços. A abordagem é genérica uma instanciação para apoiar o teste estrutural de serviços e aplicações escritos em Java é apresentada. Estudos de casos e experimentos controlados foram realizados para validar a abordagem instanciada. Os resultados mostram que a abordagem é viável e apresenta bons resultados quando comparada com o uso apenas da técnica funcional. 

Software oriented computing aims at developing software by the composition of services. It promotes software reuse and the implementation of dynamic, flexible and low coupling applications. Services provide specific business functionalities and are provided as a black-box. The use of services is only possible if the developers of service applications (integrators) trust the third party services. Particularly, testing is one of the solutions to obtain confidence on third party software. However, testers can only use specification based testing techiniques due to unavailability of the source code. In this context, testers cannot use the benefits of combining specification and implementation-based testing techniques. This works aims at proposing an an approach to introduce the structural testing technique in the context of service-based applications, but without revealing the source code. The proposed approach promotes the development of testable services, which are services with high testability and exposes operations through a testing interface to support structural testing. Integrators can test testable services and get, without having access to the source code, a coverage analysis on structural criteria. Test metadata are also provided along with testable services to help integrators on creating more test cases to increase the coverage obtained. The proposed approach is also used to support monitoring activities. The approach is generic and an instantiation is presented to create testable services written in Java. Formal experiments and case studies were conduct to validate the proposed approach and the instantiation. The results provide evidences of the applicability and the benefits of the approach for both testing and monitoring activities when compared to only using the functional approach. 



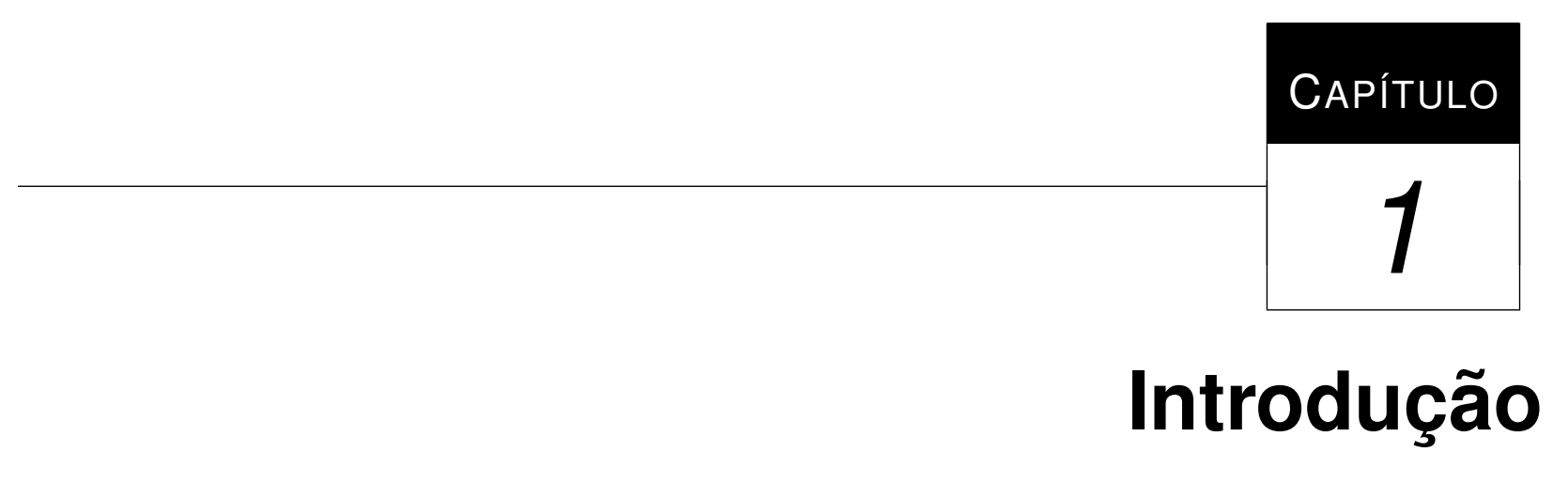

\subsection{Contexto: engenharia de software e serviços}

A Engenharia de Software surgiu na década de 60 com o objetivo de solucionar os principais problemas relacionados ao desenvolvimento de software, como, por exemplo, estimativas de custo e de prazo imprecisas, baixa produtividade dos profissionais e baixa qualidade dos produtos desenvolvidos (Pressman, 2002). Seu principal objetivo é sistematizar o processo de produção, operação e manutenção de sistemas de software (IEEE, 1990).

Esses problemas ficaram mais evidentes quando mais empresas passaram a depender de sistemas de software para operar seus negócios. O surgimento da Engenharia de Software contribuiu significativamente para a melhoria da indústria de desenvolvimento de software, mas o cenário atual enfrenta, inevitavelmente, os mesmos problemas com prazos, custos, qualidade e falta de profissionais qualificados (Valle, 2011).

A demanda de software e de profissionais qualificados aumentou na última década por causa do baixo custo e da alta disponibilidade da tecnologia, que fizeram com que sistemas de software passassem a fazer parte do cotidiano das pessoas, tanto no ambiente profissional quanto no particular. Novas linguagens e paradigmas de programação e de desenvolvimento de software surgiram para acompanhar esse crescimento e para adequar o software aos seus vários domínios de aplicação.

As linguagens e os paradigmas de programação evoluíram de modo a decompor os sistemas em partes mais gerenciáveis para diminuir a complexidade de seu desenvolvimento, aumentar sua flexibilidade, compreensibilidade, manutenibilidade e reusabilidade (Parnas, 1972; Tarr et al., 1999; Ossher e Tarr, 2000). A decomposição de sistemas em módulos autocontidos e gerenciáveis possibilitou o aumento da reusabilidade de software que, segundo Pressman (2002), pode ser definida 
como a medida em que um programa (ou partes dele) pode ser reusado em outras aplicações e contextos.

Nesse cenário surgiram abordagens que promovem o reúso de software para diminuir o tempo e o custo de desenvolvimento. Essas abordagens partem do princípio de que existem muitas aplicações semelhantes e que partes delas podem ser reusadas para construir sistemas semelhantes. Entre as abordagens que promovem o reúso de software está o Desenvolvimento Baseado em Componentes (DBC), que tem o foco nas técnicas e práticas usadas para construir sistemas de software a partir de componentes previamente existentes. Os componentes usados na construção do software podem ser implementados localmente ou adquiridos de terceiros. O foco deste paradigma de desenvolvimento está na identificação, qualificação, adaptação, integração e atualização de componentes de software reusáveis (Szyperski, 1998; Kunda e Brooks, 2000; Pressman, 2002).

O crescimento do uso da internet como ferramenta corporativa para fazer negócios e a evolução do conceito de componentes e sistemas distribuídos levou ao surgimento da computação orientada a serviços, em que os blocos fundamentais de construção de um software são serviços disponíveis em pontos diferentes de uma rede (Tsai, 2005; Gross, 2005; Baresi et al., 2006). De forma particular, um novo estilo arquitetural foi introduzido, a Arquitetura Orientada a Serviços (do inglês SOA - Service Oriented Architecture), em que fornecedores utilizam repositórios para distribuir seus serviços e os consumidores os utilizam para encontrar serviços necessários para a composição de sua aplicação. A composição de serviços pode ser feita dinâmica e automaticamente em tempo de execução.

Diferentemente do desenvolvimento baseado em componentes, os serviços que compõem as aplicações não são fisicamente implantados do lado da aplicação (Gross, 2005). Nesse caso, os desenvolvedores das aplicações usam contratos de utilização dos serviços para garantir que eles estarão disponíveis durante o tempo de contrato e atendendo a níveis de qualidade especificados (SLA - Service Level Agreement) (Canfora e Penta, 2009).

O desenvolvimento de aplicações baseadas em serviços foi concebido para promover, além do reúso, a criação de aplicações altamente dinâmicas e flexíveis. Essas aplicações possuem fraco acoplamento, não dependem de tecnologia de implementação e facilitam a integração de sistemas heterogêneos (Papazoglou et al., 2008).

\subsection{Motivação}

Apesar de prometer trazer diversas vantagens para o desenvolvimento e para a manutenção de sistemas de software, as aplicações baseadas em serviços não têm sido amplamente adotadas, principalmente por problemas de confiança nos serviços fornecidos por terceiros (Bozkurt et al., 2012). Uma das formas de resolver a questão da confiança é a aplicação de técnicas de teste para avaliar se os serviços possuem a qualidade esperada, tanto para os requisitos funcionais quanto para os requisitos não funcionais. Por isso é natural pensar que os consumidores dos serviços desejam 
testá-los antes de usá-los, quer seja por não confiar no teste realizado pelos fornecedores quer seja por querer avaliar a qualidade do serviço em diferentes perspectivas e contextos de utilização (Weyuker, 1998).

Testar um serviço isoladamente ou sua integração com outros serviços no contexto de uma aplicação, entretanto, é uma tarefa desafiadora. Segundo Canfora e Di Penta (2006), serviços possuem baixa testabilidade e seu teste isolado é limitado porque é difícil de controlá-lo e observá-lo, já que eles são invocados remotamente e somente por meio de suas interfaces. Testar a integração de um serviço com outros serviços também pode ser difícil quando os serviços usados na aplicação serão conhecidos apenas em tempo de execução ou podem ser substituídos por outros serviços ou outras versões sem notificação prévia. Além disso, os serviços sempre estão em ambiente de produção e não em ambiente de teste e, portanto, os casos de teste executados representam operações de negócio reais e não apenas simulações. Também podem existir custos associados ao teste de serviços quando eles são cobrados por uso ou quando permitem apenas um número reduzido de invocações gratuitas por um período determinado (Hou et al., 2008).

Em particular, a baixa testabilidade dos serviços é uma limitação que, segundo Canfora e Penta (2009), é percebida diferentemente por diferentes perspectivas relacionadas ao teste de serviços. O desenvolvedor do serviço possui o código fonte e pode testar o serviço usando tanto a técnica funcional quanto a técnica estrutural. O integrador, que é o responsável por combinar os serviços e criar uma aplicação, consegue realizar o teste estrutural da aplicação, mas não consegue usar critérios estruturais para testar tanto o serviço isoladamente quanto sua integração com os outros serviços. O certificador, que é uma entidade independente responsável por avaliar a qualidade de serviços desenvolvidos por terceiros, possui as mesmas limitações experimentadas pelo integrador.

Segundo Myers (1979), é desejável que testadores utilizem mais de uma técnica de teste para revelar os erros de uma aplicação. Em especial, as técnicas de teste funcional e estrutural são complementares. A primeira procura garantir que todas as funcionalidades do sistema foram testadas e a segunda procura garantir que todas as partes do código foram exercitadas. A baixa testabilidade dos serviços impede que os benefícios deste tipo de combinação estejam presentes no teste de serviços e de aplicações baseadas em serviços. Esta dificuldade enfrentada pelas perspectivas de teste, entretanto, também traz consigo uma oportunidade de pesquisa.

\subsection{Objetivo}

A tese subjacente a este trabalho é de que é possível e benéfico o uso de teste estrutural de serviços, combinado com teste funcional, mesmo usando critérios de teste que, para serem aplicados, exigem que o código fonte esteja disponível. Nesse contexto, o objetivo desta tese de doutorado é propor uma abordagem de teste para possibilitar a aplicação da técnica de teste estrutural no teste de serviços sem, contudo, ferir o princípio de encapsulamento promovido por este estilo de 
desenvolvimento. A abordagem proposta chama-se BISTWS (Built-in Structural Testing of Web Services) e apoia principalmente as perspectivas do desenvolvedor e do integrador de serviços.

A abordagem proposta apoia o desenvolvedor na criação de serviços mais transparentes e capazes de fornecer a seus clientes facilidades para a realização de teste estrutural. Os serviços criados segundo a abordagem são chamados de serviços testáveis. Ela é genérica, tratando-se de um arcabouço conceitual (framework) que pode ser instanciado para diferentes tipos de plataformas de desenvolvimento e vale-se integralmente do conceito de serviços para a instrumentação, execução e cálculo da cobertura obtida. A proposta é validada com uma instanciação para o ambiente da linguagem Java e por meio de estudos de caso e experimentos controlados.

A abordagem também tem o objetivo de apoiar o integrador, que pode utilizar as facilidades de teste oferecidas pelos serviços testáveis para usar a técnica de teste estrutural para testar os serviços, tanto isoladamente quanto no contexto de uma aplicação em que eles estão integrados. Além disso, a abordagem também permite que os integradores usem informações de teste estrutural fornecidas pelos serviços testáveis para apoiar as atividades de monitoração.

\subsection{Organização}

Este trabalho está dividido da seguinte forma. No Capítulo 2 é apresentada uma visão geral sobre o desenvolvimento baseado em componentes e os fatores relacionados à atividade de teste de componentes. São discutidas as dificuldades inerentes à atividade de teste considerando a baixa testabilidade dos componentes e as soluções encontradas por pesquisadores para amenizar essas limitações. Componentes e serviços possuem muitas similaridades (Gross, 2005) e por isso conceitos e técnicas usadas para testar sistemas baseados em componentes podem ser usados ou adaptados para testar aplicações baseadas em serviços, o que foi feito também nesta tese.

No Capítulo 3 é apresentada uma visão geral da computação orientada a serviços e, em especial, a arquitetura orientada a serviços. Também são apresentados conceitos e desafios relacionados ao teste de serviços. Com base em revisões sistemáticas realizadas e na consulta de artigos que resumem o estado da arte do teste de serviços (surveys) são apresentados alguns trabalhos relacionados ao teste de serviços e aplicações baseadas em serviços.

No Capítulo 4 a abordagem BISTWS é apresentada em detalhes. A abordagem é apresentada como um arcabouço conceitual e que pode ser instanciado de várias formas para orientar o desenvolvedor na criação de um serviço testável com o auxílio de um serviço de teste. Também é apresentada a forma pela qual o integrador pode utilizar as facilidades de teste disponíveis para realizar o teste estrutural e utilizar metadados fornecidos pelo serviço testável para aumentar o conjunto de casos de teste caso seja necessário.

A abordagem BISTWS é genérica e uma implementação para a geração de serviços testáveis escritos em Java é apresentada no Capítulo 5 para a validação da proposta. São apresentados dois estudos de caso e um experimento formal que foram conduzidos para avaliar a abordagem e testar 
a hipótese de que o uso da técnica de teste estrutural no teste de serviços é possível e traz benefícios à atividade. Os resultados dos estudos de caso e do experimento mostram que a proposta é viável e melhora a qualidade do teste das aplicações baseadas em serviços.

O mecanismo de detecção de mudanças usado por estratégias de monitoração geralmente é baseado na execução de casos de teste. No Capítulo 6 é apresentada uma abordagem de monitoração criada para usar as informações de teste estrutural oferecidas pelos serviços testáveis. As informações estruturais são usadas para descobrir mudanças no código do serviço, disparar um conjunto reduzido de casos de teste para testar somente a parte modificada e em seguida verificar se a cobertura estrutural foi alterada. São apresentados três estudos de caso e um experimento formal que foram realizados para avaliar a abordagem. Os resultados das avaliações são apresentados e mostram que com a utilização de informações estruturais é mais fácil identificar as mudanças ocorridas nos serviços e selecionar uma quantidade reduzida de casos de teste para verificar o comportamento do serviço monitorado.

Por fim, no Capítulo 7 são apresentadas as conclusões, as contribuições e os trabalhos futuros resultantes desta tese de doutorado. 



\section{Teste de componentes de software}

\subsection{Considerações iniciais}

O desenvolvimento de software baseado em componentes propõe a decomposição das aplicações em unidades chamadas de componentes de software que encapsulam funções de negócio específicas. Uma vez que as aplicações de um mesmo domínio tendem a possuir muitos pontos em comum, este tipo de desenvolvimento tem o foco na identificação, provisionamento, adaptação e composição dos componentes para formar o sistema completo (Kunda e Brooks, 2000; Pressman, 2002). Na fase de identificação deve-se especificar quais componentes deverão ser usados na aplicação. O provisionamento consiste na busca e análise de componentes que atendam aos requisitos exigidos pela fase de identificação. Os componentes podem ser desenvolvidos, reusados ou adquiridos de terceitos (COTS - Commercial off-the-shelf). Se necessário, o componente passa por uma etapa de adaptação para ser integrado com outros componentes. Os desenvolvedores devem escrever o código de integração dos componentes ( glue code), quando necessário.

Os componentes são geralmente fornecidos e usados como caixa-preta e podem ser invocados somente por suas interfaces públicas. Esse tipo de decomposição permite o reúso mais efetivo de funcionalidades porque são reaproveitados tanto o código quanto o projeto e a análise de uma solução. Esta característica também impõe restrições ao tipo de teste ao qual o componente pode ser submetido. Se o código fonte não está disponível, técnicas de teste baseadas em implementação não podem ser usadas pelo cliente.

O objetivo deste capítulo é fornecer uma visão geral sobre componentes de software e as técnicas de teste utilizadas para testá-los, tanto como unidade quanto no contexto de sua integração com uma aplicação. Na Seção 2.2 são apresentados os conceitos básicos de componentes de software 
e os benefícios de usá-los no desenvolvimento de uma aplicação. Na Seção 2.3 são apresentados e discutidos fatores a serem considerados sobre o teste de componentes, como as perspectivas de teste e as dificuldades encontradas pelos testadores. Na Seção 2.4 são apresentadas algumas abordagens de teste de componentes e são destacados os trabalhos cujos conceitos foram utilizados como base para a criação da abordagem proposta nesta tese de doutorado. Por fim, na Seção 2.5, são apresentadas as considerações finais deste capítulo.

\subsection{Componentes de software}

O conceito de componentes de software pode variar de acordo com seu contexto de utilização (arquitetural, negócio, especificação, implementação). Brown e Wallnau (1998) apresentam visões sobre o que é um componente, definindo-o como (i) um elemento arquitetural, que deve prover e estar em conformidade com um conjunto de interfaces; (ii) um elemento implementacional, que faz parte de um contexto arquitetural específico e deve ser invocado por meio de interfaces bem documentadas que podem ser descobertas em tempo de execução; e (iii) um elemento de negócio, que representa a implementação de um conceito autônomo de negócio ou processo, consistindo dos artefatos de software necessários para expressar, implementar e executar o conceito como um elemento reutilizável de um grande processo de negócio.

Fuentes e Troya (2000) caracterizam conceitualmente um componente como uma unidade independente e coesa de um projeto lógico contendo classes e funções, em que o encapsulamento das informações é o princípio básico para a construção do seu núcleo. Os componentes de software em geral funcionam como caixa-preta e seus clientes precisam apenas conhecer suas interfaces oferecidas e requeridas para usá-lo.

Segundo Szyperski (2002), um componente de software é uma unidade de composição claramente identificável, com interfaces contratualmente especificadas e com dependências de contexto explícitas; uma unidade de instalação independente que está sujeita a composição com outros componentes; e uma unidade que não possui estado observável externamente.

Szyperski (2002) define interface como um conjunto de assinaturas de operações que podem ser invocadas por um cliente. Segundo Councill e Heineman (2001), a interface descreve o comportamento de um componente. A conexão entre os componentes é realizada por meio de suas interfaces, de maneira direta, e as próprias interfaces dos componentes são o elemento de conexão entre eles.

A documentação é também indispensável para o reúso dos componentes. Ela deve ser suficiente para que se possa recuperar um componente, avaliar sua adequabilidade para o contexto da reutilização, fazer adaptações (se for o caso) e integrar o componente ao seu novo ambiente.

O uso de componentes no desenvolvimento de software promete trazer benefícios tais como a redução do tempo e do custo de desenvolvimento, o que permite às empresas uma maior competitividade no mercado (Kunda e Brooks, 2000; Meijler e Nierstrasz, 1997; Szyperski, 2002). Além 
disso, a utilização de componentes melhora a gestão das mudanças que podem ocorrer no software porque existe uma separação entre interface e implementação (Cheesman e Daniels, 2000).

Segundo Meijler e Nierstrasz (1997), componentes que foram reusados em várias aplicações tendem a ser mais confiáveis do que componentes novos porque já foram testados em vários contextos.

\subsection{Fatores a serem considerados no teste de compo- nentes}

O teste de sistemas baseados em componentes pode ser visto por duas perspectivas: a do desenvolvedor e a do cliente. O desenvolvedor cria componentes genéricos, independentes de contexto e que atendem a um determinado conjunto de requisitos. Para o desenvolvedor não há muitas restrições na atividade de teste porque ele é o proprietário do componente. É possível então testar seus componentes usando as técnicas adequadas à situação e ao seu processo de desenvolvimento.

O cliente, por sua vez, tem duas possibilidades: testar o componente isoladamente e/ou testar sua integração com outros componentes no sistema em que será usado. Em ambos os casos, o encapsulamento reduz o nível de controle e observação que os cliente tem sobre os componentes, o que faz com que eles apresentem baixa testabilidade (Wang et al., 1997) e traga dificuldades para a atividade de teste, uma vez que o cliente fica impedido de aplicar técnicas de teste baseadas na implementação.

Além do encapsulamento, outro fator que reduz a testabilidade de um componente é a falta de especificações detalhadas e informações sobre o seu desenvolvimento e detalhes internos (Beydeda e Gruhn, 2003).

Existem pesquisadores que afirmam que a baixa testabilidade dos componentes de software não é uma limitação significativa porque eles não precisam ser testados novamente antes de serem integrados em uma aplicação porque já foram adequadamente testados pelos seus desenvolvedores ou então foram amplamente reusados em outras aplicações e contextos (Meijler e Nierstrasz, 1997). Weyuker (1998), entretanto, afirma que essa concepção sobre o teste de componentes é um erro e apresenta o exemplo do foguete Ariane 5 para motivar tanto a necessidade de testar os componentes antes de serem reusados quanto a necessidade de aplicar técnicas de teste baseadas em implementação juntamente com as técnicas de teste baseadas em especificação e interface.

O foguete Ariane 5 reusou um componente de sua versão anterior, o foguete Ariane 4, que implementa um sistema de referência inercial (SRI - Inertial Reference System). No teste de um sistema complexo como o de um foguete, nem sempre todos os componentes estão integrados no sistema ao mesmo tempo, pois às vezes o componente de software está embutido em um componente físico que será integrado ao foguete posteriormente. Durante os testes do foguete foi usado um simulador do componente SRI. Os testes foram realizados para todos os tipos de situações aos 
quais o foguete poderia ser submetido segundo os requisitos especificados e nenhuma falha foi encontrada.

No lançamento do foguete, entretanto, o componente SRI apresentou uma falha. A anomalia interna do componente SRI ocorreu durante a execução de uma conversão de dados de um número de 64 bits em ponto flutuante para um inteiro de 16 bits com sinal. Isso ocorreu porque nenhum teste foi realizado para saber se o componente funcionaria corretamente quando submetido à contagem regressiva, à sequência de tempo do lançamento e à trajetória real do Ariane 5. Uma explicação para ausência deste teste é que nos requisitos do sistema não havia uma especificação dos dados relacionados à trajetória do foguete (LIONS, 1996).

É possível identificar dois motivos principais para a falha ocorrida com o foguete Ariane 5 (LIONS, 1996). O primeiro é a falta do requisito com os dados da trajetória do foguete. Esse problema motiva a adoção de técnicas baseadas em implementação em conjunto com técnicas baseadas em especificação. A técnica funcional procura garantir que todos os requisitos funcionais do sistema foram testados, mas ela não pode garantir que todos os requisitos do sistema foram especificados. O uso da técnica de teste estrutural procura garantir que todas as partes do código foram executadas, sem se preocupar com os requisitos. A combinação dessas técnicas faz com que o testador procure executar todas as partes do código enquanto testa todos os requisitos. Se alguma parte do código não foi testada, é possível que não haja requisitos explícitos relativos ao trecho de código que não foi executado e por isso nenhum caso de teste foi criado para executá-lo. Não há garantias de que o teste estrutural teria detectado a falta do requisito no foguete Ariane 4, mas o uso desse tipo de teste oferece mais confiança aos testadores.

O segundo motivo foi o risco assumido pelos desenvolvedores do foguete Ariane 5 de que o componente SRI estava validado pelo seu uso na versão anterior do foguete. Esse é um risco que não pode ser corrido por desenvolvedores de software e motiva a ideia de testar os componentes reusados antes e depois de serem integrados a uma aplicação, usando tanto os requisitos do componente quando do sistema em que ele será integrado.

Além da necessidade de testar um componente de software em diferentes fases, como no teste de unidade, integração e sistema, Brenner et al. (2006) afirmam que os sistemas baseados em componentes e os componentes em si devem ser testados também em tempo de execução. Eles apresentam a seguinte classificação para as fases de teste: teste em tempo de desenvolvimento e teste em tempo de execução. O teste em tempo de desenvolvimento é feito pelo desenvolvedor antes de disponibilizar seus componentes para uso. O teste em tempo de execução é realizado pelo cliente e pode ser dividido em duas etapas: teste em tempo de implantação e teste em tempo de serviço.

No teste em tempo de implantação o cliente deve testar a integração entre os componentes usados para compor a aplicação. Nesta atividade aplicam-se estratégias de integração (bottom-up ou top-down, por exemplo) e heurísticas de ordenação para reduzir o esforço de teste na criação de drivers e stubs. 
No teste em tempo de serviço deve-se testar os componentes de uma aplicação enquanto ela está em operação. Esta atividade é realizada com o objetivo de descobrir se os componentes continuam atendendo aos requisitos especificados. Particularmente, o teste em tempo de serviço pode ser usado para descobrir se componentes distribuídos usados em sistemas relacionados à computação ubíqua continuam disponíveis ou se foram substituídos.

\subsection{Abordagens de teste de componentes}

Diversos trabalhos têm sido propostos para testar sistemas baseados em componentes em suas diversas perspectivas e fases. Muitos autores reusaram e adaptaram técnicas de teste tradicionais e as aplicaram no contexto de teste de componentes. Na Tabela 2.4 é apresentada uma lista feita por Vincenzi et al. (2003) com abordagens de teste de programas orientados a objetos mais antigas e que foram ou podem ser aplicadas a sistemas baseados em componentes. As diversas abordagens abrangem as fases de teste de unidade, de integração e de sistema.

Alguns dos trabalhos relacionados consideraram o encapsulamento dos componentes e aplicaram somente técnicas de teste baseadas em especificação e/ou interface. Outros autores partiram do princípio de que o código fonte dos componentes está disponível e propuseram o uso de técnicas de teste baseadas em implementação, como o trabalho de Harrold e Rothermel (1994), por exemplo. Por outro lado, mesmo considerando o encapsulamento dos componentes, Vincenzi et al. (2003) propuseram o uso da ferramente JaBUTi (Vincenzi et al., 2006) para realizar o teste estrutural de componentes escritos em Java, uma vez que a ferramenta pode usar o bytecode do componente para gerar os requisitos de teste e avaliar a cobertura estrutural.

Tabela 2.1: Abordagens de teste orientado a objetos aplicadas a componentes.

\begin{tabular}{|l|l|l|}
\hline Técnica & Critério & Fases \\
\hline Funcional & Método de partição-categoria (Offut e Irvine., 1995) & U I S \\
\hline Estrutural & Fluxo de dados (Harrold e Rothermel, 1994) & U I \\
\hline Estrutural & FREE (Binder, 1996a) & U I \\
\hline Estrutural & Teste modal (Binder, 1996) & U I \\
\hline Baseada em erros & Mutação de classes (Kim et al., 1999, 2000) & U I \\
\hline Baseada em erros & Mutação em programas distribuídos (Ghosh e Mathur, 2000) & I \\
\hline Baseada em erros & Mutação de programas concorrentes (Delamaro et al., 2001) & U I \\
\hline Baseada em estados & FREE (Binder, 1996a) & U I S \\
\hline Baseada em estados & Teste modal (Binder, 1996) & U I S \\
\hline
\end{tabular}

U-Unidade, I-Integração, S-Sistema

Brenner et al. (2007) afirmam que as abordagens de teste tradicionais não são suficientes para testar adequadamente sistemas baseados em componentes por causa do seu encapsulamento, baixa testabilidade e a necessidade de testá-los em tempo de execução. Alguns autores propuseram soluções para aumentar a testabilidade de componentes e facilitar o teste em tempo de execução. 
Destacam-se, entre essas abordagens, as técnicas de teste embutido (Wang et al., 1997, 1999; e C. M. Toyota, 1999; Wang e King, 2002; Hornstein e Edler, 2002; Gross, 2005) e o uso de metadados (Orso et al., 2000b; Bundell et al., 2000; Edwards, 2001; Teixeira et al., 2007a,b) para fornecer ao cliente maior controle e observação sobre os componentes. A seguir são apresentados mais detalhes sobre essas abordagens.

\subsubsection{Teste embutido}

Um dos trabalhos relacionados ao aumento da testabilidade dos componentes é o mecanismo de teste embutido (built-in test), que é derivado de técnicas de auto-teste e detecção de defeitos de componentes eletrônicos. Os primeiros pesquisadores a apresentar essa idéia foram Wang et al. (1997, 1999). A ideia geral é incorporar funcionalidades aos componentes para facilitar o seu teste. As funcionalidades de teste compreendem tanto a implementação de interfaces que contenham operações para controlar ou verificar o estado interno dos componentes quanto a implementação de casos de teste para o componente (Wang e King, 2002; Hornstein e Edler, 2002; Gross, 2005).

Com base nos conceitos de teste embutido, um projeto europeu chamado de Component+ estabeleceu uma arquitetura para o desenvolvimento e uso de componentes testáveis. A arquitetura é composta basicamente de três tipos de componentes (Wang e King, 2002; Hornstein e Edler, 2002; Gross, 2005):

- Componente testável: é o componente que será testado e por isso possui mecanismos de teste embutido.

- Componente testador: é o componente que possui casos de teste implementados para testar componentes testáveis por meio da invocação de suas operações regulares ou de teste. É o testador que verifica se o componente está executando corretamente.

- Tratador de exceção (Handler): é utilizado para sinalizar os erros encontrados no componente testado. Esse tipo de componente é importante para a criação de sistemas tolerantes a falhas.

O componente testável possui interfaces para oferecer serviços relacionados à sua funcionalidade e uma interface de teste. A interface de teste deve conter as seguintes operações (Gross, 2005):

- IBITQuery: determina se o componente fornece uma interface de teste nos padrões da arquitetura de teste embutido.

- IBITSetToStateX: operação que altera o componente para um dos estados pré-definidos.

- IBITIsInStateX: verifica se o componente está em um estado pré-definido.

- IBITSetTester: atribui um componente testador para o componente testável. 
- IBITInvokeTester: operação que invoca um componente testador. Entidades externas, como um ambiente de implantação de componentes apresentado por Brenner et al. (2006), por exemplo, podem iniciar a execução dos testes.

Um exemplo genérico de um componente testável pode ser visto na Figura 2.1.

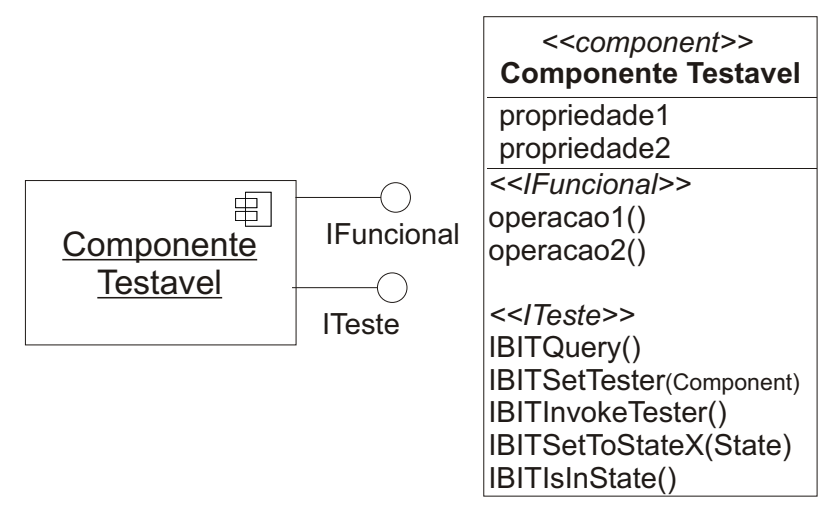

Figura 2.1: Um componente testável.

Um exemplo de arquitetura genérica de um sistema com componentes testáveis e testadores pode ser visto na Figura 2.2. O componente Testavell tem uma interface com operações funcionais (IFuncional) e uma interface de teste (ITeste) que são usadas pelo componente Testadorl. O componente Testador 1 possui casos de teste para exercitar as funcionalidades do componente Testavell e validar os contratos das operações por meio da interface de teste. Os componentes testáveis podem requerer operações de outros componentes testáveis, assim como o componente Testavell requer operações da interface funcional do componente Testavel2. O componente Testavel2 é testado pelo componente Testador 2 .

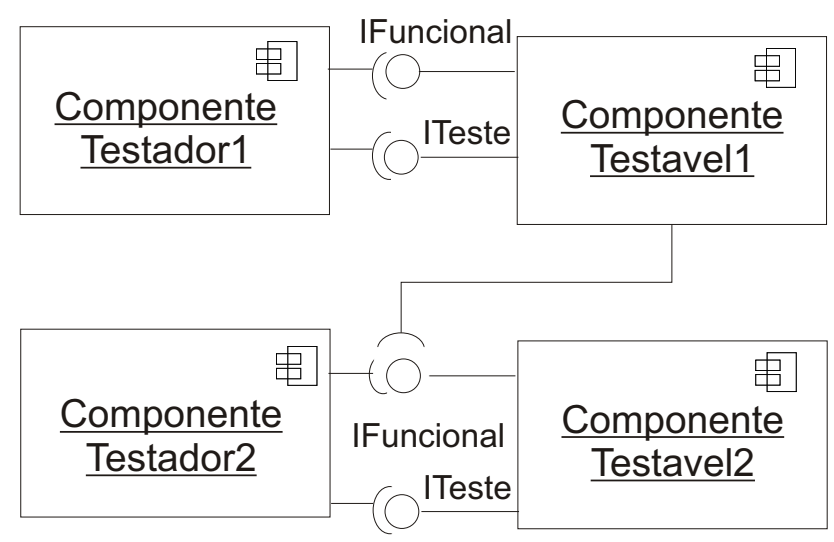

Figura 2.2: Uma arquitetura genérica de componentes testáveis e testadores.

Entre os trabalhos que utilizam componentes com teste embutido, destaca-se o trabalho de Brenner et al. (2006), que desenvolveram um ambiente em que os componentes precisam possuir 
funcionalidades de teste para serem testados em tempo de execução. No ambiente desenvolvido, pode-se configurar tarefas que ativarão componentes testadores em diversas ocasiões:

- Lookup-time: quando um componente fizer referência a outro componente, uma rotina de teste será disparada para testar o componente referenciado.

- Call-time: quando um componente invocar uma operação da interface de outro componente, uma rotina de teste será disparada para testar o componente invocado.

- Topology-change: uma rotina de teste será disparada para testar o sistema inteiro quando um componente for trocado por outro ou um novo componente entrar na arquitetura.

- Idle-time: uma rotina de teste para testar o sistema será invocada todas as vezes que um recurso (processador, por exemplo) estiver ocioso. Neste caso é possível determinar o quão ocioso o recurso precisa estar para que a rotina seja ativada.

- Periodic: pode-se configurar a ativação das rotinas de teste em períodos de tempo determinados (horas, dias, etc.).

Durante a realização dos testes em tempo de execução, o ambiente pode ter reações automáticas de acordo com os resultados do teste. Uma reação é o shut down, em que o sistema é interrompido, e a outra é o try next, em que o componente que não apresenta comportamento esperado é substituído por outro do repositório que tenha a mesma função até que o componente apresente o comportamento esperado de acordo com os testes realizados.

Existem situações em que componentes adquiridos de terceiros não possuem capacidade de teste embutido e não é possível integrá-lo em uma arquitetura específica como a de Brenner et al. (2006). Para resolver o problema, Barbier et al. (2003) criaram a biblioteca BIT/J e um conjunto de ferramentas capazes de introduzir funcionalidades de teste no componente reusado. Com a ferramenta são gerados automaticamente o componente testável e o componente testador. O código gerado do componente testável deverá ser alterado manualmente para adicionar os estados e suas transições. O componente testador deverá ser alterado para incluir os casos de teste.

Uma evolução da biblioteca BIT/J foi proposta por Bruel et al. (2003). A evolução consistiu no uso de aspectos para introduzir as funcionalidades de teste nos componentes. Nesta mesma linha, Moreira et al. (2005) propuseram que, a partir de um modelo de estados de um componente, sejam criados aspectos para introduzir atributos que controlam o estado por meio de declarações intertipos e controlam as transições de estados por meio de adendos. Essas abordagens, no entanto, só podem ser aplicadas quando é possível manipular o código objeto do componente por meio de bibliotecas específicas ou linguagens como as orientadas as aspectos, por exemplo. 


\subsubsection{Metadados}

O uso de metadados incorporados aos componentes tem o objetivo de fornecer ao usuário informações adicionais sobre o componente. Essas informações podem variar desde diagramas de análise, projeto, até informações detalhadas sobre testes realizados.

Para o uso de metadados em componentes, Orso et al. (2000b) definem três propriedades básicas: o desenvolvedor do componente deve estar envolvido na produção dos metadados; os metadados devem ser empacotados com o componente; e o desenvolvimento e a apresentação dos metadados devem ser apoiados por ferramentas.

Bundell et al. (2000) propõem que se forneçam informações adicionais sobre o componente para apoiar as atividades de análise e teste. Sugerem também a preparação de especificações de teste que descrevam implementações do componente, interfaces fornecidas para cada implementação e um conjunto de teste apropriado para testar as interfaces.

Um dos trabalhos encontrados na literatura propõe uma estratégia de teste na qual o desenvolvedor fornece ao cliente informações sobre a atividade de teste estrutural desenvolvida com o componente, uma vez que o cliente não possui o código fonte para fazer este tipo de teste. Para viabilizar essa estratégia foi proposta a ferramenta FATEsC (Ferramenta de Apoio ao Teste Estrutural de Componentes)(Teixeira et al., 2007b), que é uma extensão da ferramenta JaBUTi (Vincenzi et al., 2006).

A ferramenta FATEsC possui duas perspectiva: a do desenvolvedor e a do cliente. Na perspectiva do desenvolvedor do componente é possível: criar casos de teste para cada método público do componente; definir, textualmente, para cada caso de teste as suas características, que poderão auxiliar o usuário do componente a obter a cobertura apontada; e empacotar com o código do componente em um arquivo de extensão .JAR, as medidas de cobertura obtidas com a execução dos casos de teste e as descrições informais dos casos de testes (Teixeira et al., 2007a).

Na perspectiva do cliente do componente é possível: criar casos de teste para cada método público da aplicação no formato JUnit; comparar as medidas de cobertura obtidas com as fornecidas nos metadados; ver as descrições de cada caso de teste do desenvolvedor e, como apoio à análise de cobertura, marcá-los como não-executável (infeasible) se necessário (Teixeira et al., 2007a).

A proposta é que o desenvolvedor realize o teste estrutural e a ferramenta gere metadados sobre o teste. Os metadados produzidos pela ferramenta são: medidas de cobertura obtidas para cada caso de teste (por método público) para os critérios implementados pela ferramenta JaBUTi; e uma descrição informal para cada caso de teste (Teixeira et al., 2007a). Os metadados são então empacotados junto com o componente e disponibilizados aos clientes do componente.

O cliente deve criar sua aplicação utilizando componentes com os metadados disponíveis e desenvolver casos de teste para a aplicação completa. Ao executar os casos de teste, a ferramenta FATEsC gera um relatório com a cobertura de cada componente a partir dos testes da aplicação completa. O relatório inclui uma comparação com a cobertura alcançada pelo desenvolvedor do 
componente. Essas informações devem auxiliar o usuário do componente a avaliar a adequação dos seus próprios conjuntos de testes em exercitar os requisitos estruturais do componente.

Pode haver situações em que alguns requisitos de teste estrutural dos componentes nunca serão cobertos com os casos de teste da aplicação, pois alguma restrição da aplicação limitou certos tipos de entrada. Neste caso, o cliente do componente pode selecionar o caso de teste relacionado a este requisito e marcá-lo como não-executável. Após fazer essa marcação, o relatório de cobertura será atualizado com a nova cobertura alcançada.

Briand et al. (2006) também apresentaram um trabalho relacionado ao uso de metadados para apoiar o teste de componentes. O desenvolvedor gera restrições CSPE (Constraints on Succeeding and Preceding Events) para as operações das interfaces do componente. O desenvolvedor também é responsável por implementar métodos embutidos para facilitar o controle e observação do componente.

As restrições CSPE são definidas como uma 3-tupla (operação precedente, operação sucessora, predicado), que indica que uma chamada a uma operação sucessora pode ser executada após a chamada à operação precedente. A 3-tupla (op1, op2, true), por exemplo, indica que a operação op2 sempre pode ser chamada após op1 (sempre válido). A 3-tupla (op2, op5, false) indica que a operação op5 nunca pode ser chamada após op2 (nunca válido). A 3-tupla (op3, op7, p) indica que a chamada de op7 após op3 é possível dependendo do valor do predicado p (possivelmente válido ou inválido). Com essas restrições é possível determinar sequências de pares de operações que podem ser invocadas e determinar sequências de teste de pares de operações para cobrir os critérios de cobertura sempre válido, sempre inválido, possivelmente válido e possivelmente inválido.

Considerando-se algumas operações de uma pilha, por exemplo, pode-se definir algumas restrições CSPE. A restrição (init, push, true) indica que sempre é possível inserir um elemento na pilha após sua inicialização. A restrição (init, pop, false) indica que nunca é possível retirar um elemento da pilha após sua inicialização. Já a restrição ( $p o p, p o p$, si ze) indica que retirar um elemento da pilha após um elemento já ter sido retirado pode ser possível ou não, dependendo do valor do predicado s i ze que representa a quantidade de elementos da pilha. Se si ze for 0 então não é possível, se for maior do que 0 então é possível.

Algumas das abordagens de teste de componentes mencionadas anteriormente resolveram parcialmente a limitação trazida pelo encapsulamento dos componentes, mas nem todas elas podem ser reusadas diretamente para o teste de serviços. Diversas abordagens baseiam-se na manipulação do código objeto do componente, como o bytecode Java, por exemplo, para apoiar o teste estrutural ou aumentar o controle e observação do estado interno do componente por meio da introdução de uma interface de teste. Essas estratégias, entretanto, não podem ser aplicadas no teste de serviços, mesmo os que estão escritos em Java, pois nem o bytecode está disponível para seus clientes. A invocação dos serviços é feita apenas remotamente e eles não são fisicamente integrados à aplicação. 


\subsection{Considerações finais}

O desenvolvimento baseado em componentes fornece aos desenvolvedores mecanismos para desenvolver aplicações em tempo reduzido de desenvolvimento. A reutilização de componentes traz a falsa expectativa de que eles não precisam ser testados novamente ao serem integrados em uma nova aplicação. A expectativa é falsa porque o ambiente em que o componente será implantado pode exigir do componente requisitos diferentes em relação ao ambiente para o qual ele foi desenvolvido (Weyuker, 1998; Beydeda e Gruhn, 2003). Um exemplo clássico de falha de um sistema por usar um componente que foi reusado sem ser adequadamente testado no novo contexto é o foguete Ariane 5 (Weyuker, 1998).

Utilizar componentes de terceiros, portanto, exige que testes sejam realizados antes e depois de integrá-lo à aplicação. A principal limitação da atividade é que os componentes de software são geralmente usados como caixa-preta e por isso possuem baixa testabilidade. Algumas abordagens de teste de componentes conseguiram superar parte das limitações do encapsulamento dos serviços por meio da manipulação de seu código objeto, o que não pode ser feito com serviços, pois nem o código objeto está disponível. Os conceitos utilizados por algumas das abordagens, entretanto, podem ser usados e adaptados ao contexto de componentes, como a abordagem de teste embutido e de metadados. 



\section{Teste de serviços}

\subsection{Considerações iniciais}

A computação orientada a serviços promove o desenvolvimento de aplicações com baixo acoplamento e alto dinamismo em que os blocos fundamentais de construção são serviços disponíveis em diferentes pontos de uma rede. Serviços são unidades de composição com funcionalidades de negócio específicas e que podem ser invocados somente por meio de suas interfaces externas. A Arquitetura Orientada a Serviços é um estilo arquitetural em que fornecedores utilizam repositórios para distribuir seus serviços e os consumidores utilizam esses repositórios para encontrar serviços necessários para a composição de sua aplicação. A arquitetura orientada a serviços promove o reúso de software, assim como o desenvolvimento baseado em componentes, e promete mudar o cenário de desenvolvimento de software da manufatura de um produto para o fornecimento de soluções de software como serviços (Bozkurt et al., 2012).

A ampliação do uso da arquitetura orientada a serviços é fortemente dependente da confiança que o cliente tem de que os serviços fornecidos por terceiros atendem corretamente suas necessidades. Sem a confiança de que um serviço adquirido irá fornecer as funcionalidades requeridas e com a qualidade esperada o seu uso se torna impraticável. O teste de software é uma das formas de verificar a qualidade dos serviços e aumentar a confiança dos clientes. Diversas abordagens têm sido propostas para que clientes de serviços possam testar adequadamente um serviço isoladamente e também no contexto de sua integração com outros serviços.

$\mathrm{O}$ alto dinamismo das aplicações baseadas em serviços exige que a atividade de teste continue mesmo em tempo de execução. Serviços usados em uma aplicação podem ser substituídos por outros serviços ou seus fornecedores podem alterá-los sem notificação. Uma das técnicas para 
verificar se os serviços continuam atendendo às expectativas das aplicações é chamada de Monitoração.

O objetivo deste capítulo é apresentar uma visão geral sobre a arquitetura orientada a serviços e as abordagens de teste propostas na literatura para verificar a qualidade de serviços fornecidos por terceiros e também sua integração com aplicações baseadas em serviços. Na Seção 3.2 são apresentados os conceitos básicos da arquitetura orientada a serviços. Na Seção 3.3 são apresentadas as perspectivas e os níveis de teste envolvidos na atividade de teste de serviços e aplicações baseadas em serviços, bem como dificuldades e desafios introduzidos por este novo estilo de desenvolvimento. Na Seção 3.4 são apresentadas e discutidas as técnicas de teste propostas para o teste de serviços e aplicações baseadas em serviços. Conceitos sobre a monitoração de serviços e algumas abordagens são apresentados na Seção 3.4.3. Por fim, as considerações finais deste capítulo são apresentadas na Seção 3.5.

\subsection{Arquitetura Orientada a Serviços}

A arquitetura orientada a serviços é uma estratégia utilizada para construir aplicações a partir da composição de serviços. Ela surgiu com base no desenvolvimento baseado em componentes e na computação distribuída (Tsai et al., 2005; Krafzig et al., 2004). Seu objetivo é desenvolver principalmente sistemas de informação empresariais que se adequem a um fluxo de negócio específico e que tenham fraco acoplamento entre seus módulos, independência de tecnologia de implementação e padrões bem definidos (Papazoglou e Heuvel, 2007).

A unidade básica de composição em uma arquitetura orientada a serviços é chamada de serviço. Serviços são módulos independentes e autocontidos, que oferecem funcionalidades de negócio específicas e são descritos de forma padronizada. A comunicação com os serviços ocorre por meio de invocações remotas de suas interfaces públicas. A arquitetura orientada a serviços é independente de tecnologia específica porque é exigido que os serviços sejam definidos por uma linguagem de descrição padronizada (WSDL) e tenham interfaces com operações de negócio bem definidas. Com essas arquiteturas, as empresas podem criar, implantar e integrar serviços e compor novas funções e processos de negócio pela combinação de novos e antigos recursos de software.

Os serviços são semelhantes aos componentes, pois são unidades independentes e autocontidas que podem ser invocadas somente por meio de suas interfaces (Gross, 2005). A diferença entre eles é que nos sistemas baseados em componentes o desenvolvedor pode integrar fisicamente os componentes em sua aplicação e controlar suas mudanças, enquanto que os serviços não são integrados fisicamente e são vistos apenas como uma interface que pode ser invocada remotamente. Neste caso, as mudanças (correções, atualizações) dos serviços não podem ser previstas pelo desenvolvedor porque são de responsabilidade de seus fornecedores (Canfora e Penta, 2006, 2009).

Uma implementaçâo popular de serviços adotada atualmente são os serviços Web (web services). Os serviços Web podem ser escritos em qualquer linguagem, desde que sigam os padrões de 
publicação e comunicação definidos pela arquitetura. Cada serviço deve ser identificado por um URI (Uniform Resource Identifier) e descrito por um arquivo WSDL (Web Services Description Language), que tem a função de descrever o endereço em que o serviço está disponível, as assinaturas de suas operações, incluindo os parâmetros de entrada e de retorno, as exceções previstas e o protocolo de rede utilizado (Papazoglou, 2003; Pulier e Taylor, 2005). Com estas informações os consumidores são capazes de saber como invocar o serviço. Em geral as ferramentas de desenvolvimento utilizam essas informações para criar stubs locais que representam o serviço Web localmente.

A comunicação com os serviços é feita por meio de mensagens SOAP (Simple Object Access Protocol). Uma mensagem SOAP é formada basicamente pelas seguintes partes: envelope, cabeçalho (header) e corpo (body). O envelope determina o início e o fim da mensagem e indica para o ponto de rede que o pacote recebido contém uma mensagem SOAP. O cabeçalho é opcional e pode ser usado para adicionar metadados sobre o conteúdo da mensagem e/ou instruções específicas sobre como processar a mensagem recebida. Os cabeçalhos são mecanismos-chave para a extensão do protocolo SOAP por meio de adição de entradas que instruem nós de processamento a se comportarem de modo específico em determinados contextos, como autenticação, autorização, transações, etc. O corpo da mensagem SOAP é que contém a mensagem transmitida do provedor para o consumidor e vice-versa.

Os serviços podem assumir dois papéis na comunicação entre os elementos da arquitetura: provedor e consumidor. O provedor é o que oferece a operação de negócio e consumidor é o que utiliza a operação de negócio do provedor. A comunicação entre serviços pode ser feita de forma direta quando o consumidor conhece o endereço do fornecedor. Quando o endereço não é conhecido, o consumidor precisa de um serviço intermediário (broker) para localizar o serviço do provedor desejado. O serviço intermediário funciona de forma semelhante a uma lista telefônica, em que os serviços podem ser registrados e localizados por palavras-chave, tais como nome, funções oferecidas, empresas fornecedoras, etc.

Na Figura 3.1 é apresentado um padrão de arquitetura orientada a serviços. Os componentes da arquitetura são o provedor, o consumidor e o intermediário. Um provedor oferece um serviço e o publica em um ambiente de publicação/descoberta de serviços (intermediário ou broker). $\mathrm{O}$ consumidor usa o serviço de publicação/descoberta para achar um serviço adequado para interagir e executar alguma tarefa. O serviço de publicação/descoberta oferece funções para armazenar, classificar e localizar serviços registrados (Heckel e Mariani, 2005). O consumidor também pode conectar-se ao serviço desejado de forma direta, no caso de já conhecer o endereço de rede do serviço, ao invés de procurar o serviço em um intermediário (Tsai et al., 2005).

Uma especificação comumente implementada para os componentes intermediárias são os registros UDDI (Universal Description Discovery and Integration) (Papazoglou, 2003; Pulier e Taylor, 2005). Os registros UDDI em geral possuem uma API (Application Programming Interface) com operações para a criação, leitura, atualização, remoção e busca de serviços e de suas informações. Eles armazenam metadados sobre os serviços publicados para o consumidor conhecer detalhes so- 


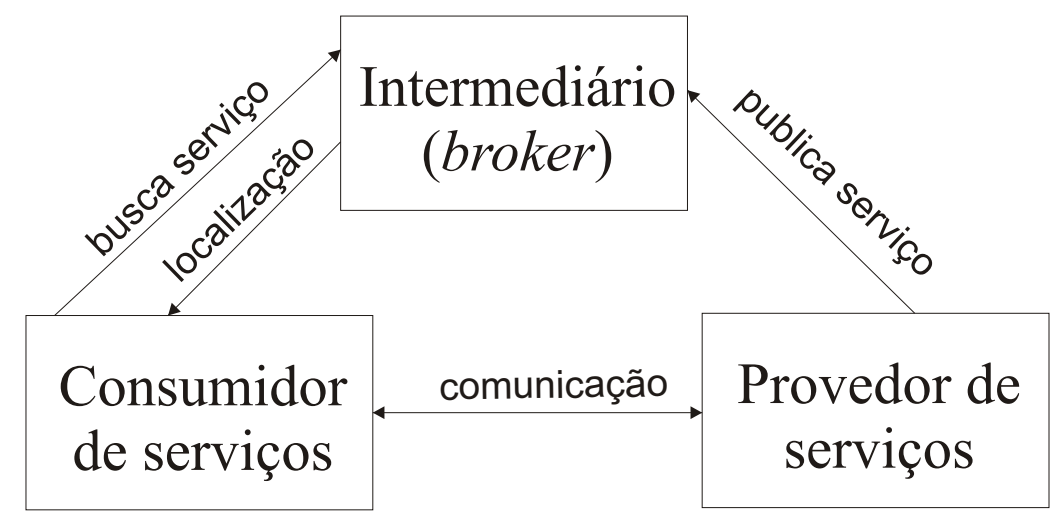

Figura 3.1: Arquitetura Orientada a Serviços.

bre o serviço. Tipicamente os serviços são descritos por meio de um arquivo WSDL (WebService Description Language).

As aplicações formadas por serviços podem ser tão dinâmicas e flexíveis quanto for necessário. Em uma situação mais conservadora, o sistema pode ser formado por serviços com localizações, interfaces e operações previamente conhecidas. Nesse caso, a aplicação é semelhante a um sistema baseado em componentes, com a diferença de que os serviços não estão sob o controle do integrador da aplicação e podem ser independentemente atualizados, tornarem-se indisponíveis ou deixar de atender a requisitos de qualidade esperados, o que pode afetar a qualidade global da aplicação (Baresi et al., 2006).

Em uma situação totalmente dinâmica, o sistema será formado por serviços cujas interfaces são abstratas e serão concretizadas somente em tempo de publicação. Nestes casos, o sistema deve ser capaz de descobrir novos serviços em ambientes de publicação/descoberta quando precisarem ou quando os serviços utilizados estiverem indisponíveis ou deixarem de atender a algum requisito específico. Baresi et al. (2006) chamam esse ambiente dinâmico de mundo aberto (open-world), no qual a previsão das mudanças é difícil ou impraticável, em oposição ao mundo fechado (closedworld), no qual as mudanças são planejadas e controladas.

Os serviços podem ser oferecidos de duas formas: simples ou compostos. Os serviços simples em geral oferecem apenas uma funcionalidade específica e os compostos consistem em um processo que integra informações e funções de múltiplos serviços (Papazoglou, 2003). A composição de serviços simples para formar serviços mais complexos pode ser feita por meio de qualquer linguagem e ambiente capazes de usar serviços e interligá-los para atender a um propósito específico, como a linguagem Java, por exemplo. Uma linguagem comumente utilizada para a especificação de composições de serviços é a BPEL (Business Process Execution Language), que é usada para compor um conjunto de serviços em um fluxo de negócios e funciona basicamente como um código de ligação (glue code) para a integração de serviços. A linguagem possui meios para especificar parceiros, variáveis, atividades, tratamento de dados, eventos e exceções. 


\subsection{Testabilidade de serviços}

A testabilidade é um importante indicador de qualidade e refere-se às facilidades que um software oferece para que ele seja adequadamente testado (Pressman, 2002). Aplicações baseadas em serviços podem apresentar diferentes níveis de testabilidade de acordo com três fatores principais: a perspectiva de teste considerada, a forma como os serviços utilizados estão distribuídos e o custo associado à atividade. Segundo Canfora e Penta (2009), para entender os fatores relacionados à testabilidade das aplicações baseadas em serviços é necessário entender sob qual perspectiva a aplicação será testada. Segundo eles, existem cinco perspectivas, das quais se destacam três: desenvolvedores, integradores e certificadores.

Os desenvolvedores são os criadores dos serviços e por isso têm total controle sobre eles. Esta perspectiva de teste pode utilizar, a princípio, qualquer técnica de teste, e, portanto, os serviços possuem alta testabilidade para eles porque testar o serviço desenvolvido não é muito diferente do que testar qualquer outro programa desenvolvido. A limitação do teste dos desenvolvedores é que os serviços são testados isoladamente ou em contextos genéricos, o que não pode garantir que o serviço testado funcionará corretamente em qualquer ambiente em que for inserido.

Os integradores são os responsáveis por utilizar os serviços adquiridos de terceiros ou desenvolvidos localmente para compor uma aplicação maior e mais complexa. A função dos integradores é escrever o código de integração dos serviços (glue code). As atividades de teste conduzidas pelos integradores para garantir a confiabilidade da aplicação construída podem ser feitas em diferentes situações: (i) o teste isolado de cada serviço utilizado na aplicação; (ii) o teste de integração da aplicação com os serviços; e (iii) o teste de unidade da aplicação.

Na primeira situação os testadores enfrentam problemas com a baixa testabilidade dos serviços, pois eles são fornecidos como caixa-preta e podem ser executados somente por meio de suas interfaces. Neste caso os integradores podem apenas utilizar técnicas de teste baseadas em especificação e/ou interface. Na segunda situação os integradores possuem mais facilidades de teste, uma vez que são os proprietários do código de integração. Para este teste os integradores podem utilizar, por exemplo, o teste estrutural e o teste baseado em estados, além do funcional. A limitação é que os serviços que compõem a aplicação continuam sendo caixa-preta, impedindo os integradores de realizarem um teste mais extensivo para verificar com mais detalhes a integração entre a aplicação e os serviços. No teste de unidade da aplicação os integradores também podem utilizar as técnicas de teste que estiverem disponíveis para testar as operações da aplicação. Nesta terceira situação a aplicação possui alta testabilidade uma vez que os integradores possuem a especificação e a implementação da aplicação composta de serviços.

Considerando as duas últimas situações, os integradores possuem outros desafios na atividade de teste além das restrições de técnicas de teste a serem utilizadas considerando os serviços fornecidos como caixa-preta. Os serviços que compõem uma aplicação podem ser conhecidos apenas em tempo de execução, o que impede a realização do teste completo de integração e de unidade 
da aplicação em tempo de desenvolvimento (Baresi et al., 2006; Canfora e Penta, 2009). Além disso, mesmo quando os serviços são conhecidos em tempo de desenvolvimento, os integradores precisam constantemente verificar se os serviços utilizados na aplicação continuam fornecendo a mesma qualidade de serviço durante todo seu ciclo de vida, pois eles estão sob o controle de seus fornecedores e podem ser atualizados e ficarem indisponíveis sem prévia notificação.

Os certificadores são entidades independentes que testam os serviços para fornecer uma certificação de que os serviços apresentam a qualidade especificada. Em geral, os certificadores utilizam apenas testes baseados em especificação e/ou interface pois não possuem a implementação do serviço. Além disso, os certificadores não conseguem garantir que o serviço certificado apresentará o mesmo nível de qualidade apresentado na certificação porque o serviço é testado isoladamente ou em um ambiente de integração genérico. É possível que quando for integrado em outros ambientes os serviços apresentem um comportamento diferente do apresentado durante os testes realizados pelos certificadores.

O segundo fator que influencia a testabilidade dos serviços é a forma como são distribuídos. Serviços podem ser disponibilizados juntamente com seu código fonte ou um modelo de projeto, por exemplo, ou apenas com o arquivo de descrição WSDL. Um serviço publicado junto com seu código fonte oferece apoio ao teste baseado em implementação. Um serviço disponibilizado junto com um modelo oferece maior apoio ao teste baseado em modelos. Um serviço disponibilizado apenas com um arquivo WSDL oferece apoio ao teste baseado em especificação e interface, o que inclui critérios da técnica funcional tais como o particionamento em classes de equivalência, análise de valor-limite e teste do protocolo SOAP (Tsai et al., 2006).

O terceiro fator que influencia a testabilidade dos serviços é o custo que pode estar associado a esta atividade. Os desenvolvedores não possuem limitações deste fator porque seus testes são realizados em ambiente de desenvolvimento, mas para as outras perspectivas o custo de um serviço é um fator limitante. Os serviços, de forma geral, estão hospedados nos servidores de seus fornecedores e atendem às requisições de diversos clientes. $\mathrm{O}$ teste desses serviços é restrito porque é possível que haja um custo associado a cada invocação ou, mesmo que o serviço seja gratuito, é possível que somente seja permitido certo número de invocações por um período determinado de tempo. Existem serviços que fazem este tipo de restrição para que o uso exaustivo do serviço não afete seu comportamento para as requisições de outros clientes e para que não haja problemas como negação de serviço, por exemplo. Além disso, o efeito do teste em algumas aplicações, como, por exemplo, em sistemas de venda de ações, nos quais cada uso do serviço representa uma transação de negócio.

\subsection{Técnicas e critérios de teste para serviços}

É possível utilizar técnicas de teste tradicionais para testar aplicações baseadas em serviços, mas é necessário que sejam feitas adaptações e extensões para acomodar as características trazidas 
por este novo estilo de desenvolvimento. Segundo Brenner et al. (2007), em situações em que as capacidades dinâmicas ou a natureza pública dos serviços utilizados não estão presentes, a utilização de técnicas tradicionais pode ser suficiente. Quando estão presentes, entretanto, novas técnicas e combinações de técnicas devem ser aplicadas (Canfora e Penta, 2006, 2009; Brenner et al., 2007).

Canfora e Penta (2009) propuseram uma classificação para os diversos tipos (níveis) de teste usados para testar serviços: teste funcional, teste não funcional, teste de integração e teste de regressão. O teste funcional aqui definido não se refere à técnica funcional tradicional (caixapreta), mas sim a qualquer técnica utilizada para testar os requisitos funcionais dos serviços, quer seja usando técnicas baseadas em implementação, em especificação ou em erros. Este tipo de teste é realizado por desenvolvedores, fornecedores, integradores e certificadores usando as técnicas de teste possíveis em cada perspectiva para testar o serviço como uma unidade.

O teste não funcional é o teste dos requisitos não funcionais. Esses requisitos em geral são definidos por um acordo feito entre o consumidor e o fornecedor do serviço e é chamado de SLA(Service Level Agreement). Nesse acordo é estipulada a qualidade esperada do serviço em termos de desempenho, uso de memória, custo de utilização, etc. Fatores como a configuração da rede e o balanceamento da carga do servidor podem afetar o desempenho de um serviço e provocar uma violação no acordo de nível de serviço. O teste não funcional deve ser usado exaustivamente para medir os níveis de qualidade estipulados no acordo. Este tipo de teste pode ser aplicado plenamente pelos integradores e com restrições pelos desenvolvedores, fornecedores e certificadores.

O teste de integração é realizado para testar a integração entre os serviços que compõem a aplicação. Em um cenário conservador, os serviços são conhecidos e o teste de integração pode ser feito com técnicas semelhantes ao teste de integração de sistemas tradicionais. Em um cenário mais dinâmico os serviços são ligados dinamicamente por um workflow que invoca interfaces abstratas que serão posteriormente concretizadas. Os métodos tradicionais não são adequados neste caso e deve-se monitorar a aplicação para detectar mudanças na arquitetura. O teste não funcional também se torna mais complexo porque o resultado global não depende só das entradas, mas também da combinação dos serviços que podem não ser conhecidos previamente. Este tipo de teste é aplicado pelos integradores.

O teste de regressão deve ser utilizado porque os serviços de uma arquitetura orientada a serviços podem mudar durante o ciclo de vida da aplicação sem que as interfaces sejam alteradas. Essas mudanças são imprevisíveis e podem alterar o comportamento global do sistema. Para evitar situações desastrosas, a execução de testes de regressão deve ser realizada sempre que um serviço for atualizado, substituído ou ficar indisponível. A dificuldade é identificar a ocorrência de um desses eventos uma vez que o fornecedor tem o controle do serviço e pode alterá-lo sem notificação. Para isso, abordagens de monitoração têm sido propostas para identificar mudanças nos serviços utilizados em uma aplicação. Em muitas delas o teste de regressão é usado para descobrir mudanças ao invés de ser executado apenas após uma mudança conhecida. 
Diante das dificuldades e desafios relacionados ao teste de serviços, várias abordagens têm sido propostas com o objetivo de propor métodos, técnicas, ferramentas e critérios adequados para o teste de serviços, tanto em tempo de desenvolvimento quanto em tempo de execução. Uma revisão sistemática formal foi realizada há aproximadamente três anos com o objetivo de identificar essas abordagens e recentemente foi atualizada de forma informal por meio de novas pesquisas em repositórios de artigos científicos e pela leitura e análise de artigos contendo um resumo dos trabalhos que já foram publicados na área (survey), como o trabalho de Bozkurt et al. (2012), por exemplo. Uma visão geral sobre os trabalhos relatados na revisão sistemática é apresentada na próxima seção. Os trabalhos que mais se relacionam a esta tese de doutorado são apresentados com mais detalhes neste capítulo e nos capítulos posteriores são comparados com a abordagem proposta.

Os trabalhos apresentados a seguir estão divididos de acordo com a classificação de Canfora e Penta (2009) para os tipos de teste, com exceção do teste não funcional. As abordagens relacionadas ao teste funcional (requisitos funcionais) geralmente são utilizadas para o teste de unidade, e por isso são apresentadas na classificação de teste de unidade. As abordagens relacionadas ao teste de regressão são apresentadas na subseção de Monitoração.

\subsubsection{Teste de Unidade}

O teste de unidade pode ser considerado a mais básica e natural estratégia de teste aplicada a qualquer sistema (Bozkurt et al., 2012). Este tipo de teste pode ser aplicado por qualquer uma das perspectivas de teste de serviços. A maioria dos trabalhos publicados para o teste de unidade baseia-se na geração de casos de teste a partir das especificações. Um resumo dos trabalhos de teste de unidade de serviços pode ser visto na Tabela 3.1. As abordagens aqui listadas consideram, geralmente, a operação do serviço ou da aplicação como uma unidade, mas existem casos em que a menor unidade do sistema é o serviço ou a própria aplicação. Na primeira coluna da tabela aparece a técnica de teste utilizada na abordagem. Na segunda coluna aparece o recurso utilizado pela abordagem como base para a geração de casos de teste e/ou a ferramenta utilizada e/ou desenvolvida para automatizar a abordagem. Na terceira coluna são listados os autores da abordagem. Em alguns destes trabalhos as mesmas técnicas utilizadas para o teste de unidade podem ser usados para testar a integração entre operações do mesmo serviço.

O arquivo WSDL é a especificação das interfaces dos serviços, incluindo suas operações, tipos e protocolos utilizados. Diversas abordagens baseiam-se nessa especificação para a geração automática de casos de teste com base em critérios de particionamento em classes de equivalência, análise de valor-limite, exceções e mutação com base nos tipos, mensagens e portas definidas (Bai et al., 2005; Sneed e Huang, 2006; Mei e Zhang, 2005; Siblini e Mansour, 2005; Bertolino et al., 2007; Bartolini et al., 2009b; Bai et al., 2008; Ye et al., 2010). Enquanto algumas abordagens usam o WSDL original, outras abordagens propuseram aumentar ou transformar as informações do WSDL em outras especificações por meio de marcações semânticas para facilitar a geração de 
Tabela 3.1: Abordagens de teste de unidade

\begin{tabular}{|c|c|c|}
\hline Técnica & Recurso & Autores \\
\hline Funcional & WSDL & Tsai et al. (2002b) \\
Funcional & WSDL & Bai et al. (2005) \\
Funcional & WSDLTEST/WSDL & Sneed e Huang (2006) \\
Funcional & WSDL & Bertolino et al. (2007) \\
Funcional & OWL-S & Bai et al. (2008) \\
Funcional & WS-TAXI/WSDL & Bartolini et al. (2009b) \\
Funcional & WSDL & Li et al. (2009) \\
Funcional & BPEL & Ye et al. (2010) \\
Funcional & Takuan/BPEL & Palomo-Duarte et al. (2010) \\
Funcional & BPEL & Ilieva et al. (2010) \\
Funcional & Outros & Bozkurt e Harman (2011) \\
\hline Baseado em Modelos & WSDL-S & Sinha e Paradkar (2006a) \\
\hline Baseado em erros & Msg SOAP & Offutt e Xu (2004) \\
Baseado em erros & Msg SOAP & Xu et al. (2005) \\
Baseado em erros & WSDL & Mei e Zhang (2005) \\
Baseado em erros & WSDL & Siblini e Mansour (2005) \\
Baseado em erros & Msg SOAP & Almeida e Vergilio (2006) \\
Baseado em erros & WSDL & Wang et al. (2008) \\
\hline Estrutural & - & Bartolini et al. (2011a) \\
\hline
\end{tabular}

casos de teste significativos (Tsai et al., 2002b; Wang et al., 2008) ou para fazer a verificação e validação do serviço com base em técnicas de verificação de modelos (Tsai et al., 2005).

Bozkurt e Harman (2011) acreditam que a geração automática de casos de teste é importante, porém muitas vezes os dados de teste não são realísticos e significativos. A geração manual de casos de teste é mais realística e significativa, porém propensa a erros e custosa. Assim, eles introduzem uma abordagem de geração de casos de teste realísticos e automatizados por meio de ontologias e dados de teste de serviços e projetos relacionados.

Offutt e Xu (2004) e Xu et al. (2005) apresentaram uma técnica de teste baseada na modificação/mutação de dados. O método consiste em modificar a mensagem de requisição enviada aos serviços e analisar a resposta. Almeida e Vergilio (2006) estenderam os operadores de perturbação de mensagens em XML definidas por Offutt e Xu (2004) e Xu et al. (2005) e desenvolveram uma ferramenta para automatizar o processo.

Realizar o teste de unidade de um serviço que é uma composição de serviços é semelhante ao teste de um serviço simples. Palomo-Duarte et al. (2010) criaram uma ferramenta para gerar, dinamicamente, invariantes de um serviço composto especificado como um processos BPEL. As invariantes propostas refletem a lógica interna do processo e são geradas a partir da execução de casos de teste. Ilieva et al. (2010) também propuseram o uso de uma ferramenta chamada TASSA para testar processos BPEL por meio de simulações. A ferramenta é capaz de injetar dados na simulação, analisar as dependência entre as operações e gerar casos de teste. 
Bartolini et al. (2011a) propuseram uma abordagem chamada de SOCT (Service-Oriented Coverage Testing) para a criação de serviços testáveis com o objetivo de aumentar a testabilidade dos serviços e possibilitar o teste estrutural. Nessa abordagem, os desenvolvedores devem inserir instruções no serviço para que detalhes de sua execução sejam enviados a um serviço chamado TCov. Os integradores podem testar os serviços testáveis e utilizar o serviço TCov para obter um relatório de cobertura estrutural da sessão de teste realizada. Uma ilustração da abrdagem é apresentada na Figura 3.2. O relatório de cobertura estrutural feito por TCov depende dos critérios de teste implementados pelo desenvolvedor na instrumentação do serviço. A avaliação dessa proposta foi feita por meio de uma implementação de TCov e de serviços testáveis na linguagem PHP.

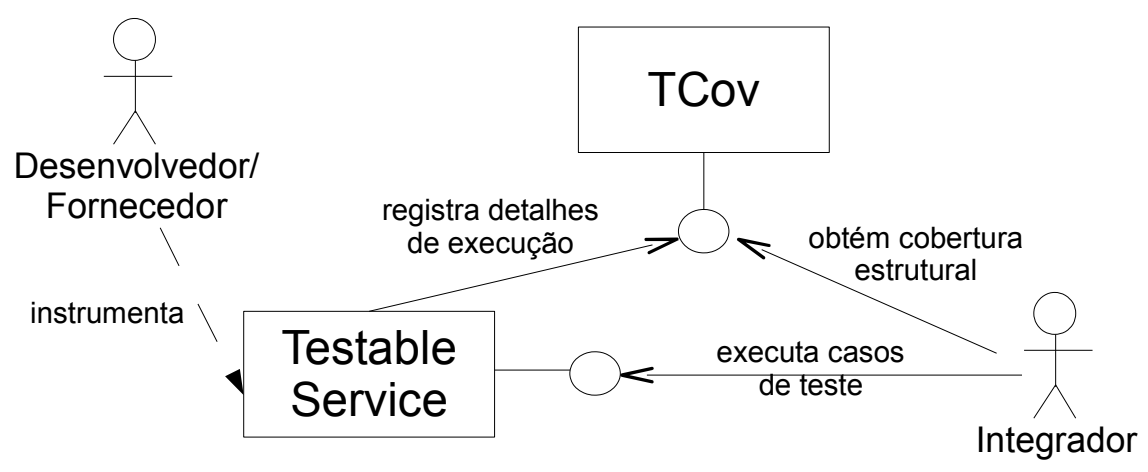

Figura 3.2: Uma ilustração da abordagem SOCT

Um fator que pode dificultar a adoção da abordagem SOCT é o fato do desenvolvedor ter que instrumentar o serviço para que informações de sua execução sejam coletadas. A instrumentação manual pode ser propensa a erros e representa um esforço adicional para o desenvolvedor. A vantagem desta estratégia é que, não dependendo de instrumentação automática, a abordagem é independente de tecnologias de implementação.

Pela análise dos trabalhos relacionados ao teste de unidade, é evidente que a maioria das abordagens baseia-se nas especificações dos serviços para gerar e avaliar seus casos de teste, pois o código fonte dos serviços não está disponível. A única exceção é o trabalho de Bartolini et al. (2011a), que tem o objetivo de aumentar a testabilidade dos serviços e permitir o teste estrutural mesmo quando os clientes externos não possuem implementação do serviço.

\subsubsection{Teste de Integração}

O teste de integração de serviços é realizado pela perspectiva do integrador. A maioria das abordagens encontradas na literatura refere-se ao teste de aplicações baseadas em serviços que são previamente conhecidos, em contraste com as aplicações em que os serviços serão conhecidos apenas em tempo de execução. Uma listagem dessas abordagens pode ser vista na Tabela 3.2.

O teste baseado em modelos é um dos candidatos a prover o apoio necessário para o teste de aplicações baseadas em serviços. Em particular, com essa técnica é possível abstrair as interações 
Tabela 3.2: Abordagens de teste de integração

\begin{tabular}{|c|c|c|}
\hline Técnica & Recurso & Autores \\
\hline Baseado em modelos & OWL-S & Huang et al. (2005) \\
Baseado em modelos & WSDL & Bertolino et al. (2006) \\
Baseado em modelos & WSDL & Ramsokul et al. (2007) \\
Baseado em modelos & Weum et al. (2006) \\
Baseado em modelos & WSDL & Sinha e Paradkar (2006b) \\
Baseado em modelos & BPEL & Dong e YU (2006) \\
Baseado em modelos & BPEL & L. Baresi e Spoletini (2007) \\
Baseado em modelos & BPEL & (Angelis et al., 2010) \\
Baseado em modelos & BPEL/WSDL & Endo e Simao (2011) \\
Baseado em modelos & Tabela Decisão/Eventos & Belli et al. (2011) \\
\hline Funcional & Coyote/WSDL & Tsai et al. (2002a) \\
Funcional & BPEL-UNIT/BPEL & Li e Sun (2006) \\
\hline Estrutural & BPEL & Yan et al. (2006) \\
Estrutural & BPEL & Yuan et al. (2006) \\
Estrutural & BPEL & Karam et al. (2007) \\
Estrutural & BPEL & Mei et al. (2008) \\
Estrutural & BPEL & Endo et al. (2008) \\
\hline
\end{tabular}

entre serviços por meio de um modelo formal e gerar casos de teste a partir disso. Além disso, as mudanças das interações podem ser acomodadas nos modelos e os conjuntos de casos de teste das aplicações podem ser atualizados conforme as alterações ocorrem (Endo e Simao, 2011).

Por esses motivos vários são os trabalhos propostos para testar serviços usando teste baseado em modelos. Os modelos usados nas abordagens propostas são geradas a partir das especificações fornecidas pelo WSDL (Bertolino et al., 2006; Ramsokul et al., 2007; Keum et al., 2006; Sinha e Paradkar, 2006b; Endo e Simao, 2011), OWL-S (Huang et al., 2005), BPEL (Dong e YU, 2006; L. Baresi e Spoletini, 2007; Endo e Simao, 2011) e tabelas de decisão, eventos e restrições (Belli et al., 2011). Outros autores propõem a especificação formal das propriedades que os parceiros de uma composição de serviços devem atender e verificam se a composição se comporta como previsto usando técnicas de verificação de modelo (L. Baresi e Spoletini, 2007; Angelis et al., 2010).

Tsai et al. (2002a) propuseram um framework para testar a interação entre serviços. O framework foi chamado de Coyote e é dividido em duas partes: gerenciador e motor. O gerenciador permite especificar cenários, definir casos de teste a partir dos cenários e executar tarefas tais como análise de dependências, análise de completeza e análise de consistência. O motor interage com os serviços sob teste e fornece o rastreamento e resultados das execuções dos casos de teste. Li e Sun (2006) propuseram uma abordagem para o teste de unidade de processos BPEL e introduziram uma ferramenta chamada BPEL-UNIT, que é uma extensão do JUnit. A idéia principal é transformar interações entre serviços em colaborações entre classes e aplicar técnicas de teste orientadas a objetos. Segundo os autores, as vantagens em se usar BPEL-UNIT é a de poder simular 
os parceiros de processos, simplificar a codificação dos casos de teste e sua execução e permitir testes de regressão automáticos.

Os integradores podem realizar o teste estrutural de suas aplicações porque possuem o código, seja ele um processo BPEL ou uma aplicação escrita em Java. Os serviços da aplicação, entretanto, continuam sendo caixa-preta. Várias abordagens propuseram a utilização de um grafo de fluxo de controle (ou um modelo semelhante) em que os serviços da aplicação são os nós e a comunicação entre eles e a aplicação são as arestas (Yan et al., 2006; Yuan et al., 2006; Karam et al., 2007; Mei et al., 2008; Endo et al., 2008). A partir deste mapeamento são criados casos de teste para testar a aplicação e relatórios de cobertura de critérios estruturais podem ser gerados.

É possível perceber que quando se trata de teste de integração é mais comum encontrar abordagens baseadas em teste estrutural do que quando se trata do teste de unidade porque o código da aplicação está disponível para os integradores, uma vez que eles são os desenvolvedores das aplicações. Dessa forma eles podem usar tanto testes baseados em especificação quanto testes baseados em implementação. A limitação dos integradores é que os serviços utilizados na aplicação são caixa-preta e não é possível testar mais extensivamente a integração entre a aplicação e o serviço, isto é, verificar o quanto do código do serviço é executado a partir da execução dos casos de teste da aplicação.

\subsubsection{Monitoração}

Segundo Canfora e Di Penta (2006), a falta de controle sobre os serviços que compõem uma aplicação é uma dificuldade encontrada pelos integradores de aplicações uma vez que os serviços podem ser alterados pelos seus fornecedores sem prévia notificação. As mudanças sofridas pelos serviços podem ser perfectivas, corretivas ou adaptativas, mas durante este processo é possível que a qualidade do serviço seja deteriorada, tanto em termos de requisitos funcionais quanto em termos de requisitos não funcionais e propriedades de contratos estabelecidas com os integradores. Dessa forma, os integradores precisam utilizar técnicas de monitoração para continuar verificando a qualidade dos serviços utilizados na aplicação ao invés de testá-los apenas durante o desenvolvimento da aplicação (Canfora e Penta, 2009).

A monitoração dos serviços de uma aplicação pode ser feita de forma passiva ou ativa (Brittenham, 2003). A monitoração passiva consiste em interceptar as mensagens trocadas entre o serviço e a aplicação para verificar se as propriedades estabelecidas em contrato continuam sendo atendidas. A monitoração ativa é baseada na execução de casos de teste com o objetivo de verificar a qualidade do serviço em tempo de execução. Uma forma popular de implementar uma estratégia de monitoração ativa é o uso de testes de regressão (Canfora e Penta, 2009). Classicamente, o teste de regressão é utilizado para verificar se um programa continua funcionando adequadamente após uma mudança conhecida. Em geral testa-se apenas a parte do software que foi modificada e as partes afetadas pela mudança. Nas estratégias de monitoração o teste de regressão tem sido 
usado com o objetivo de descobrir as mudanças sofridas pelos serviços com base nos resultados dos casos de teste.

Um dos problemas de usar o teste de regressão para descobrir se o serviço mudou é que podem existir custos associados à execução dos casos de teste. Alguns serviços são cobrados por invocação ou possuem quota de invocação. A quota de invocação refere-se a uma quantidade de chamadas que pode ser feita para o serviço em um determinado período. Se a quota for ultrapassada é possível que seja lançada alguma exceção na interação com o serviço ou então o serviço deixa de atender às chamadas recebidas de quem excedeu a quota (Hou et al., 2008). Por este motivo é recomendável que sejam executados poucos casos de teste para esta atividade e não é recomendável que eles sejam executados frequentemente (Canfora e Penta, 2006; Canfora e Di Penta, 2006; Hou et al., 2008).

Várias abordagens de monitoração foram encontradas na literatura. Na Tabela 3.3 são apresentados alguns trabalhos referentes à estratégia de monitoração ativa de propriedades funcionais dos serviços e que são baseados em teste de regressão. Na primeira coluna da tabela é identificado se a abordagem refere-se à estratégia ativa ou passiva. Algumas abordagens são classificadas como passiva e ativa, pois são abordagens que monitoram alguma propriedade para saber se houve alguma mudança antes de executar os casos de teste de regressão. A segunda coluna refere-se ao recurso utilizado pela abordagem para identificar as modificações. Na terceira coluna são apresentados os autores da abordagem.

Tabela 3.3: Abordagens de monitoração

\begin{tabular}{|c|c|c|}
\hline Estratégia & Recurso & Autores \\
\hline Ativa & Resultados dos casos de teste & Bruno et al. (2005a) \\
\hline Passiva/Ativa & Grafo & Lin et al. (2006) \\
\hline Passiva/Ativa & Grafo & Ruth et al. (2007) \\
\hline Passiva/Ativa & BPEL & Liu et al. (2007) \\
\hline Passiva/Ativa & Resultados de casos de teste & Denaro et al. (2007) \\
\hline Passiva & Propriedades funcionais/não funcionais & Baresi et al. (2007) \\
\hline Passiva/Ativa & BFG & Wang et al. (2008) \\
\hline Passiva/Ativa & XBFG & Li et al. (2010) \\
\hline Passiva & Log/invariantes & Andrés et al. (2011) \\
\hline Passiva/Ativa & Outros & Nguyen et al. (2011) \\
\hline
\end{tabular}

Bruno et al. (2005a) propuseram o uso de casos de teste como uma forma de estipular contratos entre provedores e consumidores de serviços. Essa forma de contrato permite que os consumidores realizem testes de regressão para garantir que novas versões dos serviços utilizados continuam atendendo aos requisitos e contratos estipulados. Os casos de teste são publicados pelos fornecedores dos serviços como parte de sua descrição. Os consumidores podem utilizar os casos de teste disponíveis e estendê-los. Os integradores devem executar periodicamente os casos de teste para descobrir se alguma mudança ocorreu na implementação do serviço.. 
Denaro et al. (2007) propuseram uma abordagem de composição de serviços autoadaptativas, baseada em mecanismos para a adaptação dinâmica das aplicações. A solução é apoiada por uma ferramenta que dispara um monitor quando algum serviço é invocado para verificar se a sua implementação mudou desde a última invocação. Se houve mudança, um mecanismo de diagnóstico é ativado para executar um conjunto de casos de teste para revelar possíveis problemas. Se ocorrer algum problema, existem mecanismos para tentar resolvê-los, seja pela notificação do fornecedor seja pela substituição do serviço defeituoso.

Baresi et al. (2004), Baresi e Guinea (2005), L. Baresi e Spoletini (2007) e Baresi et al. (2007) propuseram uma arquitetura simples que permite a criação de processos BPEL instrumentados por meio de anotações específicas. Os processos instrumentados interagem com um proxy específico para ativar as atividades de monitoração e permitir configurar dinamicamente o nível de monitoração desejado. O ambiente projetado chama-se Dynamo e é utilizado para verificar se o sistema se comporta corretamente e se as propriedades funcionais e não funcionais são atingidas. Além disso, o Dynamo possui estratégias de reação e recuperação se algum erro ocorrer. Nesse ambiente, os integradores podem criar processos BPEL que tratam apenas dos requisitos funcionais sem se preocuparem em introduzir atividades de monitoração, pois é possível definir a regras de monitoração externamente. As regras de monitoração definem o que os integradores querem controlar, como controlar e como reagir em situações em que restrições são violadas. Os integradores podem definir o local em que deve haver monitoração, prés- e pós-condições que devem ser atendidas e estratégias de reação. Essas regras podem ser especificadas por linguagens de asserção utilizadas no Dynamo.

Nguyen et al. (2011) propõem uma abordagem de seleção de casos de teste com base na observação de documentos que contêm informações sobre as mudanças ocorridas nos serviços. Esses documentos são disponibilizados pelos próprios serviços e podem ser utilizados para rastrear quais casos de teste estão relacionados a quais partes do serviço. Sempre que o serviço é alterado esse documento também muda e é possível então selecionar os casos de teste adequados para exercitar as partes do serviço que precisam ser testadas porque foram afetadas pelas mudanças.

Rothermel e Harrold (1997) e Harrold et al. (2000) propuseram uma abordagem para selecionar e minimizar o número de casos de teste usados no teste de regressão de programas monolíticos e de componentes, respectivamente. O código do programa ou do componente é mapeado para um grafo de fluxo de controle que é usado para identificar em que partes do código ocorreu alguma mudança. As mudanças são identificadas em termos de nós e arestas do grafo que foram modificados. Quando ocorre alguma mudança, são selecionados somente os casos de teste de regressão cujo caminho de execução inclui algum dos nós ou arestas afetados na mudança.

Os trabalhos de Rothermel e Harrold (1997) e Harrold et al. (2000) foram utilizados em abordagens cuja proposta é monitorar um serviço isolado (Lin et al., 2006; Ruth et al., 2007) ou uma aplicação baseada em serviços (Liu et al., 2007; Wang et al., 2008; Li et al., 2010; Chen et al., 2010). Entre as abordagens para monitorar um serviço isoladamente, Lin et al. (2006) propõem usar, além dos nós e arestas, um código hash de cada nó para identificar mudanças que não cau- 
sam impacto na estrutura do grafo. Tanto nos trabalhos de Lin et al. (2006) quanto o de Ruth et al. (2007) os autores afirmam que a abordagem proposta não pode ser diretamente aplicada aos serviços porque o código fonte não está disponível. A solução encontrada por Lin et al. (2006) foi utilizar os esqueletos de código e simuladores gerados pelas tecnologias de invocação fornecidos pela plataforma Java para gerar um grafo de fluxo de controle que representa o serviço monitorado.

Nas abordagens de monitoração de composições de serviços o grafo de fluxo de controle é construído a partir das interações entre os serviços e a aplicação, em que os serviços são os nós e as comunicações são as arestas. Alguns autores propuseram a adição de pesos para as arestas para priorizar a seleção dos casos de teste (Chen et al., 2010) e outros propuseram a geração de um grafo de fluxo específico para processos BPEL (BFG - BPEL Flow Graph) (Wang et al., 2008; Li et al., 2010).

As abordagens de monitoração baseadas na execução de casos de teste também são limitadas pela baixa testabilidade dos serviços. As abordagens baseadas no trabalho de Rothermel e Harrold (1997) e Harrold et al. (2000) sao adequadas para identificar mudanças nos serviços sem executar casos de teste. Após as mudanças serem identificadas, apenas um número reduzido de casos de teste são executados, o que é um grande benefício considerando os custos envolvidos na invocação das operações dos serviços monitorados (Hou et al., 2008). A limitação dessas abordagens é que elas não podem ser aplicadas a serviços porque o código deles não está disponível para que sejam gerados os grafos de fluxo de controle. Segundo Bozkurt et al. (2012), essas abordagens só podem ser usadas pela perspectiva dos desenvolvedores.

\subsection{Considerações finais}

O desenvolvimento baseado em serviços influenciou consideravelmente os conceitos de negócio da indústria de software, mas a adoção desse estilo de desenvolvimento pelos fabricantes de software ainda está em um ritmo mais lento (Bozkurt et al., 2012). Um dos impedimentos para a ampla adoção da arquitetura orientada a serviços é a falta de confiança nos serviços fornecidos por terceiros. O teste de software é uma das formas de ganhar confiança nos serviços utilizados. $\mathrm{O}$ teste de serviços envolve, segundo Canfora e Penta (2009), aplicar teste funcional (dos requisitos funcionais), teste não funcional, teste de integração e teste de regressão (monitoração).

Testar um serviço, entretanto, é uma tarefa desafiadora porque ele possui baixa testabilidade e alto dinamismo. A testabilidade dos serviços é influenciada por três fatores principais: a perspectiva de quem os usa, a forma de distribuição e o custo. Em geral o fator determinante para a baixa testabilidade é a forma de distribuição, pois serviços são tipicamente fornecidos como caixa-preta e seus clientes não têm possuem o código fonte ou o código objeto. Eles são invocados remotamente via operações públicas de uma interface. Essa limitação faz com que técnicas baseadas em implementação não possam ser combinadas com técnicas baseadas em especificação, o que é recomendável em uma atividade de teste (Myers, 1979). 
As abordagens de teste das funcionalidades dos serviços propostas até agora baseiam-se principalmente em técnicas de teste baseadas em especificação e interface. A técnica de teste estrutural é utilizada somente quando se trata do teste das aplicações baseadas em serviços, pois os integradores possuem o código fonte da aplicação, mas os serviços continuam sendo testados como caixa-preta. A única exceção é o trabalho de Bartolini et al. (2011a), cujo objetivo é aumentar a testabilidade dos serviços para apoiar o teste estrutural.

O mesmo ocorre com as abordagens de monitoração. As estratégias ativas em geral executam um conjunto de casos de teste de regressão para descobrir mudanças nos serviços. Algumas abordagens propõem a utilização de informaçõs estruturais para selecionar os casos de teste a serem executados, mas em geral essas abordagens não podem ser aplicadas por causa do encapsulamento dos serviços.

Segundo Bozkurt et al. (2012), apesar de haver crescido o número de abordagens criadas para o teste de serviços, algumas questões fundamentais permanecem sem solução definitiva. Ainda é necessária a criação de técnicas para descobrir quando o teste em tempo de execução é necessário e como minimizar o número de casos de teste executados (monitoração). Além disso, é preciso soluções para gerar dados realísticos para casos de teste, além dos casos de teste gerados automaticamente com base nas interfaces. Ainda, é necessário que surjam abordagens para aumentar a testabilidade dos serviços e facilitar as tarefas dos integradores e testadores.

De acordo com a revisão sistemática das abordagens de teste e monitoração realizado, percebeuse que há oportunidades para contribuições na área. Nos próximos capítulos é apresentada a proposta desta tese para aumentar a testabilidade dos serviços com o objetivo de apoiar o teste estrutural. Além disso, também é apresentada uma proposta de monitoração que usa informações do teste estrutural para decidir quando e como selecionar casos de teste de regressão para verificar mudanças nos serviços monitorados. 
CAPÍTULO

4

\section{Uma abordagem de teste estrutural de serviços}

\subsection{Considerações Iniciais}

Neste capítulo é apresentada uma abordagem chamada BISTWS (Built-in Structural Testing of Web Services) (Eler et al., 2010, 2011a) criada para apoiar diversas perspectivas relacionadas ao teste de serviços. O objetivo geral da abordagem é (i) apoiar desenvolvedores na criação de serviços com maior testabilidade e (ii) apoiar integradores no teste de aplicações baseadas em serviços. Os serviços desenvolvidos por meio da abordagem BISTWS são chamados de serviços testáveis.

Serviços testáveis são serviços capazes de oferecer aos integradores facilidades para o uso da técnica de teste estrutural, mas sem expor sua implementação. Eles possuem uma interface de teste que exporta operações para que os integradores possam consultar a cobertura estrutural obtida com base na execução de um conjunto de casos de teste. Além disso, os serviços testáveis também oferecem metadados de teste para auxiliar os integradores na criação de casos de teste significativos para que uma boa cobertura estrutural seja alcançada.

A abordagem BISTWS contribui com o aumento da testabilidade dos serviços porque ela cobre dois dos três fatores principais relacionados à testabilidade dos serviços: perspectiva de teste e forma de distribuição. Em relação à perspectiva de teste, a abordagem apoia o desenvolvedor na criação de serviços testáveis que possuem alta testabilidade, o que pode representar uma vantagem uma vez que a testabilidade é um importante fator de qualidade (Tsai et al., 2006), e o integrador e o certificador, que podem usar as facilidades oferecidas pelo serviços testáveis para combinar a 
técnica de teste estrutural com as técnicas baseadas em especificação durante o teste ou a certificação dos serviços. Portanto, mesmo as perspectivas limitadas pelo encapsulamento do serviço podem aplicar outras técnicas de teste além das técnicas caixa-preta. Em relação à forma de distribuição, apesar de não exportarem o código fonte para clientes externos, os serviços gerados pela abordagem BISTWS são distribuídos juntamente com uma interface de teste que possui operações que permitem uma melhor observação de sua estrutura.

De acordo com os níveis de teste de serviços definidos por Canfora e Penta (2009), a abordagem BISTWS apoia o teste das funcionalidades e o teste de regressão dos serviços, sem considerar o teste de integração e o teste dos requisitos não funcionais. Os serviços testáveis podem ser testados usando tanto a técnica caixa-preta quanto a técnica caixa-branca. As informações estruturais dos serviços testáveis podem ser usadas para definir quando os serviços devem ser testados em tempo de execução e como devem ser selecionados casos de teste para verificar possíveis mudanças em seu comportamento. Mais detalhes sobre o teste de regressão são apresentados no Capítulo 6, em que é apresentada uma abordagem de monitoração usando teste estrutural. A abordagem BISTWS não se propõem a apoiar o teste não funcional e nem o teste de integração entre serviços.

Uma ilustração da abordagem BISTWS é apresentada na Figura 4.1. Existem três atores importantes na abordagem: o desenvolvedor, o Serviço de Teste e o integrador. O desenvolvedor é o responsável por usar um Serviço de Teste fornecido pela abordagem BISTWS para criar um serviço testável a partir de um serviço comum. A transformação de um serviço comum em um serviço testável é chamada de instrumentação e é o processo pelo qual o serviço ganha a capacidade de registrar informações sobre sua execução sempre que for executado no contexto de uma sessão de teste. Além disso, o serviço recebe uma interface de teste contendo operações que oferecem apoio ao teste estrutural.

O integrador é o responsável por testar os serviços testáveis isoladamente ou no contexto de uma aplicação. Durante a atividade de teste, o serviço testável registra informações sobre sua própria execução em um arquivo ou banco de dados localizados no mesmo servidor em que ele está publicado. Após o teste, o integrador pode solicitar que o serviço testável gere um relatório de cobertura estrutural com base nos casos de teste executados. O serviço testável envia as informações de execução para o Serviço de Teste. O Serviço de Teste usa as informações de execução para verificar quais requisitos de teste foram cobertos. Para isto ele consulta os requisitos de teste que foram gerados durante a instrumentação do serviço testável e que ficam armazenadas localmente. Ao calcular a cobertura, o Serviço de Teste envia um relatório para o serviço testável que é imediatamente repassado ao integrador.

Além da cobertura estrutural, o integrador pode utilizar metadados de teste fornecidos pelo serviço testável e que foram gerados pelo desenvolvedor. Os metadados auxiliam o integrador na geração de casos de teste significativos para cobrir os requisitos de teste do serviço testável e atingir uma alta cobertura estrutural. Os serviços testáveis também possuem a funcionalidade de calcular a cobertura estrutural com base em um perfil de utilização, em que a cobertura é calculada com 


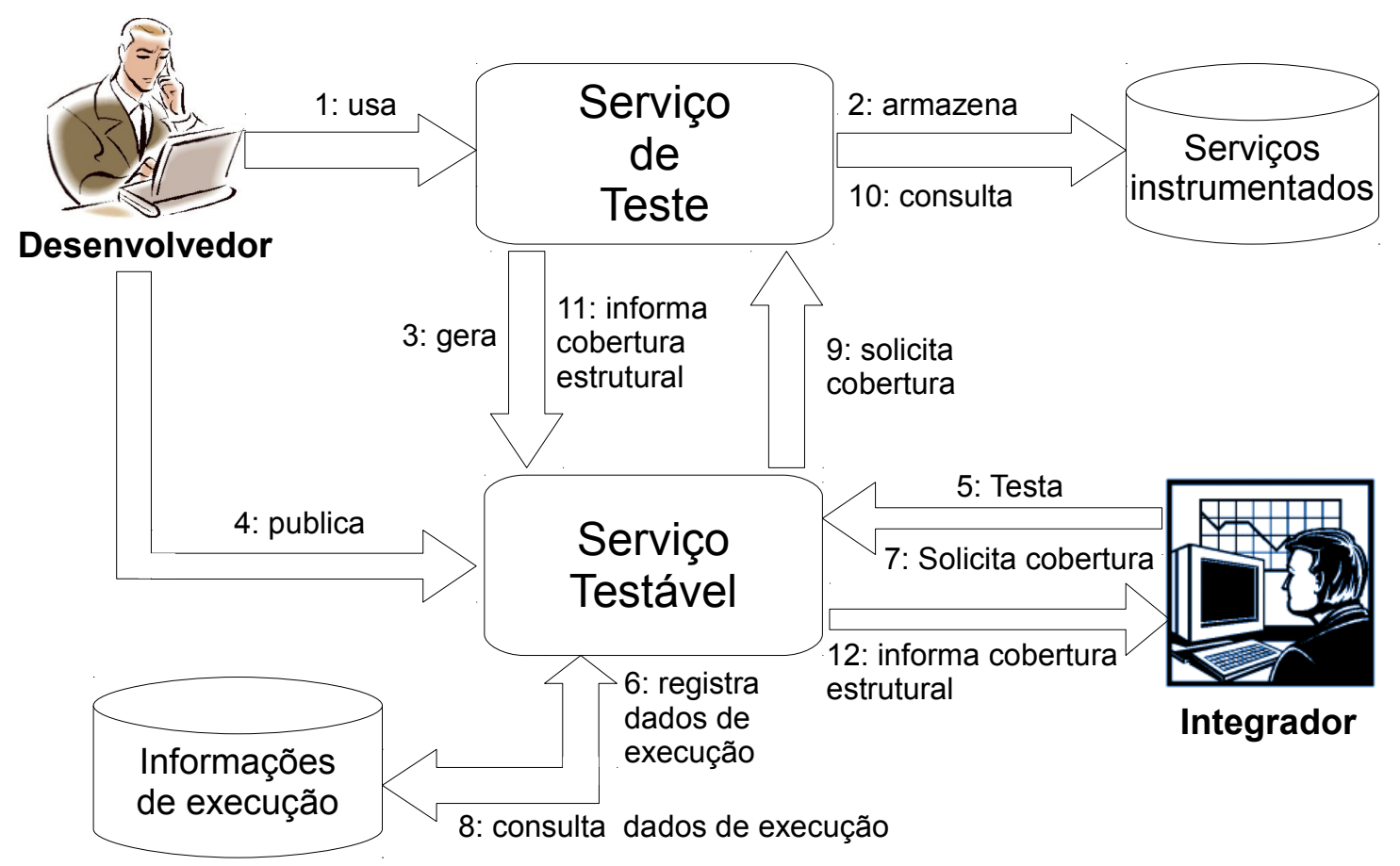

Figura 4.1: Uma ilustração da abordagem BISTWS

base nas operações e funcionalidades do serviço que são realmente usadas, ao invés de calcular a cobertura para todo o serviço.

Para que o uso da abordagem BISTWS seja possível é necessário que os atores da abordagem sigam regras de governança, que são regras criadas para garantir que cada ator desempenhará adequadamente o seu papel na abordagem. Os desenvolvedores devem concordar em fornecer o código para o Serviço de Teste e concordar em expor detalhes internos do serviço para os integradores por meio dos relatórios de cobertura, mas sem expor o código. O Serviço de Teste, em contrapartida, deve manter sigilo sobre as informações recebidas. Uma lista de regras de governança que devem ser seguidas pelos atores da abordagem é apresentada na Seção 4.5.

A seguir são apresentadas em detalhes as funções de cada ator e as interações que ocorrem entre eles para que seja possível a aplicação da abordagem e a utilização do teste estrutural no contexto de arquiteturas orientadas a serviços.

\subsection{Desenvolvedor}

O desenvolvedor é o responsável por criar os serviços que são utilizados pelos integradores e o fornecimento de serviços com alta testabilidade pode representar uma vantagem competitiva (Tsai et al., 2006; O'Brien et al., 2007; Canfora e Penta, 2009). Dessa forma, a abordagem BISTWS apoia o desenvolvedor no processo de transformação de serviços comuns em serviços testáveis que oferecem maior testabilidade por possuir facilidades de teste estrutural. A seguir é apresentada 
uma lista de tarefas que devem ser executadas pelo desenvolvedor para que um serviço comum seja transformado em um serviço testável.

\subsubsection{Instrumentação}

A instrumentação de um serviço comum para transformá-lo em um serviço testável é uma atividade fundamental na abordagem BISTWS. Esta tarefa é que vai dar ao serviço a capacidade de oferecer aos integradores a possibilidade de realizar o teste estrutural. A instrumentação consiste em inserir comandos no código do serviço para que os detalhes de sua execução possam ser registrados quando ele for executado. Os detalhes da execução podem se referir aos comandos executados, às variáveis utilizadas e aos caminhos percorridos em uma execução do código, por exemplo.

A complexidade do processo de instrumentação depende de quais critérios de teste serão considerados. Se um desenvolvedor deseja que o teste estrutural do serviço testável seja feito considerando apenas os nós e arestas do serviço, então as instruções inseridas deverão fazer o registro dos blocos de instruções executados e dos caminhos percorridos em uma execução do código. As informações sobre a execução do serviço testável devem ser armazenadas pelo serviço em um arquivo local ou por outra forma de armazenamento, como em uma base de dados, por exemplo.

Como nem sempre o serviço testável será executado no contexto de uma sessão de teste, é importante que as instruções inseridas na instrumentação para registrar os detalhes da execução do serviço possam ser ativadas e desativadas pelos integradores quando a sessão de teste iniciar e terminar, respectivamente. Isso deve ser feito para evitar que o código da instrumentação permaneça ativo e traga algum overhead para uma aplicação que já esteja em operação e esteja utilizando o serviço. Inevitavelmente, haverá ocasiões em que o serviço será usado, ao mesmo tempo, por aplicações sob teste e por aplicações em operação. O código da instrumentação deve prover mecanismos para que o serviço identifique e registre separadamente as informações de cada execução, ainda que executadas ao mesmo tempo.

Instrumentar manualmente o código de um serviço e criar instruções para a realização do teste estrutural não é uma tarefa fácil. Essa tarefa pode trazer um grande esforço adicional para a atividade de desenvolvimento de serviços, além de ser propensa a erros. Por essas razões, na abordagem BISTWS, tanto a instrumentação quanto o cálculo de cobertura estrutural são feitos por uma ferramenta ou um serviço especializado, como o Serviço de Teste especificado pela abordagem. Dessa forma, a tarefa do desenvolvedor na abordagem BISTWS para transformar seu serviço comum em um serviço testável é submetê-lo à instrumentação realizada pelo Serviço de Teste.

\subsubsection{Especificar e implementar uma interface de teste}

O desenvolvedor deve especificar uma interface que permita que os integradores que usam o serviço testável usem suas funcionalidades de teste. Interfaces que expõem operações para fa- 
cilitar a aplicação de alguma técnica de teste são chamadas de interfaces de teste (Gross, 2005). Segundo a abordagem BISTWS, a interface de teste de um serviço testável deve conter as seguintes operações:

- iniciarTeste (IDSessaoTeste), para informar ao serviço testável que uma sessão de teste será iniciada. Cada sessão iniciada deve ser identificada unicamente para que os integradores possam se referir a ela para obter o cálculo de cobertura. Quando o serviço testável entra em modo de teste deve-se ativar o código inserido na instrumentação para iniciar a coleta das informações de sua execução.

- finalizarTeste (IDSessaoTeste), para informar o serviço testável que a sessão de teste referenciada pelo identificador informado foi encerrada. As instruções inseridas na instrumentação devem ser desativadas neste momento.

- obterCoberturaEstrutural (IDSessaoTeste, perfilUso), para fornecer aos integradores a cobertura estrutural obtida na sessão de teste identificada pelo parâmetro recebido pela operação. O cálculo da cobertura estrutural deve ser feito para os critérios considerados na instrumentação do serviço. Na abordagem BISTWS o cálculo da cobertura é feito pelo Serviço de Teste. Quando essa operação é executada, o serviço testável envia as informações de sua execução para o Serviço de Teste, que fará o cálculo de cobertura e retornará o resultado para o serviço testável. O Serviço de Teste, além das informações de execução do serviço, utiliza informações recebidas por meio do parâmetro perfiluso para fazer um cálculo personalizado da cobertura de acordo com as operações e circunstâncias de uso do serviço testável. Mais detalhes sobre o perfilUso são apresentados na Seção 4.4.2.

- obterMetadados (Tipo), para fornecer aos integradores os metadados de teste disponibilizados pelo desenvolvedor. O parâmetro recebido pela operação deve ser usado para que o tipo correto de metadado seja fornecido. Mais detalhes sobre os metadados de teste dos serviços testáveis são informados na descrição da próxima atividade.

As operações descritas anteriormente são as operações básicas que a interface de um serviço testável deve possuir. Os nomes e os parâmetros das operações apresentados são sugestões da abordagem genérica e podem ser alterados e estendidos pela implementação de cada desenvolvedor ou Serviço de Teste usado para automatizar a tarefa. É necessário, entretanto, que o serviço testável forneça esse conjunto mínimo de funcionalidades.

Além de inserir as especificações das operações na interface de teste, é necessário que elas sejam implementadas para que as funcionalidades especificadas sejam realizadas. Novamente, inserir e implementar as operações das interfaces de teste para todos os serviços testáveis desenvolvidos exige um grande esforço e é uma atividade propensa a erros. Uma vez que as operações das interfaces são padronizadas, optou-se por deixar sob a responsabilidade do Serviço de Teste, além de realizar a instrumentação, também adicionar a interface de teste a a implementação de suas operações. 
Apesar de ser responsabilidade do Serviço de Teste, as atividades de instrumentação e de especificação e implementação da interface de teste estão descritas sob responsabilidade dos desenvolvedores por dois motivos. O primeiro motivo é que, apesar de ser mais fácil utilizar um serviço para automatizar a tarefa, os desenvolvedores podem optar por fazer isso manualmente e usar as recomendações e conceitos da abordagem BISTWS apenas como ponto de partida para criar seu próprio processo de criação de serviços testáveis. O segundo motivo é que, conceitualmente, a instrumentação e as facilidades de teste são vistas pelos integradores como atividades realizadas pelos desenvolvedores, pois estes possuem o código fonte e são capazes de realizar essa tarefa.

\subsubsection{Especificar metadados de teste}

Quando uma cobertura baixa é obtida no teste de software tradicional, os testadores geralmente analisam os grafos de fluxo de controle e o código fonte das aplicações sob teste para saber quais requisitos de teste não foram cobertos e assim criar mais casos de teste. Este mesmo processo não pode ser aplicado pelos integradores de serviços testáveis quando a cobertura obtida é baixa porque o código fonte não está disponível.

As únicas informações disponíveis sobre detalhes internos dos serviços são aquelas fornecidas pelo desenvolvedor. No caso dos serviços testáveis, a abordagem BISTWS determina que eles sejam publicados juntamente com metadados de teste que vão auxiliar integradores a criar mais casos de teste e aumentar a cobertura estrutural obtida quando necessário.

De acordo com a abordagem BISTWS, os metadados de teste publicados juntamente com os serviços testáveis devem ser de dois tipos: a priori e sob demanda. Os metadados do tipo a priori são estáticos e publicados juntamente com o serviço. Os metadados do tipo sob demanda são gerados em tempo de execução.

Os metadados de teste do tipo a priori correspondem ao conjunto de casos de teste criado pelo desenvolvedor para testar o serviço em tempo de desenvolvimento (semelhante aos casos de teste que são publicados juntamente com os componentes criados com a técnica de built-in testing). Assume-se, neste caso, que os casos de teste fornecidos como metadados representam o melhor esforço do desenvolvedor e a cobertura alcançada é a maior possível. Em alguns casos a cobertura estrutural obtida pode não ser $100 \%$ porque podem existir requisitos não executáveis.

Os metadados de teste a priori devem ser publicados seguindo um formato XML padronizado. Cada caso de teste deve ser completamente especificado e contar com as seguintes informações:

- identificador único;

- o nome da operação para a qual o caso de teste foi criado;

- o nome, o tipo e os valores de cada parâmetro de entrada;

- as dependências com outros casos de teste, ou seja, quais casos de teste deveriam ser executados antes que este caso de teste seja executado; 
- o resultado esperado dado por um oráculo; e,

- uma rápida descrição textual explicando porque aquele caso de teste foi criado. Aqui a motivação pode ser tanto para cobrir requisitos funcionais quanto estruturais.

Os metadados gerados sob demanda são baseados nos metadados do tipo a priori e correspondem a sugestões de casos de teste fornecidos para os integradores para que eles possam melhorar a cobertura estrutural obtida. O processo funciona da seguinte forma: o integrador faz o teste dos serviços testáveis, seja isoladamente seja no contexto de uma aplicação, obtém a cobertura estrutural e, se preciso, faz requisição das sugestões de casos de teste para melhorar o conjunto de casos de teste criado. Nesse momento, o serviço testável verifica quais casos de teste dos metadados do tipo a priori conseguem cobrir os requisitos de teste que não foram cobertos pelos casos de teste dos integradores. Os casos de teste que conseguem cobrir os requisitos ainda não cobertos são então fornecidos para os integradores como sugestões de casos de teste a serem executados.

Quando um integrador testa o serviço isoladamente, basta utilizar o conjunto de casos de teste fornecido pelos metadados do tipo a priori que já corresponde a um conjunto de dados de teste que deve ser capaz de alcançar uma cobertura alta, pois são os casos de teste criados pelos desenvolvedores. Quando o integrador testa o serviço no contexto de uma aplicação, deve requisitar as sugestões de casos de teste e estudá-los para poder criar casos de teste significativos e relevantes para a aplicação em que o serviço está integrado. Mais detalhes sobre este tipo de uso dos metadados são apresentados na Seção 4.4.2.

$\mathrm{Na}$ abordagem BISTWS, propõe-se que a ordem em que os casos de teste aparecem na lista de sugestões não seja deixada ao acaso. A sugestão é de que a lista seja ordenada de forma decrescente de acordo com o número de requisitos de teste cobertos pelo caso de teste sugerido. Assim, o primeiro caso de teste sugerido é aquele que será capaz de cobrir mais requisitos de teste do que os demais da lista quando for executado. Ao invés de utilizar todas as sugestões da lista, os integradores podem, por exemplo, melhorar incrementalmente seu conjunto de casos de teste utilizando os casos de teste sugeridos do início da lista até que uma cobertura satisfatória seja obtida.

\subsection{Serviço de Teste}

O Serviço de Teste desempenha um papel fundamental na abordagem BISTWS, pois é ele quem faz a instrumentação dos serviços testáveis e também o cálculo da cobertura estrutural. Ele deve ser capaz de instrumentar o serviço com base em critérios estruturais implementados, como, por exemplo, os critérios todos-nós e todas-arestas. Para isso o serviço deve oferecer pelo menos as seguintes operações para serem usadas pelos desenvolvedores:

- instrumentarServico (implementacaoServico, nivelDetalhes), para receber o código de um serviço e instrumentá-lo; e 
- calcularCoberturaEstrutural (dadosExec, perfilUso), para calcular acobertura estrutural.

O Serviço de teste deve receber a implementação de um serviço (código fonte ou binário) por meio da primeira operação para realizar a instrumentação. Durante a instrumentação o Serviço de Teste deve inserir uma série de instruções para que o serviço testável seja capaz de registrar informações sobre sua execução. Além disso, o Serviço de Teste deve gerar os requisitos de teste do serviço testável de acordo com os critérios de teste estrutural considerados na instrumentação. Esses requisitos devem ser armazenados para serem utilizados no cálculo da cobertura.

Além de inserir instruções para registro de execução, o Serviço de Teste também deve inserir a interface de teste do serviço testável e sua implementação. Para isso ele precisa, além de inserir as implementações das operações no código, manipular os documentos de especificação da interface do serviço para que as operações da interface de teste sejam publicadas com as operações regulares.

O parâmetro nivelDetalhes é usado para que o desenvolvedor tenha liberdade de definir o quanto quer revelar da implementação do serviço em relação ao relatório de cobertura estrutural emitido. No nível 1, por exemplo, é permitido apenas a geração de um relatório com base na cobertura geral obtida para todo o serviço e para as operações da interface. No nível 2 o relatório pode ser feito para cada classe que implementa o serviço. No nível 3 o relatório pode ser feito para cada método que compõe as classes do serviço, incluindo os privados.

A segunda operação definida pelo Serviço de Teste é usada para calcular a cobertura estrutural obtida em uma sessão de teste. Quando o integrador finaliza uma sessão de teste e solicita ao serviço testável o relatório de cobertura estrutural, o serviço usa os dados de execução que foram registrados e os envia para o Serviço de Teste. Para isso o serviço testável usa a operação calcularCoberturaEstrutural do Serviço de Teste. O serviço testável também envia, junto com os dados de execução, um perfil de utilização informado pelo integrador. O perfil de utilização informa ao Serviço de Teste quais funcionalidades do serviço testável são realmente utilizadas para que seja feito o cálculo de cobertura personalizado para esse determinado perfil de uso. Dessa forma, O Serviço de Teste usa os requisitos de teste do serviço testável, descarta os requisitos relacionados às funcionalidades que não são usadas pelo integrador, e verifica quais deles foram cobertos de acordo com os dados de execução recebidos. Os dados de execução do serviço podem ser, por exemplo, quais caminhos os casos de teste percorreram dentro do código quando foram executados. Mais detalhes sobre o perfil de utilização e como podem ser definidos para obter um cálculo de cobertura personalizado são apresentados na Seção 4.4.2.

O Serviço de Teste deve estar sempre disponível porque ele é o responsável por fazer a análise de cobertura dos casos de teste executados para testar os serviços testáveis. Os integradores executam os casos de teste para testar o serviço testável isoladamente ou no contexto de uma aplicação e invocam a operação para obter o relatório de cobertura. Neste momento, o serviço testável envia para o Serviço de Teste os detalhes de sua execução e o cálculo da cobertura é realizado. O 
integrador não precisa saber quem de fato faz o cálculo de cobertura é o Serviço de Teste e não o serviço testável.

A descrição do Serviço de Teste feita aqui é genérica e independente de linguagem e tecnologia. A implementação deste serviço é que vai determinar, por exemplo, como a instrumentação do serviço testável será realizada e para quais critérios e linguagens de programação, quais operações serão inseridas na interface de teste e quais os formatos dos dados de execução registrados pelos serviços testáveis. Um exemplo de implementação desse serviço será apresentado no Capítulo 5.

\subsection{Integrador}

O integrador é o responsável por utilizar o serviço testável em uma aplicação. O integrador pode decidir testar o serviço isoladamente antes de integrá-lo em sua aplicação e depois testá-lo no contexto da aplicação. Em ambos os casos o integrador precisa informar ao serviço que uma sessão de teste será iniciada e ao término da sessão informar que o teste terminou para então obter o relatório de cobertura estrutural. Os detalhes sobre como o integrador pode utilizar um serviço testável para testá-lo isoladamente ou no contexto de uma aplicação são apresentados a seguir.

\subsubsection{Teste de um serviço testável isoladamente}

O integrador pode criar casos de teste para o serviço testável ou então reusar os casos de teste do tipo a priori fornecidos pelo desenvolvedor. A Figura 4.2 mostra uma ilustração, por meio de um diagrama de sequência, de um integrador testando um serviço testável isoladamente. O integrador primeiramente invoca a operação in i ciarTeste do serviço testável com o identificador de uma sessão de teste e, em seguida, as operações regulares do serviço são invocadas durante a execução de casos de teste. O integrador encerra a sessão de teste invocando a operação f inali zarTeste e em seguida a operação obterCoberturaEstrutural usando o identificador da sessão de teste que acabou de ser realizada. Nesse momento, o serviço testável envia para o Serviço de Teste os detalhes de sua execução. O perfil de uso do serviço testável que deveria ser usado nas operações de cálculo de cobertura do serviço testável e do Serviço de Teste é nulo porque, nesse exemplo, o integrador deseja obter o cálculo de cobertura considerando todas as funcionalidades do serviço.

O detalhamento da análise de cobertura recebida pelo integrador depende da implementação do Serviço de Teste. Alguns serviços podem fornecer uma cobertura generalizada levando em consideração todo o serviço e a média de cobertura de todos os critérios implementados e outros serviços podem fornecer uma cobertura detalhada para cada operação e critério de teste considerado. 


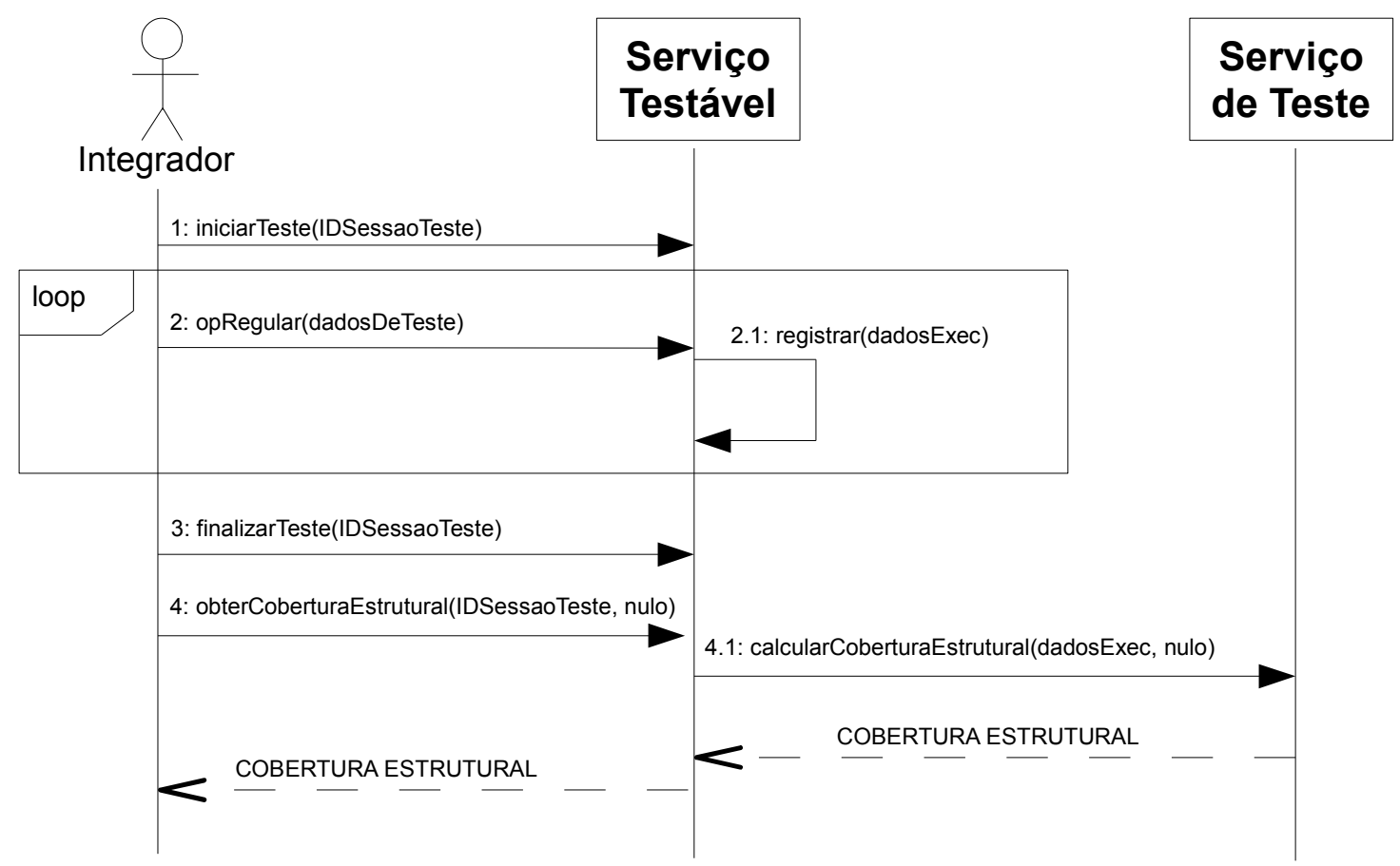

Figura 4.2: Diagrama de sequência de uma sessão de teste de um serviço testável

\subsubsection{Teste de um serviço testável no contexto de uma aplicação}

O integrador também pode testar os serviços integrados por meio de chamadas feitas internamente à aplicação. Para isso, ele deve criar casos de teste para a aplicação e verificar se os serviços atendem aos requisitos da aplicação, tanto funcionais quanto não funcionais. Um integrador que utiliza um serviço testável em sua aplicação pode, além de verificar se os requisitos são atendidos, obter uma cobertura estrutural do serviço e avaliar o quanto sua estrutura foi execitada a partir dos casos de teste projetados para testar a aplicação.

Uma ilustração do teste de um serviço testável no contexto de uma aplicação é mostrada na Figura 4.3 por meio de um diagrama de sequência. O integrador inicia a atividade colocando o serviço testável usado pela aplicação em modo de teste. Em seguida, o integrador executa os casos de teste da aplicação que invocam suas operações. Durante sua execução, a aplicação chama as operações regulares do serviço testável. Sempre que o serviço testável é executado um registro dos detalhes de sua execução é realizado. Ao fim da sessão de teste, o integrador informa o serviço testável que a atividade foi encerrada (operação finalizarTeste) e invoca a operação calcularCoberturaEstrutural usando o identificador da sessão e o perfil de uso do serviço. Nesse momento, o serviço testável envia as informações de sua execução para o Serviço de Teste, juntamente com o perfil de uso informado pelo integrador. O Serviço de Teste faz o cálculo da cobertura estrutural e retorna para o serviço testável, que responde imediatamente à solicitação do integrador.

O integrador pode utilizar a análise de cobertura estrutural obtida para avaliar se são necessários mais casos de teste para exercitar melhor a integração entre a aplicação e o serviço testável. O 


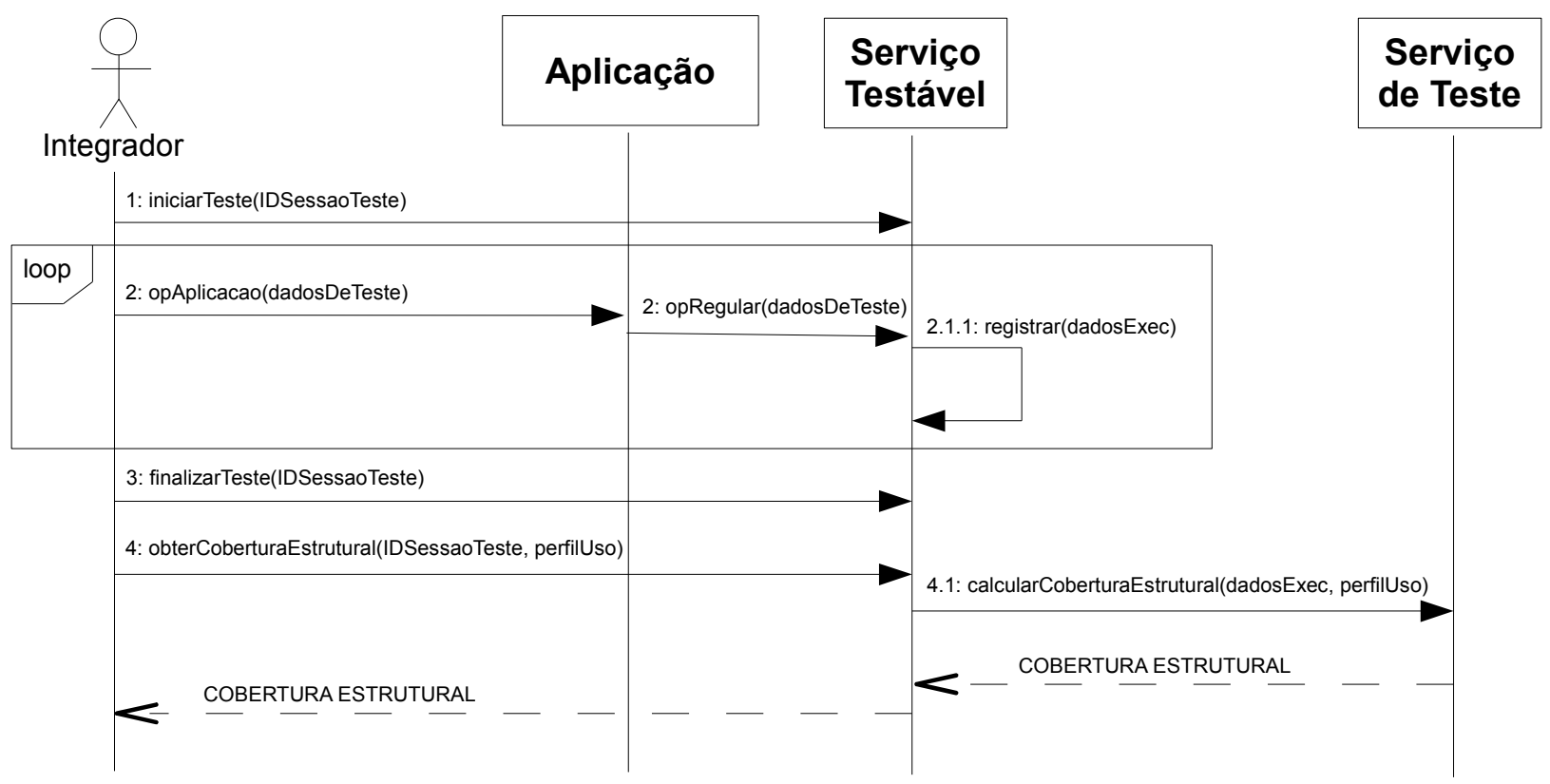

Figura 4.3: Diagrama de sequência de uma sessão de teste de um serviço testável usado no contexto de uma aplicação

integrador tem duas opções quando a cobertura alcançada é insatisfatória. A primeira opção é analisar os requisitos da aplicação e do serviço testável com o objetivo de criar casos de teste para exercitar combinações de entradas de dados que ainda não foram utilizadas. A segunda opção é utilizar os metadados gerados sob demanda fornecidos pelo serviço testável.

Os metadados gerados sob demanda são sugestões de casos de teste feitas ao integrador para que ele aumente a cobertura estrutural. Os casos de teste sugeridos foram feitos para testar as operações do serviço testável e não podem ser usados diretamente para testar a aplicação. O integrador deve analisar os dados de teste sugeridos e criar casos de teste para a aplicação de tal forma que a aplicação invoque o serviço usando os mesmos dados dos casos de teste recebidos como sugestão. Imagina-se que esta não seja uma tarefa difícil para o integrador porque ele conhece o código fonte da aplicação e sabe de que forma os dados de entrada são manipulados até chegarem à invocação do serviço testável sob teste.

O integrador pode aumentar iterativamente o conjunto de casos de teste da aplicação utilizando os primeiros casos de teste sugeridos pelo serviço testável. Se ainda assim a cobertura continuar baixa, dois podem ser os motivos principais: requisitos não-executáveis e cobertura relativa.

Os requisitos de teste não-executáveis são aqueles que nunca serão cobertos, independentemente da combinação e do número de dados de entrada. Um exemplo de um requisito nãoexecutável é um caminho não-executável. Considere a seguinte sentença: if $(5<3)$ then doSomething ( ). Neste caso, os requisitos referentes à execução da instrução doSomething não são executáveis porque esta instrução jamais será executada. Assim, se o serviço testável tiver requisitos não-executáveis eles nunca serão cobertos e a cobertura não aumentará. 
Uma das soluções para esta situação é comparar a cobertura alcançada pela invocação do serviço dentro da aplicação com a cobertura alcançada pelos casos de teste do desenvolvedor fornecidos como metadados do tipo a priori. O ponto de referência para medir a cobertura passa a ser a cobertura alcançada pelo desenvolvedor e não mais os $100 \%$ de cobertura. Outra solução, um pouco mais refinada e complexa, é o desenvolvedor ter a possibilidade de marcar os requisitos não executáveis e o Serviço de Teste descartá-los quando calcular a cobertura.

A cobertura relativa está relacionada aos diferentes usos que diferentes composições podem fazer de um mesmo serviço. Diferentes integradores podem usar diferentes operações de um serviço, e mesmo quando usam a mesma operação, ela pode ser usada em contextos diferentes. Considere um serviço de um banco que ofereça empréstimos bancários. Uma loja de venda de carros, uma imobiliária e uma instituição de ensino podem usar a mesma operação de empréstimo, mas para fins diferentes, o que provavelmente resulta na execução de caminhos diferentes dentro do serviço de empréstimo bancário. Desta forma, se o serviço testável usado pela aplicação for esse serviço bancário, a cobertura alcançada pelo sistema da loja de venda de carros nunca irá cobrir os requisitos específicos relativos às funcionalidades de empréstimos de longa duração, como pode acontecer com os empréstimos imobiliários. Mesmo que não faça sentido e os integradores queiram criar casos de teste para cobrir todos os requisitos, provavelmente a aplicação impedirá que algumas combinações de dados de entrada sejam utilizadas para invocar o serviço testável porque elas não são aplicáveis àquele contexto.

Para solucionar esta questão, a abordagem BISTWS define que os integradores devem fornecer, sempre que forem utilizar um serviço testável, um perfil de uso do serviço. Este perfil deve conter uma identificação da aplicação, uma lista das operações do serviço que serão utilizadas de fato e a identificação dos casos de teste sugeridos pelo serviço testável e que não são aplicáveis ao contexto da aplicação.

Os casos de teste não aplicáveis ao contexto podem ser os casos de teste de operações e/ou funcionalidades que não são utilizadas pela aplicação. Para uma aplicação de uma loja de venda de carros, por exemplo, os casos de teste para testar o serviço de empréstimo bancário com prazo de pagamento acima de 10 anos são casos de teste não aplicáveis ao contexto.

O serviço testável usará o perfil de uso para calcular uma cobertura relativa e adequada ao tipo de utilização do serviço, desconsiderando os requisitos de teste relacionados às funcionalidades que não serão utilizadas no contexto da aplicação na qual ele está sendo testado.

\subsection{Governança}

O sucesso da abordagem BISTWS só é possível com a colaboração dos diversos interessados no teste de arquiteturas orientadas a serviços. É importante que os atores sigam regras de governança que definem os direitos e os deveres de cada ator que deseja utilizar esta bordagem (Bertolino e 
Polini, 2009). Dessa forma, a seguinte lista de regras de governança foi definida para cada ator para que a abordagem BISTWS seja factível.

Os desenvolvedores devem seguir a seguinte lista de regras de governança:

- O desenvolvedor deve concordar em enviar a implementação do serviço (código fonte, código binário, etc) ao Serviço de Teste para que ele seja instrumentado e transformado em um serviço testável. Em alguns casos os desenvolvedores podem ficar desconfortáveis em enviar este artefato para um serviço terceirizado, mas para a automatização da abordagem é necessário que eles tenham confiança na confidencialidade do Serviço de Teste, o que pode ser garantido por meio de contratos firmados entre eles.

- O desenvolvedor deve fornecer os metadados do tipo a priori e gerados sob demanda juntamente com o serviço testável, caso contrário os integradores não terão apoio para melhorar seus conjuntos de caso de teste caso a cobertura estrutural alcançada seja baixa.

- O desenvolvedor deve formatar e publicar os metadados de teste no formato definidos pela implementação da abordagem. Se a instrumentação for feita pelo desenvolvedor, então a manipulação dos metadados será feita de acordo com o padrão por ele definido. Se a instrumentação for feita pelo Serviço de Teste, então a implementação das operações para manipular os metadados é que define o formato em que os metadados devem estar.

- O desenvolvedor não pode atualizar o serviço testável e substituí-lo por uma versão nãotestável. Cada vez que o serviço for atualizado ele deve ser instrumentado novamente. Além disso, os metadados também devem ser atualizados caso seja necessário.

O Serviço de Teste deve seguir as seguintes regras de governança:

- O Serviço de Teste deve instrumentar o serviço e manter sigilo sobre a implementação recebida.

- O Serviço de Teste deve atender a requisitos não funcionais, tais como autenticação, disponibilidade, controle de concorrência e mecanismos de segurança para evitar que informações confidenciais sejam divulgadas a pessoas ou entidades não autorizadas.

- O Serviço de Teste deve prover mecanismos para o cálculo de cobertura estrutural utilizando os requisitos de teste do serviço instrumentado, as informações da execução do serviço durante uma sessão de teste e o perfil de utilização fornecido.

- O Serviço de Teste deve fornecer aos desenvolvedores o formato no qual os metadados devem ser publicados para que sejam manipulados adequadamente pelos serviços testáveis instrumentados pelo serviço. 


\subsection{Comparação da abordagem BISTWS com trabalhos relacionados}

A abordagem BISTWS, embora seja uma contribuição original para a área de teste de serviços, foi projetada com base em técnicas, critérios e conceitos introduzidos por outras abordagens de teste, principalmente às relacionadas ao teste de componentes de software. A ideia de instrumentar um serviço e adaptá-lo para facilitar a aplicação de uma técnica de teste específica vem dos trabalhos relacionados ao teste embutido de componentes. Nessa técnica os componentes são instrumentados e estendidos com operações para facilitar a aplicação da técnica de teste baseado em estados, o que é uma técnica amplamente adotada para o teste de componentes. A instrumentação facilita a observação e o controle sobre os estados que podem ser assumidos pelos componentes.

A abordagem BISTWS, por outro lado, facilita a aplicação do teste estrutural. A instrumentação e as operações da interface de teste são inseridas para facilitar a observação de quais partes do código foram exercitadas, de acordo com critérios estruturais e o quanto ainda falta exercitar para que os requisitos de critérios de teste estrutural sejam totalmente atendidos. À semelhança do que ocorre com os componentes com teste embutido, o encapsulamento dos serviços testáveis também é preservado, pois o seu código não é exposto para usuários externos.

Alguns trabalhos que propõem o uso de metadados para apoiar a atividade de teste de componentes também são relacionados à abordagem proposta (Orso et al., 2000a). Em especial, destacam-se os trabalhos de Teixeira et al. (2007a,b), que propõem o uso de uma ferramenta para auxiliar os testadores a aplicar a técnica de teste estrutural em componentes e usar metadados de teste para melhorar a qualidade dos casos de teste e a cobertura obtida. Nesse trabalho, os desenvolvedores precisam criar casos de teste para os componentes que serão usados pelos clientes e disponibilizá-los junto com uma descrição detalhada. Os clientes, por sua vez, testam o componente isoladamente ou no contexto de sua aplicação. Os clientes podem, ao obter a cobertura estrutural dos componentes, analisar os casos de teste produzidos pelos desenvolvedores e aumentar seu próprio conjunto. Caso não seja possível criar casos de teste com as informações de um determinado caso de teste por restrições impostas por uma aplicação, o cliente pode marcar aquele caso de teste como não executável. O mesmo processo é feito na abordagem BISTWS, em que os casos de teste gerados sob demanda podem ser usados para aumentar a cobertura estrutural e, caso não sejam aplicáveis, eles são informados na seção de casos de teste não relevantes do perfil de utilização do serviço testável.

A abordagem de Teixeira et al. (2007a,b), de certa forma, leva o teste estrutural do componente até o cliente, semelhantemente aos serviços testáveis da abordagem BISTWS. A diferença é que os serviços testáveis possuem funções para apoiar o teste estrutural embutido e elas podem ser usadas por meio das operações da interface de teste, enquanto os componentes da proposta de Teixeira et al. (2007a,b) só podem ser testados com a técnica estrutural e usar os metadados por meio de uma ferramenta específica. 
Além disso, a aplicação da técnica, apesar de não usar o código fonte, depende de componentes que expõem sua implementação por meio de outros artefatos, como, por exemplo, o bytecode Java que pode ser manipulado pela a ferramenta JaBUTi (Vincenzi et al., 2006), que foi usada como base para o desenvolvimento da ferramenta FATESC. Uma outra diferença entre as abordagens é que o uso das facilidades de teste e dos metadados dos serviços testáveis podem ser utilizados em tempo de execução, sem depender do uso de ferramentas específicas. Os integradores não precisam de apoio de ferramentas ou ambientes para testar os serviços testáveis, pois toda as facilidades de teste estão implementadas e encapsuladas internamente ao serviço e o uso do Serviço de Teste não é perceptível aos integradores.

A abordagem SOCT de Bartolini et al. (2009a, 2011a) é o trabalho que mais se relaciona à abordagem proposta. Embora a abordagem SOCT não tenha sido usada como base para o projeto da abordagem BISTWS, há muitas semelhanças entre elas. A abordagem SOCT também se baseou nas técnicas de teste embutido para componentes para a criação de serviços testáveis que oferecem facilidades de teste estrutural. As facilidades de teste dos serviços testáveis podem ser ligadas e desligadas e é possível obter uma cobertura estrutural de acordo com os critérios implementados após a execução de um conjunto de casos de teste em uma sessão de teste. Embora muito parecidas, existem algumas diferenças.

Os serviços testáveis da abordagem SOCT devem ser instrumentados pelos próprios desenvolvedores, o que é uma tarefa que exige um grande esforço e é propensa a erros, enquanto na abordagem BISTWS a instrumentação deve ser feita por meio de uma ferramenta ou serviço de apoio. A vantagem de deixar a cargo do desenvolvedor a instrumentação do serviço é a independência de tecnologia de implementação. A instrumentação realizada por uma ferramenta é feita para serviços implementados em uma única linguagem. Para atender a um amplo número de desenvolvedores é necessário criar ferramentas para instrumentar serviços implementados em diferentes linguagens. A vantagem da instrumentação automatizada é o tempo reduzido e a maior confiabilidade. É possível que os desenvolvedores de serviços prefiram não fornecer serviços testáveis caso seja necessário um esforço muito grande para tornar seus serviços comuns em testáveis.

Na abordagem SOCT as informações de execução do serviço estruturado são enviadas a um serviço especializado, o Tcov, ao passo que na abordagem BISTWS as informações são armazenadas localmente. A desvantagem de enviar as informações para um serviço especializado é o risco de perder essas informações caso Tcov não esteja disponível. Quando os dados são armazenados localmente, por exemplo, não existe este risco, e mesmo que o Serviço de Teste não esteja disponível, é possível obter a cobertura estrutural de qualquer sessão de teste por meio de seu identificador, mesmo que ela tenha sido executada há muito tempo.

Outra diferença entre a abordagem SOCT e a abordagem BISTWS está na transparência do cálculo de cobertura estrutural. Na abordagem SOCT, o integrador deve consultar a cobertura estrutural obtida em uma sessão de teste usando o serviço Tcov, ao passo que na abordagem BISTWS o integrador só precisa ter contato com o serviço testável que invoca o Serviço de Teste. A estratégia da abordagem BISTWS permite que o acoplamento entre o ambiente do integrador com o 
serviço testável seja menor, pois não é necessário invocar nenhum outro serviço especializado para obter a cobertura obtida. Em um cenário em que existem diversas implementações de abordagens de serviço testável, é possível que para cada serviço utilizado exista um Serviço de Teste responsável por fazer o cálculo de cobertura por pertencerem a fornecedores que utilizaram diferentes abordagens. Nesse caso, é melhor que o integrador não precise se preocupar em invocar, além dos serviços testáveis, vários Serviços de Teste para obter a cobertura estrutural. O cenário é mais simples quando o uso do Serviço de Teste não é perceptível para o integrador.

As semelhanças entre as abordagens SOCT e BISTWS são muitas e isso levou os autores das duas abordagens a fazerem um trabalho em conjunto. Uma limitação das duas abordagens, inicialmente, era a falta de apoio ao desenvolvedor para poder aumentar seu conjunto de casos de teste e a cobertura alcançada caso ela tivesse sido insatisfatória. Do trabalho realizado em conjunto resultou o processo de utilização dos metadados a priori e sob demanda para auxiliar os integradores. Nesse trabalho também foi elaborada a ideia do perfil de uso dos serviços testáveis para resolver a questão da cobertura relativa com base no cálculo de cobertura personalizado para cada contexto de utilização (Eler et al., 2011a). Apesar de serem muito semelhanças, a primeira fase de ambas as abordagens foi realizada separada e independentemente pelos dois grupos, sem que um tivesse conhecimento do trabalho do outro.

\subsection{Considerações finais}

A abordagem BISTWS apresentada neste capítulo tem como objetivo introduzir o teste estrutural no contexto de arquiteturas orientadas a serviços. A abordagem é usada para criar serviços capazes de fornecer um relatório de cobertura estrutural com base na execução de um conjunto de casos de teste. A abordagem também propõe um conjunto de metadados de teste para auxiliar os testadores na geração de casos de teste significativos para atingir uma cobertura estrutural significativa.

A abordagem BISTWS beneficia principalmente os desenvolvedores e os integradores. Para os desenvolvedores é interessante poder criar serviços com alta testabilidade uma vez que este é um fator de qualidade que pode oferecer uma vantagem competitiva frente a serviços com baixa

testabilidade. É possível que os benefícios trazidos pela abordagem possam até mudar a forma com que os contratos pelos serviços são feitos. Imagina-se um cenário em que muitas versões de um mesmo serviço estejam disponíveis e com custos variando de acordo com as funcionalidades e facilidades de teste oferecidas (Eler et al., 2011a).

Os integradores, por sua vez, são beneficiados porque são capazes de combinar as técnicas de teste estrutural e funcional para testar os serviços utilizados em uma aplicação tanto isoladamente quanto no contexto da aplicação. Esta combinação dá mais segurança ao integrador de que o serviço em si e a sua integração com a aplicação foram testados extensivamente. As demais perspectivas (provedores e certificadores) também são beneficiadas porque podem realizar o teste 
de serviços combinando as técnicas de teste estrutural e funcional, semelhantemente ao integrador de serviços.

A abordagem BISTWS também possui algumas limitações. Ela é altamente dependente do Serviço de Teste e o código instrumentado pode trazer algum overhead para a arquitetura, dependendo da implementação. É possível que alguns desenvolvedores criem serviços testáveis e não forneçam os metadados, o que dificultaria a tarefa dos integradores em aumentar a cobertura alcançada caso ela não seja satisfatória. Além disso, apesar de serem úteis, os metadados podem não ser suficientes para auxiliar os integradores na criação de mais casos de teste. Existem situações em que é preciso ter analisar o código fonte para descobrir quais casos de teste precisam ser criados para exercitar partes do código que não foram executadas. Nesses casos, a interface de teste estrutural e os metadados não conseguem fazer o papel de uma ferramenta de apoio ao teste estrutural que permite os testadores interagir com o código do software sob teste e descobrir quais partes ainda não foram executadas.

A abordagem apresentada é genérica e representa um arcabouço conceitual para a geração e uso de serviços testáveis que possuem funcionalidades para apoiar o teste estrutural. Uma instanciação da abordagem foi realizada para a criação de serviços testáveis escritos em Java e é apresentada em detalhes no próximo capítulo. 



\section{Uma instânciação da abordagem BISTWS}

\subsection{Considerações iniciais}

A abordagem BISTWS apresentada no capítulo anterior é genérica e conceitual. A utilização da abordagem depende da implementação do Serviço de Teste, que é o responsável por transformar um serviço comum em um serviço testável e também calcular a cobertura estrutural com base nos dados de execução de uma sessão de teste. A instrumentação realizada pelo Serviço de Teste para gerar um serviço testável define quais critérios de teste estrutural serão considerados para que o serviço rastreie as informações corretas quando for executado para que a cobertura seja calculada adequadamente.

Neste capítulo é apresentada uma instância da abordagem BISTWS para a geração de serviços testáveis escritos em Java. Para isso foi criado um serviço chamado JaBUTiWS (Eler et al., 2009), que é uma versão orientada a serviços da ferramenta JaBUTi(Java Bytecode Understanding and Testing) (Vincenzi et al., 2006), que apoia o teste estrutural de programas escritos em Java. O JaBUTiWS foi criado inicialmente para testar programas escritos em Java mas foi estendido para se adequar aos requisitos exigidos pela abordagem BISTWS para poder desempenhar o papel do Serviço de Teste.

Este capítulo está organizado da seguinte forma. Na Seção 5.2 é apresentado o serviço JaBUTiWS criado para apoiar o teste estrutural de programas escritos em Java. Na Seção 5.3 é apresentado como o JaBUTiWS foi estendido e usado para implementar os requisitos do Serviço de Teste da abordagem BISTWS. A implementação da abordagem BISTWS por meio do serviço 
JaBUTiWS foi útil para validar a proposta, que foi avaliada por meio de um estudo de caso apresentado na Seção 5.4 e de um experimento formal apresentado na Seção 5.5. Por fim, na Seção 5.6, algumas considerações finais são apresentadas.

\subsection{JaBUTiWS - um serviço para apoiar o teste estrutural de programas Java}

O grupo de pesquisas em Engenharia de Software do ICMC-USP tem trabalhado com teste de software há alguns anos e algumas ferramentas de teste de software foram desenvolvidas nesse período. Uma das ferramentas desenvolvidas e que está em constante evolução é a JaBUTi (Vincenzi et al., 2006), que apoia o teste estrutural de programas escritos em Java. Esta ferramenta foi transformada em um serviço chamado JaBUTiWS (Eler et al., 2009) por dois motivos principais. $\mathrm{O}$ primeiro deles foi dar início à transformação de algumas ferramentas de teste para criar um ambiente que pudesse integrar ferramentas de teste fornecidas como serviço nos moldes dos sistemas TaaS (Testing as a Service). Este ambiente visa a apoiar tanto desenvolvedores de serviço quanto desenvolvedores de software tradicionais durante a atividade de teste de software. O segundo objetivo foi ter disponível um serviço de teste estrutural para automatizar e apoiar as abordagens de teste e monitoração propostas nesta tese.

A implementação do JaBUTiWS foi feita em colaboração com pesquisadores do projeto Qualipso (QUALIPSO, 2012), em especial o pesquisador André Takeshi Endo, que também tinham interesse em possuir uma ferramenta de teste de software para poder construir uma solução de teste integrando alguns serviços. Uma visão geral do JaBUTiWS é apresentada em seguida, juntamente com um exemplo de uso do serviço. Também são apresentados alguns ambientes nos quais o JaBUTiWS já está integrado e está sendo usado como um apoio ao teste estrutural de software.

\subsubsection{Uma visão geral do serviço de teste}

O JaBUTiWS foi criado com base na implementação da ferramenta JaBUTi (Vincenzi et al., 2006). JaBUTi é uma ferramenta de teste estrutural que implementa critérios de fluxo de controle e de dados para testar programas escritos em Java. Os critérios implementados pela ferramenta são os seguintes: todos-nós, todas-arestas, todos-usos e todos-p-usos. Para todos os critérios existem duas versões: uma que considera os fluxos de exceção e a outra que não considera. Nos estudos realizados com o serviço JaBUTiWS foram utilizados apenas os critérios todos-nós, todas-arestas e todos usos, sem considerar os fluxos de exceção dos programas.

A ferramenta foi concebida inicialmente para o teste de unidades de programas Java, mas com o passar do tempo ela foi estendida para apoiar o teste de integração e também de programas escritos com AspectJ (Franchin et al., 2007; Lemos et al., 2007; de Oliveira Neves et al., 2009; Neves e Masiero, 2011; Cafeo e Masiero, 2010, 2011). Uma das características da JaBUTi é que 
ela não requer o código fonte para realizar o teste de uma aplicação. A instrumentação, a execução e a análise de cobertura são feitas com base no bytecode do programa testado.

A ferramenta JaBUTi funciona basicamente como é explicado a seguir. O testador deve criar um projeto de teste e selecionar as classes que devem ser instrumentadas. A ferramenta então instrumenta as classes selecionadas e gera um conjunto de requisitos de teste para cada critério de teste implementado pela ferramenta. Após a instrumentação, o testador deve criar casos de teste de acordo com os padrões definidos pelo framework JUnit (Beck e Gamma, 1998) para cobrir os requisitos de teste gerados pela ferramenta.

Os casos de teste criados pelo testador são submetidos e executados como entradas do programa instrumentado, que gera um arquivo de rastreamento contendo informações sobre quais instruções e dados foram exercitados durante a execução dos casos de testes. Em seguida, a JaBUTi utiliza o arquivo de rastreamento gerado para verificar quais requisitos de teste foram cobertos e gera um relatório de cobertura estrutural. O relatório de cobertura pode ser feito para todo o projeto ou para cada classe, método ou critério. Os resultados de cobertura podem ser usados pelo testador para avaliar a qualidade dos casos de teste. O testador pode decidir parar ou continuar a criar casos de teste para tentar atingir uma cobertura melhor.

A ferramenta JaBUTi foi desenvolvida para ser uma aplicação que requer interação humana para a realização de suas atividades. Para a implementação do serviço JaBUTiWS, uma análise das interações humanas requeridas pela JaBUTi foi realizada e alguns cenários de uso foram criados. Estes cenários foram utilizados para especificar as operações da interface do serviço para prover as funcionalidades principais da ferramenta. A interface gráfica da JaBUTi foi removida e as operações do serviço foram implementadas sobre as classes do núcleo da ferramenta.

A arquitetura do JaBUTiWS é apresentada na Figura 5.1. O serviço é composto por quatro componentes:

- Axis2: é uma implementação Java usada para processar mensagens SOAP.

- JaBUTiWS controller: implementa as operações publicadas na interface do serviço. O controlador processa as mensagens dos clientes, usa o banco de dados e invoca as operações do núcleo da JaBUTi para realizar a instrumentação e a análise de cobertura.

- Database (DB): armazena as informações de projetos criados no serviço, incluindo classes, casos de teste e arquivos de rastreamento.

- JaBUTiCore: é um componente que encapsula as classes principais da ferramenta JaBUTi. Este componente é responsável pela instrumentação dos programas e pela análise de cobertura.

As operações especificadas na interface do JaBUTiWS são de granularidade baixa e o testador deve utilizar uma sequência de operações para realizar o teste estrutural de um programa ou serviço. A Tabela 5.1 mostra a lista de operações disponíveis na interface do serviço. 


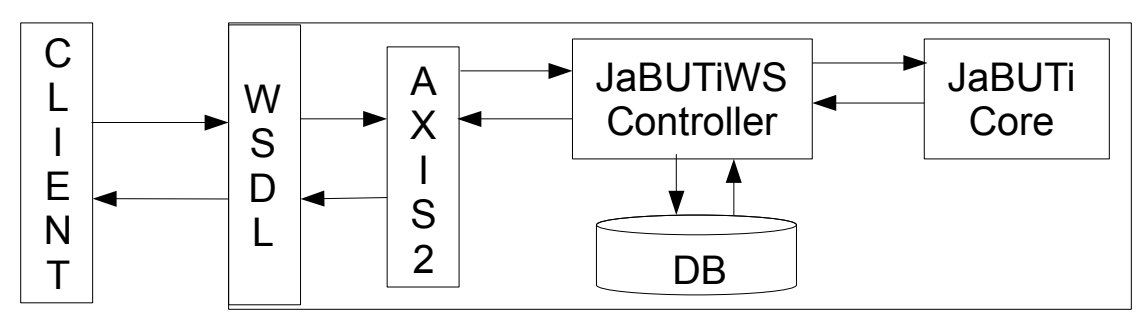

Figura 5.1: Arquitetura do JaBUTiWS.

\begin{tabular}{|c|l|}
\hline ID & Nome da operação \\
\hline \hline op1 & createProject \\
\hline op2 & updateProject \\
\hline op3 & deleteProject \\
\hline op4 & ignoreClasses \\
\hline op5 & selectClassesToInstrument \\
\hline op6 & getAllRequiredElements \\
\hline op7 & getRequiredElementsByCriterion \\
\hline op8 & getGraph \\
\hline op9 & addTestCases \\
\hline op10 & getInstrumentedProject \\
\hline op11 & sendTraceFile \\
\hline op12 & getCoverageByCriteria \\
\hline op13 & getCoverageByClasses \\
\hline op14 & getCoverageByMethods \\
\hline op15 & getAllCoveredAndUncoveredElements \\
\hline op16 & clearProject \\
\hline
\end{tabular}

Tabela 5.1: Operações da interface do serviço JaBUTiWS

O JaBUTiWS é um serviço que armazena estado e seus clientes precisam seguir uma sequência de chamadas para que o teste estrutural seja realizado adequadamente. Na Figura 5.2 é apresentada uma máquina de estados que modela o ciclo de vida de um projeto de teste criado com o serviço. Os números mostrados nas transições entre estados referem-se aos identificadores das operações apresentadas na Tabela 5.1.

Uma instância da máquina de estado é criada quando um projeto é criado (op1). A máquina vai para o estado inicial Created e para seu sub estado Idle. Em qualquer momento a partir de sua criação um projeto pode ser: atualizado (op2), quando novas classes são adicionadas ao projeto; inicializado (op16), quando as classes instrumentadas e os arquivos de rastreamento são apagados; ou removido (op3), quando o ciclo de vida do projeto de teste é encerrado. Tanto a atualização quanto a limpeza do projeto levam a máquina ao estado Idle novamente.

O testador deve selecionar classes do projeto de teste que não devem ser instrumentadas (op4) a partir do estado I dle. O testador também deve selecionar as classes que devem ser instrumentadas pelo JaBUTiWS (op5). Esta operação leva a máquina de estados para o estado Instrumented e para seu sub estado Ready, que significa que as classes do projeto estão prontas para serem 


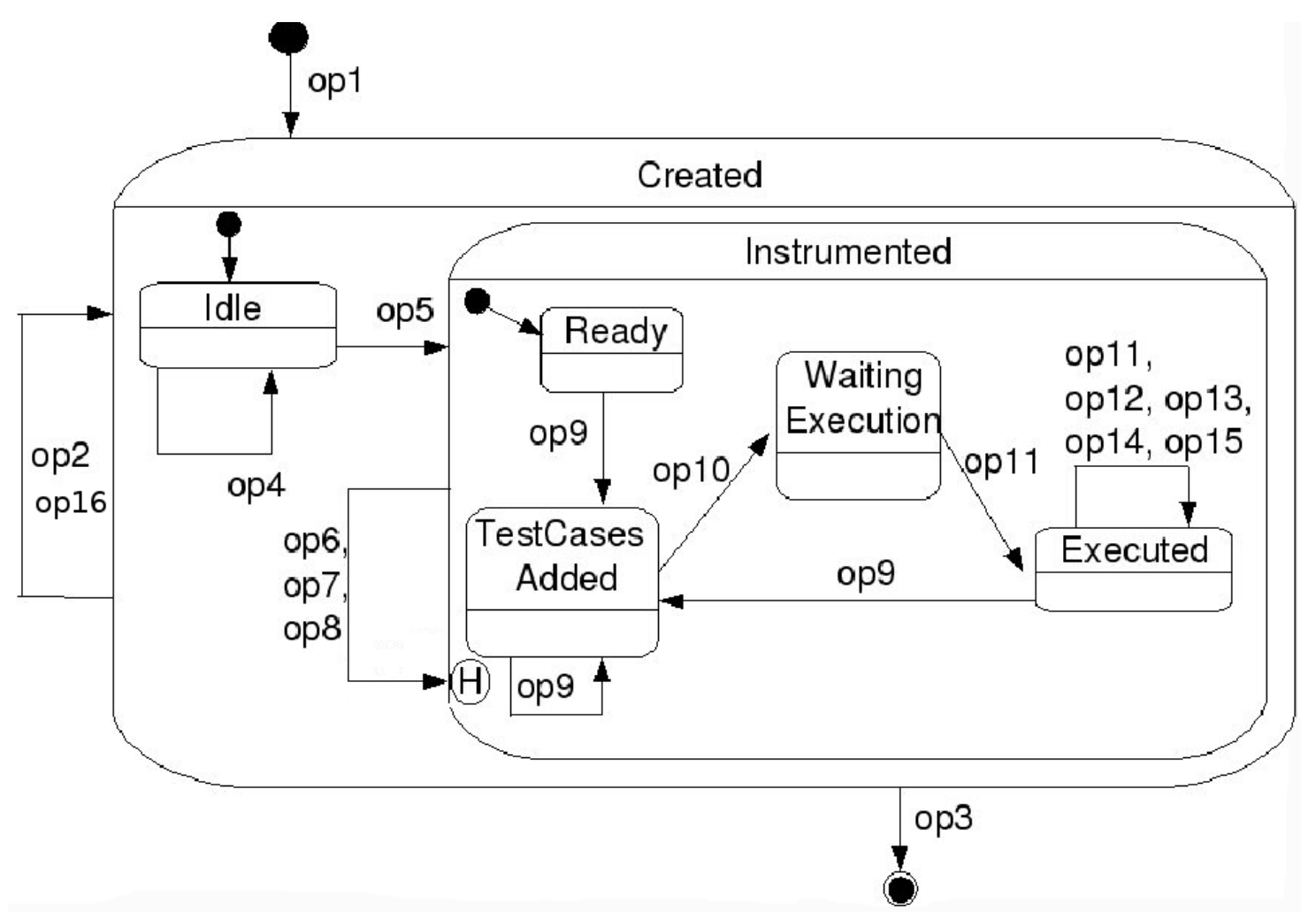

Figura 5.2: Máquina de estado de um projeto de teste criado com o JaBUTiWS

testadas, uma vez que já foram instrumentadas, e os requisitos de teste já foram gerados. As operações para obter os requisitos de teste do projeto todo (op6), obter os requisitos de teste de cada critério (op7) e obter o grafo de fluxo de controle de cada método (op8) podem ser invocadas a qualquer momento no estado Inst rumented. Estas operações não alteram o estado do projeto pois são operações de consulta.

A partir do estado Ready, o testador pode adicionar casos de teste ao projeto (op9) e levá-lo ao estado TestCases Added. Neste momento, o JaBUTiWS cria um pacote contendo as classes instrumentadas e os casos de teste adicionados pelo testador. $\mathrm{O}$ testador pode adicionar mais casos de teste enquanto o projeto estiver no estado TestCases Added. Após adicionar os casos de teste, o testador deve obter o pacote gerado pelo JaBUTiWS com as classes instrumentadas e os casos de teste adicionados. Nesse momento, a máquina vai para o estado Waiting Execution para aguardar que o testador execute o pacote recebido.

No pacote recebido pelo testador existem instruções sobre como executá-lo para que o arquivo de rastreamento seja gerado adequadamente. O testador pode criar scripts de invocação do JaBUTiWS para que o pacote seja executado automaticamente. A execução do pacote com o programa instrumentado é feita localmente (ambiente do testador) e não no servidor, porque seria difícil configurar o servidor para atender às configurações específicas de cada projeto de teste (dependências de bibliotecas externas, bancos de dados e outros sistemas).

Após executar o pacote instrumentado, o testador deve enviar o arquivo de rastreamento gerado para o JaBUTiWS (op11). A máquina de estado muda para o estado Executed quando recebe 
o arquivo de rastreamento e imediatamente realiza a análise de cobertura verificando quais requisitos de teste foram cobertos pelos casos de teste executados. A partir do estado Executed, o testador pode: adicionar novos casos de teste (op9), o que leva a máquina novamente para o estado TestCases Added; obter a cobertura geral do projeto (op12); obter a cobertura estrutural de cada classe (op13); obter a cobertura estrutural de cada método (op14); e obter uma lista dos requisitos de teste que foram cobertos e também dos que não foram cobertos pelos casos de teste (op15).

As especificações de cada operação do JaBUTiWS e outros detalhes internos do serviço podem ser vistos em sua documentação técnica que está disponível neste link: http://www.qualipso.org/sites/default/files/jabutiService - architecture.pdf.

\subsubsection{Exemplo de uso}

O conjunto de classes da biblioteca Apache-Commons-BeanUtils (BeanUtils, 2012) foi escolhido para exemplificar o uso do JaBUTiWS como um serviço de teste estrutural. A biblioteca foi desenvolvida pelo grupo Apache Foundation e possui 62 classes e 478 métodos. O exemplo apresentado refere-se ao teste de unidade das classes da biblioteca (considerando o método como uma unidade) levando em consideração os critérios todos-nós, todos-usos e todas-arestas para a análise de cobertura.

Um script foi escrito para invocar o JaBUTiWS utilizando a seguinte sequência de operações:

1. createProject (op1);

2. selectClassesToInstrument (op5);

3. addTestCases (op9);

4. getInstrumentedProject (op10);

5. sendTraceFile (op11); and

6. getCoverageByCriteria (op12).

No primeiro passo foi criado um projeto com o nome Apache-Common-BeanUtils-test e no segundo passo todas as classes da biblioteca foram selecionadas para serem instrumentadas. No terceiro passo os casos de teste para testar a biblioteca BeanUtils foram enviados para o JaBUTiWS. Neste caso, foram utilizados os 243 casos de teste implementados por 27 classes JUnit que estavam disponíveis juntamente com biblioteca. No passo 4 o pacote com as classes instrumentadas e os casos de teste foram obtidos e executados. Em seguida, o arquivo de rastreamento foi enviado para o serviço (passo 5) e a análise de cobertura estrutural foi obtida (passo 6).

Um trecho do script criado para invocar o JaBUTiWS referente aos passos 4 e 5 é apresentado na Listagem 5.1. As linhas 1 a 6 mostram os comandos utilizados para invocar o JaBUTiWS e 
obter o pacote com as classes instrumentadas e os casos de teste. O pacote é então renomeado para package . jar e armazenado em um diretório local. A linha 8 mostra a execução do pacote localmente. A string de execução foi omitida por questões de espaço, mas nela foi determinada a execução do pacote package. jar e a geração de um arquivo trace. trc contendo as informações de rastreamento da execução dos casos de teste. As linhas 10 a 17 mostram os comandos utilizados para enviar o arquivo trace. trc para o JaBUTiWS.

Listagem 5.1: Trecho do script usado para invocar o JaBUTiWS

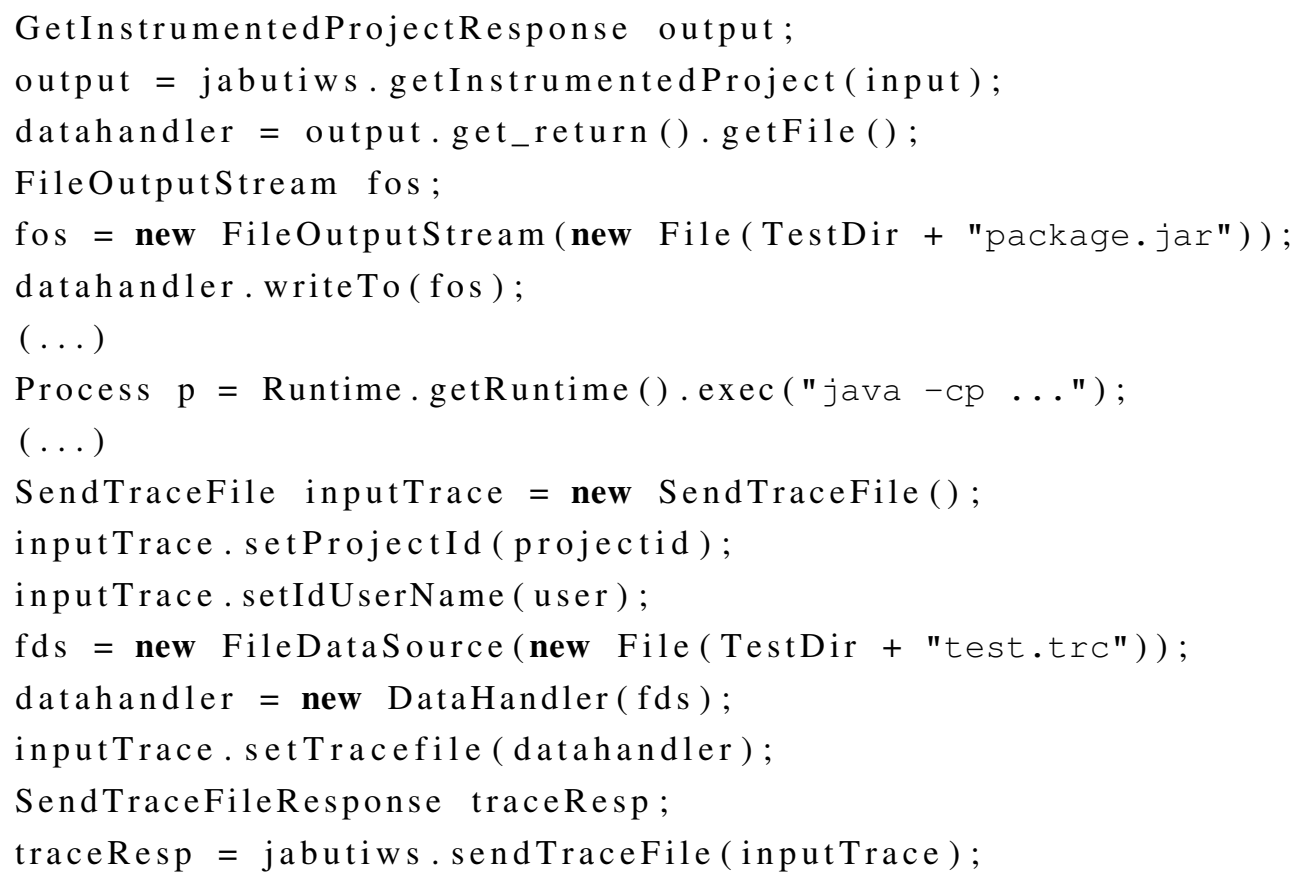

A cobertura estrutural obtida pela execução dos casos de teste da biblioteca Apache-CommonsBeanUtils pode ser vista na Tabela 5.2. O relatório de cobertura apresentado considera todos os métodos das 62 classes do projeto. A primeira coluna mostra o critério considerado. A segunda coluna mostra a soma de todos os requisitos de teste de todos os métodos do projeto cobertos pelos casos de teste. A terceira coluna mostra a soma de todos os requisitos de teste de todos os métodos do projeto. A quarta coluna mostra a porcentagem de cobertura obtida com a execução dos casos de teste. Esse relatório também poderia ter sido mostrado para cada classe ou para cada método do projeto para que o testador tivesse uma idéia melhor sobre quais classes e/ou métodos teriam necessidade de ser testados mais extensivamente.

Tabela 5.2: Cobertura estrutural obtida com a execução dos casos de teste da biblioteca Apache-Commons-BeanUtils usando o JaBUTiWS

\begin{tabular}{|c|c|c|c|}
\hline Critério & Req. de teste cobertos & Req. de teste & Cobertura \\
\hline \hline Todos-nós & 966 & 1571 & $61 \%$ \\
\hline Todas-arestas & 860 & 1583 & $54 \%$ \\
\hline Todos-usos & 1783 & 3639 & $46 \%$ \\
\hline
\end{tabular}




\subsubsection{Aplicações}

O JaBUTiWS está sendo usado atualmente em dois projetos não relacionados a esta tese de doutorado: ProgTest (Barbosa et al., 2008; de Souza et al., 2011) e Qualipso (QUALIPSO, 2012). ProgTest é uma ferramenta de apoio ao ensino de programação e de teste de software. O objetivo da ferramenta é fornecer apoio automatizado aos professores para a correção de exercícios de implementação de programas e criação de casos de teste submetidos por alunos. Para a correção, a ferramenta utiliza o JaBUTiWS para instrumentar, executar os casos de teste e avaliar a cobertura estrutural obtida pelos alunos. A cobertura estrutural obtida é comparada com um gabarito fornecido pelo professor e estas informações são utilizadas para atribuir notas aos exercícios submetidos pelos alunos.

O projeto QualiPSo (Quality Platform for Open Source Software) "propõe-se a definir e implementar tecnologias, procedimentos, leis e políticas com o objetivo de potencializar as práticas de desenvolvimento de software livre, tornando-as confiáveis, reconhecidas e estabelecidas na indústria". Para isso, o projeto desenvolveu um repositório (factory) orientado a serviços que facilita a integração entre serviços, componentes e sistemas de informação de outras empresas. $\mathrm{O}$ repositório oferece serviços para combinar tanto ambientes de desenvolvimento quanto ambientes de compartilhamento de informações, tais como: VOIP, controle de versão, bug tracker, lista de emails, gerenciamento de documentos, etc. Neste contexto, o JaBUTiWS tem sido utilizado em um ambiente integrado com ferramentas de métrica de software e de monitoração de qualidades de serviço, como o Spago4Q (Engineering Group, 2012), por exemplo.

\subsection{JaBUTiWS: uma instânciação do Serviço de Teste da abordagem BISTWS}

O serviço de teste estrutural JaBUTiWS foi estendido para atender aos requisitos da abordagem e desempenhar o papel do Serviço de Teste. Foi acrescentada a seguinte operação na interface do JaBUTiWS para receber um serviço comum implementado em Java e retornar um serviço testável com todas as características definidas pela abordagem:

- createBISTWS (name, package, implementation, level).

O parâmetro name refere-se ao nome do serviço a ser instrumentado. O parâmetro package é um arquivo .jar, .war ou .aar contendo as classes (bytecode) do serviço a ser instrumentado. O parâmetro implementation refere-se à classe que implementa as operações da interface do serviço. O parâmetro level é usado para definir em que níveis de detalhes os relatórios de cobertura serão gerados para o serviço testável (para o serviço todo, para cada operação da interface, para cada classe interna ou para cada método). O retorno desta operação é o mesmo pacote recebido, mas com a versão do serviço testável no lugar do serviço comum. Se o pacote enviado é do tipo .war ou .aar, o serviço já está pronto para ser publicado. 
Nesta implementação optou-se por utilizar as tecnologias do Axis2 que geram as especificações WSDL automaticamente na publicação do serviço. Assim, quando um serviço testável é publicado, as operações adicionadas pela instrumentação do JaBUTiWS são automaticamente publicadas no WSDL para serem usadas externamente.

A seguir são apresentados alguns detalhes sobre como o JaBUTiWS transforma um serviço comum em um serviço testável e como são feitos os cálculos de cobertura estrutural e a geração dos metadados.

\subsubsection{Instrumentação}

Os desenvolvedores que desejam transformar um serviço comum escrito em Java em um serviço testável devem utilizar a operação createBISTWS do JaBUTiWS. Cada serviço enviado ao JaBUTiWS para ser instrumentado e transformado em testável dá origem a um projeto de teste. $\mathrm{O}$ projeto de teste é criado para armazenar as classes do serviço recebidas, as versões instrumentadas das classes, os requisitos de teste do serviço e as informações de execução de cada sessão de teste realizada desde que o cálculo de cobertura tenha sido requisitado para ela.

A instrumentação é feita com a biblioteca BCEL (Byte Code Engineering Library) e instruções são inseridas no código para registrar as informações necessárias para verificar a cobertura dos requisitos gerados pelos critérios todos-nós, todas-arestas, todos-usos e todos-p-usos. Nos exemplos apresentados nesta tese somente são utilizados os três primeiros critérios. A instrumentação também insere as operações da interface de teste e suas implementações. A implementação das operações da interface de teste correspondem a uma chamada às operações de uma biblioteca de classes que é inserida no pacote de classes do serviço.

Após a instrumentação, um serviço testável gerado pelo JaBUTiWS recebe as seguintes operações de teste:

- void startTrace (String userID, String sessionID): corresponde à operação iniciarTeste definida pela abordagem BISTWS. Esta operação recebe como parâmetro o identificador de um usuário e o identificador de uma sessão de teste, que são usados pelo serviço testável para identificar os arquivos de rastreamento de sua execução. Note que, além de usar o identificador da sessão de teste, esta implementação definiu que a operação para iniciar a sessão de teste também deve receber o identificador do usuário que está iniciando a sessão de teste para evitar conflitos e duplicidade de identificadores de sessões de teste.

- void stoptrace (String userID, String sessionID): corresponde à operação finalizarTeste definida pela abordagem BISTWS e é usada para encerrar uma sessão de teste. Os identificadores recebidos como parâmetros de entrada são usados para que o serviço saiba qual sessão de teste será encerrada para que os detalhes das execuções daquele usuário e naquela sessão não sejam mais registradas. 
- XML getCoverage(String userID, String sessionid, String level): corresponde à operação obterCoberturaEstrutural definida pela abordagem BISTWS e é usada para retornar o relatório de cobertura estrutural para uma determinada sessão de teste (sessionID) executada por um determinado usuário (userID). Repare que, além de incluir o parâmetro para identificar um usuário, esta implementação incluiu o parâmetro level na especificação desta operação. O parâmetro level é usado pelo serviço para saber em que nível de detalhes o integrador deseja obter o cálculo de cobertura. O retorno da operação é um arquivo.XML contendo o relatório de cobertura estrutural.

- XML getMetadata (String type): corresponde à operação obterMetadados ( ) definida pela abordagem BISTWS e é utilizada para retornar os metados de teste publicados pelo desenvolvedor. O parâmetro type é utilizado para especificar qual tipo de metadado o integrador deseja obter (a priori ou sob demanda). O retorno da operação é um arquivo .XML contendo os metadados de teste.

Listagem 5.2: Arquivo de propriedades de um serviço testável criado com o JaBUTiWS

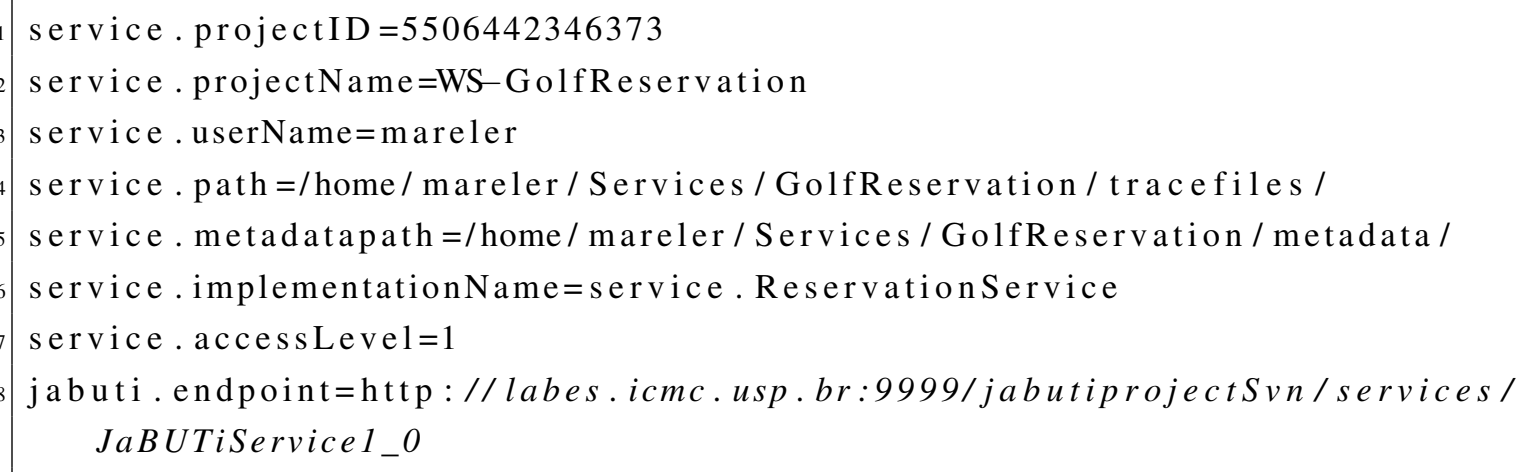

Assim que o serviço é transformado em um serviço testável, o desenvolvedor recebe de volta um pacote contendo o serviço instrumentado. Juntamente com o serviço estão as bibliotecas necessárias para a invocação do JaBUTiWS e um arquivo de propriedades. Na listagem 5.2 é apresentado um exemplo de um arquivo de propriedades de um serviço testável, que contém as seguintes informações:

- Identificador do projeto (projectID): corresponde ao identificador do projeto de teste criado no JaBUTiWS. O serviço testável utiliza esta informação toda vez que chama o JaBUTiWS, pois é por meio do identificador que o Serviço de Teste consegue encontrar o projeto em que estão armazenados os requisitos de teste para fazer o cálculo da cobertura estrutural.

- Nome do projeto (projectName): corresponde ao nome do projeto de teste criado no JaBUTiWS.

- Nome de usuário (username): corresponde ao usuário do JaBUTiWS que criou o serviço testável 
- Diretório local (path): diretório onde os arquivos de rastreamento da execução do serviço testável serão armazenados. Quando o serviço testável é executado em uma sessão de teste ele gera o arquivo de rastreamento nesse local. Quando é requisitada a análise de cobertura do serviço ele também utiliza essa informação para encontrar o arquivo de rastreamento para enviar para o JaBUTiWS calcular a cobertura.

- Diretório dos metadados (metadatapath) : diretório onde os arquivos de metadados estão armazenados. Os desenvolvedores devem definir aqui o local onde os metadados por ele produzidos estarão armazenados.

- Classe que implementa a interface do serviço (implementationName).

- Nível de acesso (accessLevel): define o quão detalhada pode ser feita a análise de cobertura. A qualquer momento o desenvolvedor pode mudar o nível de acesso e permitir que os integradores tenham relatórios mais detalhados.

- Endereço do JaBUTiWS (endpoint): indica onde o JaBUTiWS está publicado. É importante este endereço estar correto para que o JaBUTiWS seja invocado corretamente quando o cálculo de cobertura for requerido do serviço testável.

\subsubsection{Cálculo de cobertura estrutural}

Quando um integrador faz a requisição do relatório de cobertura estrutural, o serviço testável envia o arquivo com as informações de execução para o JaBUTiWS realizar o cálculo da cobertura estrutural. O JaBUTiWS obtém as informações do projeto de teste criado para o serviço e faz a análise de cobertura utilizando os dados de rastreamento da execução do serviço e os requisitos de teste armazenados.

O cálculo de cobertura pode ser feito para o serviço todo, para cada classe ou para cada método das classes. O JaBUTiWS faz esses cálculos da seguinte forma: dado um método $i$ e um critério $j$, $T R M_{i j}$ é o número de requisitos de teste do método $i$ para o critério $j$. $C T R M_{i j}$ é o número de requisitos de teste do método $i$ que foram cobertos para o critério $j$. A cobertura do método $i$ para o critério $j\left(C M_{i j}\right)$ é então dada por $\frac{C T R M_{i j}}{T R M_{i j}}$.

Dada uma classe $p$ e um critério $j$ e considerando $m$ como o número de métodos da classe $p$, $T R C_{p j}=\sum_{i=1}^{m} T R M_{i j}$ é o número de requisitos de teste da classe $p$ para o critério $j$. $C T R C_{p j}=$ $\sum_{i=1}^{m} C T R M_{i j}$ é o número de requisitos de teste da classe $p$ que foram cobertos para o critério $j$. A cobertura da classe $p$ para o critério $j$ é dado por $\frac{C T R C_{p j}}{T R C_{p j}}$.

Dado um serviço $q$, um critério $j$ e considerando $n$ como o número de classes que compõem o serviço $q, T R S_{q j}=\sum_{p=1}^{n} T R C_{p j}$ é o número de requisitos de teste do serviço $q$ para o critério j. $C T R S_{q j}=\sum_{p=1}^{n} C T R C_{p j}$ é o número de requisitos de teste do serviço $q$ que foram cobertos para o critério $j$. A cobertura do serviço $q$ para o critério $j$ é dada por $\frac{C T R S_{q j}}{T R S_{q j}}$. 
Listagem 5.3: Estrutura XML dos metadados do tipo a priori

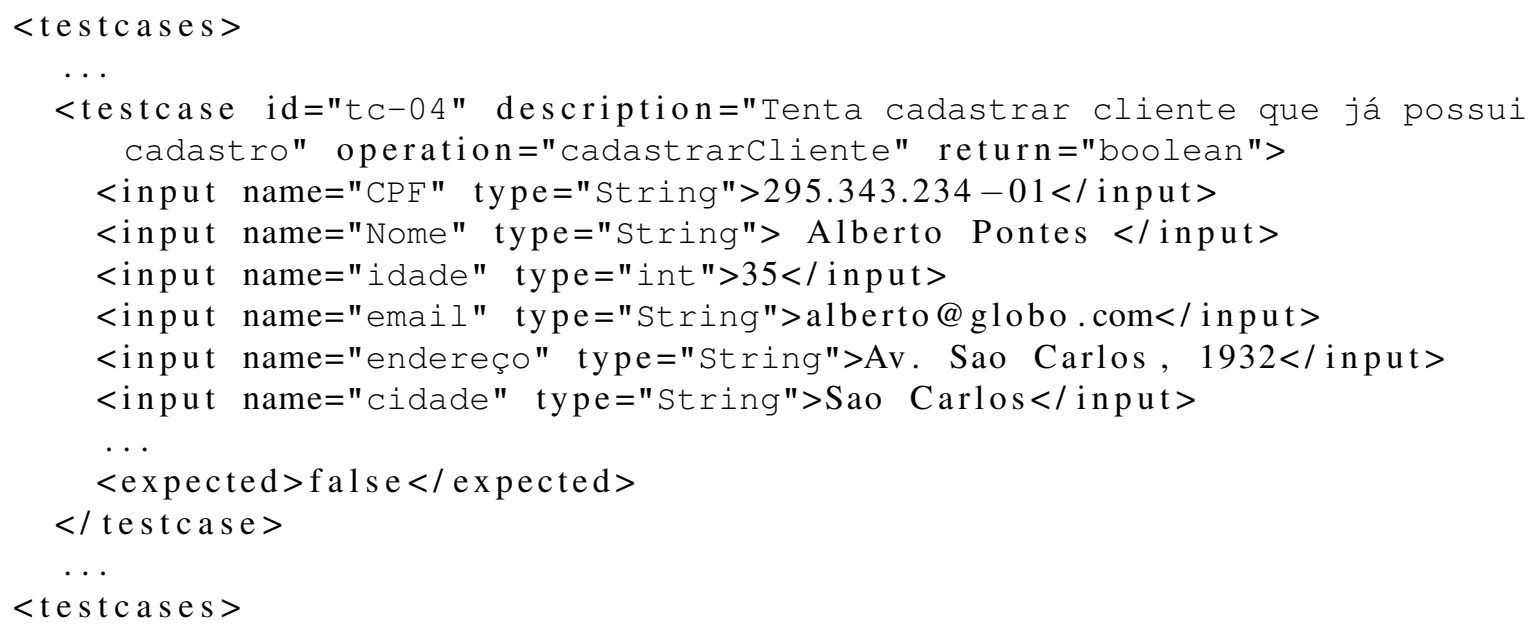

\subsubsection{Metadados}

A implementação da abordagem BISTWS usando o JaBUTiWS também definiu um formato para os desenvolvedores publicarem os metadados de teste juntamente com os serviços testáveis. É importante que os metadados estejam no formato exigido pela implementação para que os serviços testáveis possam manipular os metadados adequadamente.

A listagem 5.3 mostra um exemplo de como os casos de teste dos metadados de teste devem estar formatados. O metadado deve ser fornecido como um arquivo .XML. O tag raiz deve ser chamado de <testcases> e os casos de teste <testcase> devem estar aninhados dentro dele. Cada caso de teste deve conter um identificador, uma descrição textual, o nome da operação para a qual o caso de teste foi criado e o tipo de retorno. Cada dado de entrada do caso de teste deve conter nome, tipo e valor. O resultado esperado do caso de teste também deve estar informado.

\subsubsection{Um exemplo de uso da abordagem BISTWS para testar um ser- viço isoladamente}

A implementação da abordagem BISTWS usando o serviço JaBUTiWS é apresentada nesta seção por meio do exemplo de um serviço chamado ShippingWS e que foi transformado em um serviço testável. ShippingW.S é um serviço que tem por objetivo calcular o custo da entrega de uma encomenda com base no CEP de origem, CEP de destino, peso e tipo de serviço de entrega. Além disso, o serviço também possui uma operação para a consulta de um endereço com base em um CEP.

O cálculo da encomenda é feito com base em uma tabela disponibilizada pelo provedor do serviço e que leva em consideração as distâncias entre os CEPs de origem e de destino, o tipo de entrega ( 1 - sedex e 2 - básico) e o peso da encomenda. Encomendas com peso acima de 500g são sempre tarifadas com o tipo de entrega 1 , mesmo se a requisição for para a entrega do tipo 2. 
A seguir são apresentadas as tarefas executadas pelas perspectivas do desenvolvedor para desenvolver e transformar ShippingWS em um serviço testável e do integrador para realizar o teste de ShippingWS isoladamente.

\section{Desenvolvedor}

Inicialmente o desenvolvedor criou ShippingWS usando a linguagem Java e gerou um pacote .war para publicar o serviço. O diagrama de classes do serviço é apresentado na Figura 5.3. A interface de ShippingWS possui duas operações: calcShippingPrice and getAddress. A interface é implementada pela classe Shipping que usa as classes PriceMgre ZipMgr.

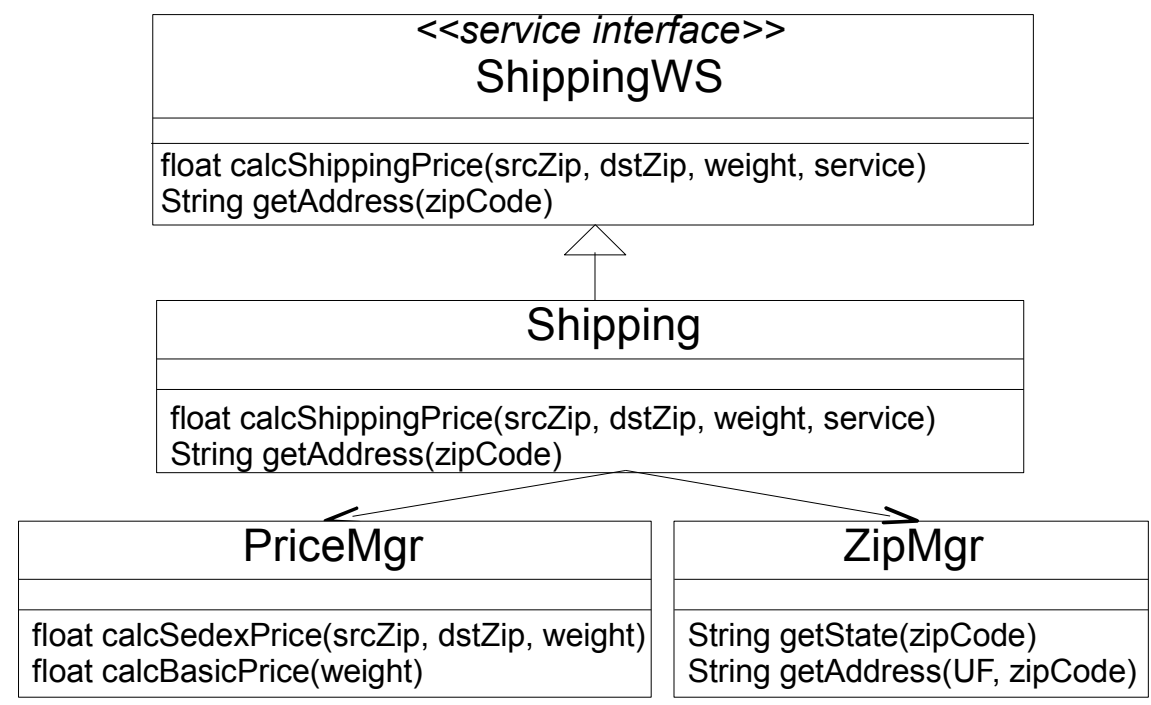

Figura 5.3: Diagrama de classes de ShippingWS.

O desenvolvedor utilizou o JaBUTiWS para instrumentar ShippingWS e gerar uma versão testável do serviço. Para isto ele criou um script acionado por uma interface gráfica para facilitar a invocação do JaBUTiWS e a geração de serviços testáveis. A interface gráfica criada e utilizada para instrumentar ShippingWS é mostrada na Figura 5.4. O desenvolvedor informou o endereço de JaBUTiWS, a localização do pacote .war contendo ShippingWS, o nome da classe que implementa a interface do serviço e a pasta em que o pacote contendo a versão testável de ShippingWS deverá ser retornado. O desenvolvedor também indicou que a instrumentação e o relatório de cobertura deste serviço pode ser feito para o nível 3 (serviço, operações da interface, classes e métodos).

Após a instrumentação, a interface de ShippingWS recebeu novas operações para apoiar o teste estrutural. A nova interface de ShippingWS pode ser vista na Tabela 5.3.

O desenvolvedor publicou como metadados do tipo a priori os casos de teste utilizados para testar o serviço em tempo de desenvolvimento juntamente com a versão testável de ShippingWS. Os casos de teste publicados pelo desenvolvedor podem ser vistos na Tabela 5.4 e alcançam 100\% 


\section{Q $\bigcirc$ Testable Web Service Generation}

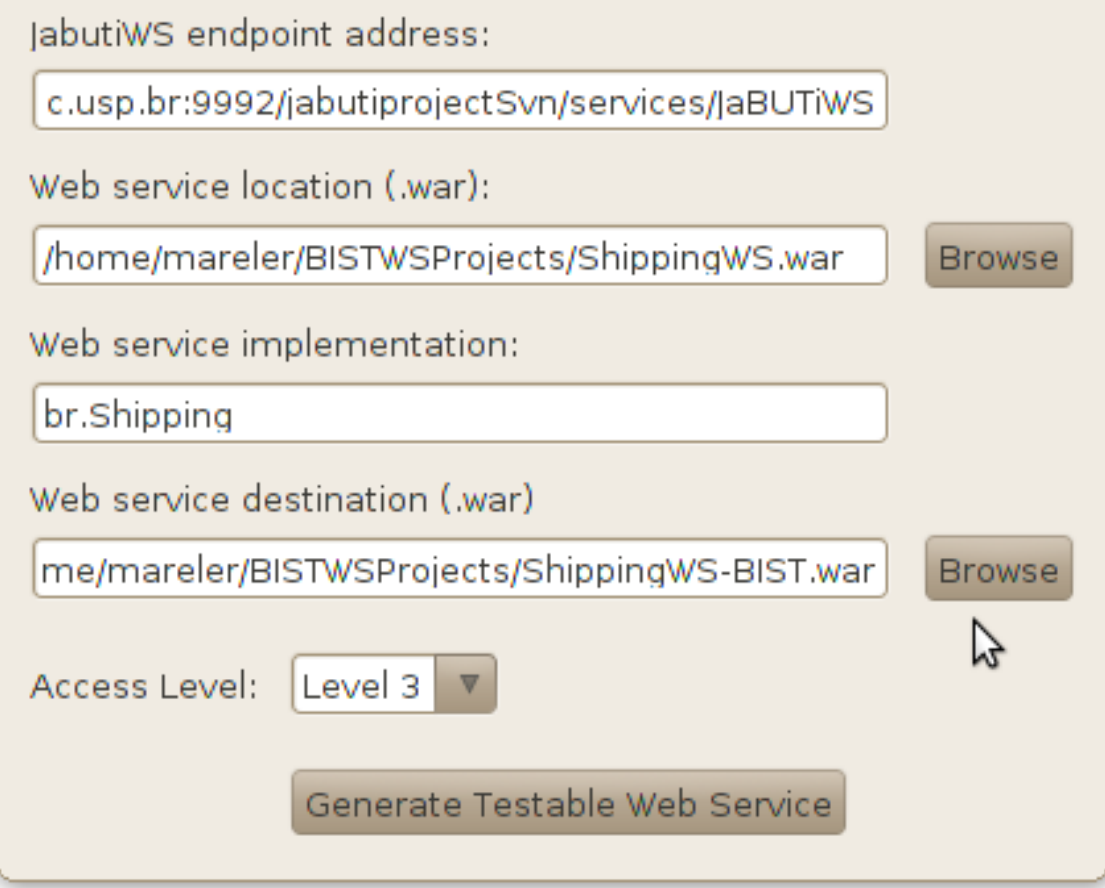

Figura 5.4: Interface gráfica usada para gerar um serviço testável

\begin{tabular}{|l|}
\hline «service interface» \\
ShippingWS \\
\hline \hline float calcShippingPrice(String srcZip, String dstZip, weight, service) \\
String getAddress(String zipCode) \\
void startTrace(String userID, String sessionID) \\
void stopTrace(String userID, String sessionID) \\
XML getCoverage(String userID, String sessionID, String level) \\
XML getMetadata(String type) \\
\hline
\end{tabular}

Tabela 5.3: Interface de ShippingWS com as operações de teste

de cobertura para todos os critérios estruturais implementados pelo JaBUTiWS e considerados na análise de cobertura (todos-nós, todas-arestas e todos-usos).

\section{Integrador}

Um integrador resolveu testar o serviço ShippingWS isoladamente antes de usá-lo em sua aplicação. Para isto criou um conjunto de casos de teste que considerou relevante para testar o serviço. Os casos de teste criados pelo integrador podem ser vistos na Tabela 5.5.

Após especificar os casos de teste, o integrador criou um script para testar ShippingWS e obter a análise de cobertura estrutural dos casos de teste executados. O diagrama de sequência que representa o script de teste criado pode ser visto na Figura 5.5. No início do teste o integrador invocou a operação startTrace para informar ao serviço ShippingWS que uma sessão de 
Tabela 5.4: Casos de teste fornecidos como metadado do tipo a priori de ShippingWS

\begin{tabular}{|c|l|l|l|}
\hline TC-ID & Entrada & Saída esperada & Descrição \\
\hline \hline CalcShippingPrice & srcZip, dstZip, weight, service & Saída esperada & Descrição \\
\hline 01 & $13566580,19500000,0.3,1$ & 11.9 & Entrega tipo 1 \\
\hline 02 & $13566580,13566580,0.4,2$ & 6.85 & Entrega tipo 2 e peso $\leq 500 \mathrm{~g}$ \\
\hline 03 & $13566580,13566580,0.7,2$ & 11.2 & Entrega tipo 2 e peso > 500g \\
\hline 04 & $13566,13566580,0.7,2$ & ZipFault & Entrega tipo 2 e CEP de origem inválido \\
\hline 05 & $13566580,130,0.7,2$ & ZipFault & Entrega tipo 2 e CEP de destino inválido \\
\hline 06 & $13566580,13566580,-0.5,2$ & InputFault & Entrega tipo 2 e peso inválido \\
\hline 07 & $13566580,13566580,0.5,3$ & InputFault & Tipo de entrega inválido \\
\hline \hline GetAddress & zipCode & Saída esperada & Descrição \\
\hline 01 & 09040240 & R. Laura & Teste com CEP válido \\
\hline 02 & 1340, & ZipFault & Teste com CEP inválido \\
\hline
\end{tabular}

Tabela 5.5: Casos de teste criados pelo integrador para testar ShippingWS isoladamente

\begin{tabular}{|c|l|l|}
\hline CalcShippingPrice & srcZip, dstZip, weight, service & Saída esperada \\
\hline calc-01 & $13564390,03356001,0.4,1$ & 13.4 \\
\hline calc-02 & $60150190,50060001,0.4,2$ & 11.5 \\
\hline calc-03 & $13566580,13566580,0.7,2$ & 19.1 \\
\hline \hline GetAddress & zipCode & Saída esperada \\
\hline address-01 & 63100000 & R. Santo Antonio \\
\hline
\end{tabular}

teste seria iniciada e que era necessário registrar as informações de sua execução. Em seguida o integrador executou os casos de teste para a operação calcShippingPrice e depois executou os casos de teste para a operação getAddress. Durante a execução dos casos de teste ShippingWS fez o rastreamento das estruturas internas exercitadas e armazenou em um arquivo chamado infoExec. Ao terminar de executar os casos de teste, o integrador informou ao serviço testável que a sessão de teste havia encerrado e requisitou uma análise de cobertura estrutural. Neste momento, ShippingWS invocou o JaBUTiWS informando o identificador do projeto em que o serviço foi instrumentado e as informações de execução registradas durante a sessão de teste. O JaBUTiWS localizou os requisitos de teste de ShippingWS utilizando o identificador de projeto e verificou quais requisitos foram cobertos pelas informações de execução recebidas. Em seguida, o JaBUTiWS gerou um relatório de cobertura estrutural e o enviou a ShippingWS que repassou o relatório ao integrador.

O relatório da cobertura estrutural obtida pelos casos de teste criados pelo integrador pode ser visto na Tabela 5.6. O relatório foi feito considerando 4 níveis de abstração: o serviço todo, as operações da interface, as classes que compõem o serviço e os métodos que compõem as classes. Para cada nível de abstração são apresentadas as coberturas para os critérios todos-nós, todasarestas e todos-usos. Para cada cobertura é apresentado o número de requisitos de teste cobertos sobre o número de requisitos de teste existentes e a porcentagem de cobertura alcançada.

No relatório de cobertura apresentado é possível perceber que o integrador não conseguiu alcançar uma cobertura de $100 \%$ com os casos de teste feitos pelo desenvolvedor. Nesta situação, o integrador obteve os metadados gerados sob demanda fornecidos por ShippingWS e pode per- 


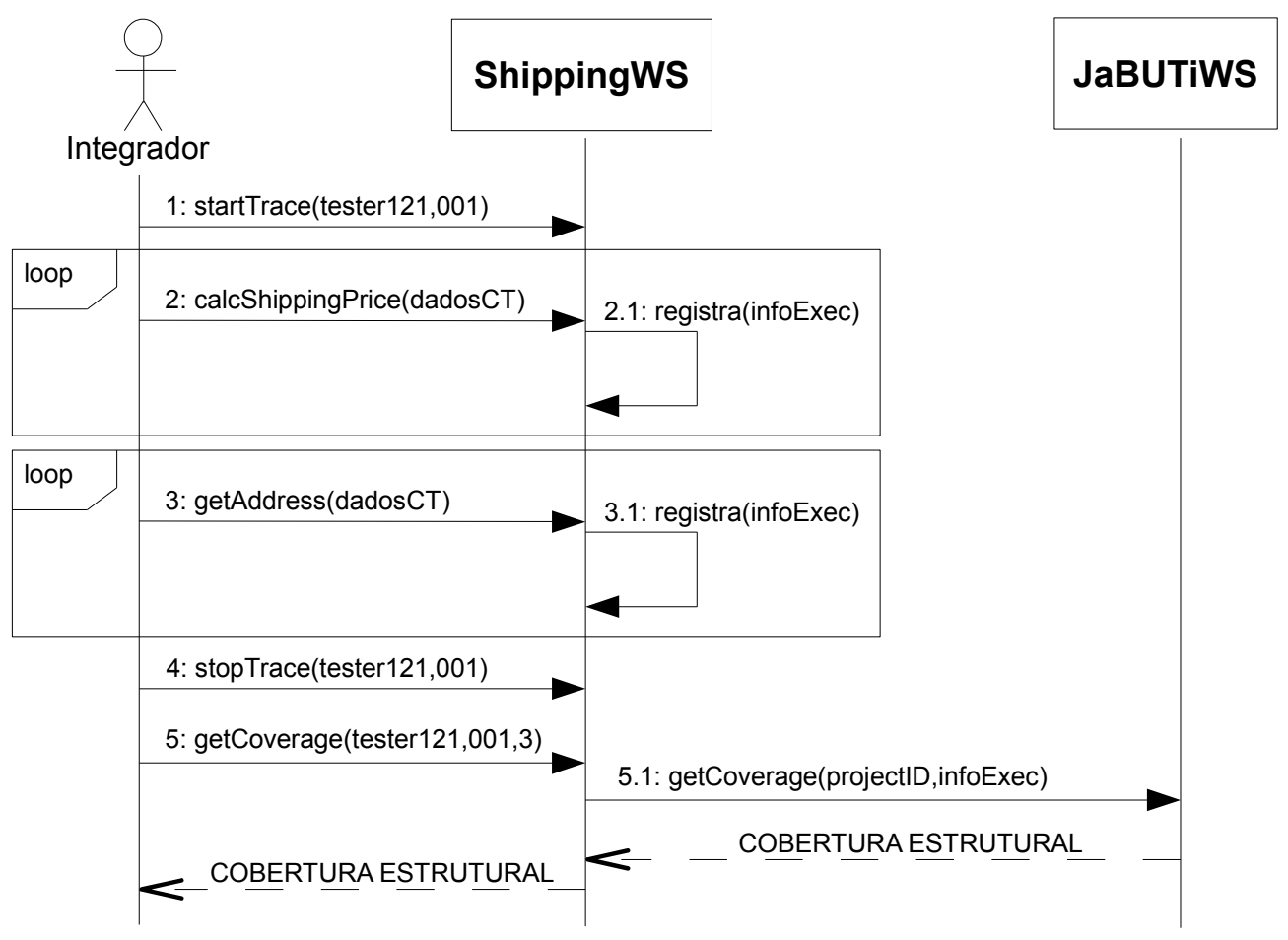

Figura 5.5: Diagrama de sequência usado pelo integrador para testar ShippingWS

ceber que não havia criado casos de teste para exercitar o serviço em situações em que os dados são inválidos. Tendo feito isto, o integrador criou mais casos de teste e conseguiu alcançar $100 \%$ de cobertura em todos os critérios e para todos os níveis de abstração.

\subsection{Um estudo de caso usando a abordagem BISTWS para testar um serviço no contexto de uma aplicação}

Um estudo de caso foi realizado para avaliar a utilização da abordagem BISTWS para auxiliar um integrador no teste de um serviço testável no contexto de uma aplicação. Neste estudo foi utilizada uma aplicação real chamada Broad Leaf Commerce ${ }^{1}$. A aplicação é um framework de comércio eletrônico dividido em vários serviços que oferecem funcionalidades tais como gerenciamento de catálogo de produtos e de clientes, carrinho de compras, pedidos, entregas e pagamentos. Junto com o framework também está disponível a instanciação de uma aplicação e conjuntos de casos de teste para os diversos serviços oferecidos.

Na versão atual os serviços da aplicação não estão publicados e integrados por meio de uma composição de serviços, mas todo o código foi dividido em serviços para que ele funcione desta maneira nas próximas versões. Para este estudo de caso foi isolada uma parte da aplicação e os serviços que a compõem foram publicados como serviços para a investigação proposta.

\footnotetext{
${ }^{1} \mathrm{http}: / /$ www.broadleafcommerce.org
} 
Tabela 5.6: Análise de cobertura estrutural dos casos de teste do integrador

\begin{tabular}{|c|c|c|c|}
\hline Service & Todos-nós & Todas-arestas & Todos-usos \\
\hline \hline ShippingWS & $25 / 42(60 \%)$ & $9 / 51(57 \%)$ & $58 / 90(64 \%)$ \\
\hline \hline Operation & Todos-nós & Todas-arestas & Todos-usos \\
\hline \hline calcShippingPrice & $8 / 13(62 \%)$ & $8 / 18(44 \%)$ & $22 / 34(65 \%)$ \\
\hline getAddress & $2 / 3(67 \%)$ & $1 / 2(50 \%)$ & $7 / 9(78 \%)$ \\
\hline \hline Class & Todos-nós & Todas-arestas & Todos-usos \\
\hline \hline PriceMgr & $7 / 13(54 \%)$ & $10 / 16(63 \%)$ & $15 / 25(60 \%)$ \\
\hline Shipping & $10 / 16(63 \%)$ & $9 / 20(45 \%)$ & $29 / 43(67 \%)$ \\
\hline ZipMgr & $8 / 13(62 \%)$ & $10 / 15(67 \%)$ & $14 / 22(64 \%)$ \\
\hline \hline Method & Todos-nós & Todas-arestas & Todos-usos \\
\hline \hline PriceMgr.calcBasicPrice & $4 / 7(57 \%)$ & $6 / 9(67 \%)$ & $11 / 16(69 \%)$ \\
\hline PriceMgr.calcSedexPrice & $3 / 6(50 \%)$ & $4 / 7(57 \%)$ & $4 / 9(44 \%)$ \\
\hline Shipping.calcShippingPrice & $8 / 13(62 \%)$ & $8 / 18(44 \%)$ & $22 / 34(65 \%)$ \\
\hline Shipping.getAddress & $2 / 3(67 \%)$ & $1 / 2(50 \%)$ & $7 / 9(78 \%)$ \\
\hline ZipMgr.getAddress & $4 / 7(57 \%)$ & $5 / 8(53 \%)$ & $8 / 13(62 \%)$ \\
\hline ZipMgr.getState & $4 / 6(67 \%)$ & $5 / 7(71 \%)$ & $6 / 9(67 \%)$ \\
\hline
\end{tabular}

Da aplicação foi utilizada uma composição chamada de RegisterService que tem por objetivo fazer o registro dos usuários do sistema de comércio eletrônico. A composição usa vários serviços, entre eles o serviço CustomerService que é responsável por gerenciar os clientes cadastrados no sistema. A composição RegisterService possui duas operações públicas, enquanto CustomerServi ce possui 7 operações. Uma ilustração deste cenário é apresentada na Figura 5.6.

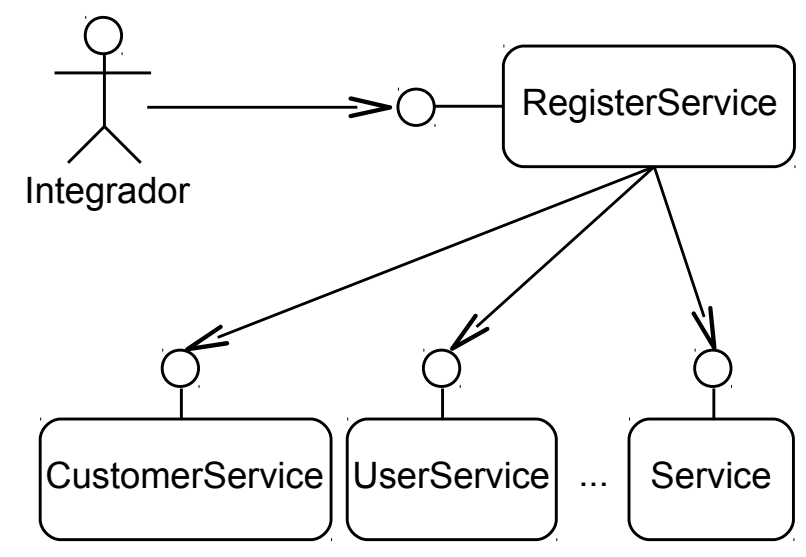

Figura 5.6: Ilustração da composição RegisterService

Os casos de teste da composição RegisterService e do serviço CustomerService estavam disponíveis juntamente com o código fonte da aplicação. O serviço CustomerServi ce foi transformado em um serviço testável usando a implementação da abordagem BISTWS feita com o JaBUTiWS e seus casos de teste foram publicados como metadados de teste do serviço. Os 
casos de teste de CustomerService publicados como metadados do tipo a priori podem ser vistos na Tabela 5.7.

Tabela 5.7: Casos de teste de CustomerService

\begin{tabular}{|c|c|c|c|c|c|c|c|c|}
\hline & \multicolumn{8}{|c|}{ Operação: createFromID } \\
\hline TC-ID & ID & user & passwd & email & chAnsw1 & chAnsw2 & register & Descrição \\
\hline tc-01 & 1001 & cust1 & clpasswd & c1@bleaf.com & - & - & true & Criar/registrar \\
\hline tc-02 & 1002 & cust2 & c2passwd & c2@bleaf.com & - & - & false & Criar/não registrar \\
\hline tc-03 & 1003 & cust3 & c3passwd & c3@bleaf.com & Answ1-ct3 & - & true & c/ chAnswer1 \\
\hline tc-04 & 1004 & cust4 & c4passwd & c4@bleaf.com & Answ1-c4 & Answ2-c4 & true & c/ chAnswer1/2 \\
\hline tc-05 & null & cust5 & c5passwd & c5@bleaf.com & - & - & true & Usar ID automato \\
\hline \multirow[t]{3}{*}{ tc-06 } & 1001 & - & - & - & - & - & - & Create using an existent ID \\
\hline & \multicolumn{8}{|c|}{ Operação: registerCustomer } \\
\hline & ID & user & passwd & email & \multicolumn{4}{|c|}{ Descrição } \\
\hline tc-07 & null & cust7 & c7passwd & c7@bleaf.com & \multicolumn{4}{|c|}{ Registrar e criar ao mesmo tempo(id=null) } \\
\hline \multirow[t]{3}{*}{ tc-08 } & 1002 & cust2 & c2passwd & & \multicolumn{4}{|c|}{ Registrar um customer não registrado (id válido) } \\
\hline & \multicolumn{8}{|c|}{ Operação: readByID } \\
\hline & ID & \multicolumn{7}{|c|}{ Descrição } \\
\hline tc-09 & 1001 & \multicolumn{7}{|c|}{ Usar ID existente } \\
\hline \multirow[t]{3}{*}{ tc-10 } & 7777 & \multicolumn{7}{|c|}{ Usar ID inexistente } \\
\hline & \multicolumn{8}{|c|}{ Operação: readByUsername } \\
\hline & user & \multicolumn{7}{|c|}{ Descrição } \\
\hline tc-11 & cust4 & \multicolumn{7}{|c|}{ Usar usuário válido } \\
\hline \multirow[t]{3}{*}{ tc-12 } & custN & \multicolumn{7}{|c|}{ Usar usuário inválido } \\
\hline & \multicolumn{8}{|c|}{ Operação: readByEmail } \\
\hline & email & \multicolumn{7}{|c|}{ Descrição } \\
\hline tc-13 & $\mathrm{c} 3 @ \ldots$ & \multicolumn{7}{|c|}{ Usar email existente } \\
\hline \multirow[t]{3}{*}{ tc-14 } & $\mathrm{cN@ \ldots}$ & \multicolumn{7}{|c|}{ Usar email inexistente } \\
\hline & \multicolumn{8}{|c|}{ Operação: changePassword } \\
\hline & user & New & Confirm & Descrição & & & & \\
\hline tc-15 & cust 23 & $\mathrm{c} 23 \mathrm{New}$ & $\mathrm{c} 23 \mathrm{New}$ & Tentar mudar p & swd de um c & nte inválido & & \\
\hline tc-16 & cust4 & c4New & c4New & Tentar mudar p & swd de um c & nte válido & & \\
\hline
\end{tabular}

A execução dos casos de teste de CustomerService atinge uma cobertura alta para os critérios todos-nós, todas-arestas e todos-usos, como pode ser visto na Tabela 5.8, e por isso eles são adequado para serem disponibilizados como metadados do tipo a priori.

Tabela 5.8: Cobertura alcançada pela execução dos metadados de teste de CustomerServi ce

\begin{tabular}{|l|c|c|c|}
\hline Serviço & todos-nós & todas-arestas & todos-usos \\
\hline Cust omerService & $97 \%$ & $93 \%$ & $87 \%$ \\
\hline Operações & todos-nós & todas-arestas & todos-usos \\
\hline createFromId & $90 \%$ & $92 \%$ & $72 \%$ \\
\hline registerCustomer & $100 \%$ & $100 \%$ & $100 \%$ \\
\hline saveCustomer & $90 \%$ & $86 \%$ & $84 \%$ \\
\hline readById & $100 \%$ & $100 \%$ & $100 \%$ \\
\hline readByUsername & $100 \%$ & $100 \%$ & $100 \%$ \\
\hline readByEmail & $100 \%$ & $100 \%$ & $100 \%$ \\
\hline changePassword & $100 \%$ & $100 \%$ & $80 \%$ \\
\hline
\end{tabular}

O objetivo deste estudo de caso é testar a composição Regi sterServi ce com o objetivo de exercitar ao máximo sua integração com CustomerService, isto é, obter uma cobertura estrutural alta para CustomerServi ce a partir da execução dos casos de teste de Reg i sterService. Para isto o integrador que irá testar a composição deve utilizar os metadados fornecidos pelo serviço testável e criar um perfil de uso para que a cobertura calculada seja adequada ao que a composição requer do serviço. 
Durante o estudo de caso algumas questões de pesquisa deverão ser respondidas:

- QP1: Os metadados fornecidos pelos serviços testáveis ajudam os integradores a aumentar a cobertura obtida da integração entre a composição e o serviço testável?

- QP2: O perfil de uso do serviço testável é útil para gerar uma cobertura adequada e relativa ao contexto da composição?

Neste estudo de caso, o integrador utilizou os casos de teste de RegisterServi ce como o conjunto inicial de casos de teste para testar a composição. O integrador iniciou a sessão de teste invocando a operação startTrace de CustomerService. Em seguida executou os 4 casos de teste do conjunto e invocou a operação stopTrace de CustomerService para indicar o fim da sessão de teste. Ao consultar a cobertura estrutural alcançada, o integrador obteve o relatório que está apresentado na Figura 5.9.

Tabela 5.9: Cobertura estrutural obtida pelo integrador ao testar CustomerServi ce no contexto da composição RegisterService

\begin{tabular}{|l|c|c|c|}
\hline Serviço & todos-nós & todas-arestas & todos-usos \\
\hline CustomerService & $50 \%$ & $34 \%$ & $34 \%$ \\
\hline Operações & todos-nós & todas-arestas & todos-usos \\
\hline createFromId & $54 \%$ & $35 \%$ & $25 \%$ \\
\hline registerCustomer & $100 \%$ & $66 \%$ & $65 \%$ \\
\hline saveCustomer & $54 \%$ & $33 \%$ & $33 \%$ \\
\hline readById & $0 \%$ & $0 \%$ & $0 \%$ \\
\hline readByUsername & $100 \%$ & $100 \%$ & $100 \%$ \\
\hline readByEmail & $0 \%$ & $0 \%$ & $0 \%$ \\
\hline changePassword & $0 \%$ & $0 \%$ & $0 \%$ \\
\hline
\end{tabular}

É possível perceber que a cobertura de CustomerService obtida pela execução dos casos de teste de RegisterService é baixa. Isso ocorreu porque os casos de teste foram insuficientes e também porque existem funcionalidades de CustomerService que possivelmente não são utilizadas por RegisterService. Para aumentar a cobertura alcançada o integrador deverá, até que esteja satisfeito ou não existam mais casos de teste significativos a serem criados, realizar as seguintes tarefas iterativamente:

1. Obter as sugestões de casos de teste fornecidas pelo serviço testável como metadados gerados sob demanda.

2. Usar os casos de teste sugeridos pelo serviço testável para criar novos casos de teste para a composição, se possível. Neste caso o integrador não pode reusar os casos de teste sugeridos diretamente porque ele foram criados para CustomerService. Os casos de teste criados para RegisterService devem ser apenas inspirados nos dados de entrada e nas descrições dos casos de teste recebidos como sugestão. 
3. Criar um perfil de uso ou atualizar um perfil existente para definir quais operações de CustomerService são de fato utilizadas pela composição. Além disso, o integrador também deve incluir no perfil de uso uma lista de casos de teste que não são relevantes ao contexto da composição.

4. Executar os novos casos de teste juntamente com os casos de teste iniciais.

5. Obter a cobertura estrutural de CustomerService.

\subsubsection{Primeira iteração}

Após executar o conjunto original de casos de teste de RegisterService, o integrador obteve as sugestões de casos de teste fornecidas por Cust omerServi ce, que foram os seguintes: tc-04, tc-03, tc-01, tc-02, tc-06, tc-08, tc-16, tc-05, tc-15, tc-09, tc-11, tc-12, tc-13. Os detalhes de cada caso de teste podem ser vistos na Tabela 5.7. Em seguida, o integrador criou novos casos de teste para RegisterService baseado nos casos de teste tc-04, tc-03 e tc-01 (os primeiros da lista, pois são os que cobrem mais requisitos de teste ainda não cobertos). Neste estudo de caso o integrador resolveu criar apenas três novos casos de teste a cada iteração.

O integrador identificou as operações de CustomerService que são de fato utilizadas pela composição e criou um perfil de uso. No perfil de uso também foram listados os casos de teste sugeridos por CustomerService mas que não são aplicáveis ao contexto de RegisterService. O perfil de uso criado pelo integrador pode ser visto na Tabela 5.10.

Tabela 5.10: Perfil de uso criado pelo integrador para usar CustomerService

\begin{tabular}{|l|l|}
\hline Nome & RegisterService \\
\hline ID & OPF-RS-001 \\
\hline Operações utilizadas: & createFromId \\
& registerCustomer \\
& saveCustomer \\
& readById \\
& readByUsername \\
\hline Casos de teste não aplicáveis ao contexto & tc-11,tc-13, tc-15,tc-16 \\
\hline
\end{tabular}

Ao executar novamente o conjunto original de casos de teste de RegisterService juntamente com os novos casos de teste, o integrador obteve o relatório de cobertura estrutural apresentado na Tabela 5.11. O relatório de cobertura apresentado já considerou o perfil de uso do serviço testável e desconsiderou as operações não utilizadas pela composição. Na tabela é também é possível ver em itálico a cobertura estrutural do serviço como um todo se o perfil de uso não fosse considerado. 
Tabela 5.11: Cobertura estrutural de CustomerServi ce na primeira iteração de uso dos metadados gerados sob demanda

\begin{tabular}{|l|c|c|c|}
\cline { 2 - 4 } \multicolumn{1}{c|}{} & \multicolumn{3}{c|}{ Primeira iteração } \\
\hline Serviço & todos-nós & todas-arestas & todos-usos \\
\hline CustomerService & $84 \%$ & $69 \%$ & $67 \%$ \\
\hline Sem perfil de uso & $67 \%$ & $58 \%$ & $56 \%$ \\
\hline Operações & todos-nós & todas-arestas & todos-usos \\
\hline createFromId & $81 \%$ & $71 \%$ & $52 \%$ \\
\hline registerCustomer & $100 \%$ & $100 \%$ & $100 \%$ \\
\hline saveCustomer & $72 \%$ & $53 \%$ & $51 \%$ \\
\hline readById & $66 \%$ & $50 \%$ & $44 \%$ \\
\hline readByUsername & $100 \%$ & $100 \%$ & $100 \%$ \\
\hline
\end{tabular}

\subsubsection{Segunda iteração}

Os seguintes casos de teste foram sugeridos por CustomerService na segunda vez em que o integrador solicitou os metadados sob demanda: tc-03, tc-04, tc-06, tc-01, tc-05, tc-09, tc02. Note que os casos de teste tc-03, tc-04 e tc-01 apareceram novamente, apesar de já terem sido usados como base para criar novos casos de teste para RegisterService. Isto não foi, entretanto, um erro do serviço testável ao gerar os metadados sob demanda. Isto aconteceu porque, apesar de usar os dados de entrada dos casos de teste sugeridos como inspiração para criar novos casos de teste, a composição trata os dados de entrada de forma diferente e possivelmente não invocou CustomerService com os mesmos dados de entrada dos casos de teste usados como base. Por este motivo nem todos os requisitos de teste cobertos pelos casos de teste tc-03, tc-04 e tc-01 foram de fato cobertos, mas é possível perceber que parte dos requisitos foi coberta. Note que a ordem em que os casos de teste aparece na lista de sugestões mudou. O caso de teste tc-04 deixou de ser o caso de teste que cobre mais requisitos de teste. $\mathrm{O}$ caso de teste tc-01 era o terceiro da lista na primeira vez em que a lista foi gerada e desta vez encontra-se na quarta posição.

Esta situação ocorrida durante este estudo de caso evidencia o fato de que composições manipulam os dados de forma diferente e nem sempre é possível repetir o mesmo cenário de teste para todas as composições. Por isso o perfil de uso torna-se interessante para que o relatório de cobertura gerado seja adequado para cada composição que utiliza o serviço testável.

Ao criar novos casos de teste para a composição, o integrador decidiu não utilizar novamente os casos de teste que foram repetidos na lista, apesar de dois deles aparecerem entre os três primeiros lugares. Desta forma, os novos casos de teste para RegisterService foram criados com base nas sugestões tc-06, tc-05 e tc-09. Não houve necessidade de atualizar o perfil de uso nesta iteração.

Depois de executar os 10 casos de teste de RegisterService (4 originais mais 6 criados nas duas iterações), o relatório de cobertura estrutural obtido foi o que está apresentado na Tabela 5.12. Pelo relatório apresentado é possível perceber que a cobertura aumentou significativamente em relação à cobertura obtida pelos casos de teste originais. 
Tabela 5.12: Cobertura estrutural obtida para CustomerService na segunda iteração

\begin{tabular}{|l|c|c|c|}
\cline { 2 - 4 } \multicolumn{1}{c|}{} & \multicolumn{3}{c|}{ Segunda iteração } \\
\hline Serviço & todos-nós & todas-arestas & todos-usos \\
\hline Cust omerService & $90 \%$ & $79 \%$ & $78 \%$ \\
\hline Sem perfil de uso & $72 \%$ & $67 \%$ & $65 \%$ \\
\hline Operações & todos-nós & todas-arestas & todos-usos \\
\hline createFromId & $90 \%$ & $92 \%$ & $72 \%$ \\
\hline registerCustomer & $100 \%$ & $100 \%$ & $100 \%$ \\
\hline saveCustomer & $72 \%$ & $53 \%$ & 51 \\
\hline readById & $100 \%$ & $100 \%$ & $100 \%$ \\
\hline readByUsername & $100 \%$ & $100 \%$ & $100 \%$ \\
\hline
\end{tabular}

\section{Terceira iteração}

O integrador solicitou novamente os metadados sob demanda de CustomerService e obteve as seguintes sugestões de casos de teste: tc-03, tc-04, tc-01, tc-02. Das sugestões recebidas, as três primeiras já foram utilizadas na criação de casos de teste para a composição. O caso de teste tc-02 possui os mesmos valores de entrada de tc-01, com exceção do parâmetro regi ster. Como este parâmetro não é um parâmetro recebido pelas operações de RegisterService, os casos de teste tc-02 e tc-01 não possuem diferenças como inspiração para a criação de casos de teste para a composição. Assim, o integrador deste estudo de caso decidiu não criar mais casos de teste porque não seria mais possível criar casos de teste significativos com base nas sugestões oferecidas por CustomerService.

\subsubsection{Comparação com geração randômica de casos de teste}

Foi realizada uma comparação entre o uso da abordagem BISTWS e o uso de geração randômica de casos de teste para melhorar a cobertura de CustomerService. Para isso foi utilizada uma aplicação para geração de dados randômicos fornecida pelo site GENERATE DATA ${ }^{2}$. A aplicação foi configurada para gerar dados de teste para as operações de RegisterService.

Na primeira iteração foram realizadas 20 sessões de teste utilizando dados randômicos. Em cada sessão o conjunto original de casos de teste de RegisterService foi executado juntamente com seis novos casos de teste criados a partir dos dados gerados randomicamente. Após as 20 execuções dos conjuntos de casos de teste gerados, a média de cobertura foi calculada. Optouse por criar apenas seis casos de teste nesta iteração para comparar com a cobertura alcançada pelos seis novos casos de teste criados com o uso da abordagem BISTWS. A média da cobertura obtida pelas sessões de teste realizadas pode ser vista na Tabela 5.13. Para ser uma comparação mais justa, a cobertura apresentada considera apenas a cobertura das operações que são usadas por RegisterService.

\footnotetext{
${ }^{2} \mathrm{http}: / /$ www.generatedata.com/
} 
Tabela 5.13: Cobertura obtida pelos casos de teste gerados randomicamente

\begin{tabular}{|l|c|c|c|c|}
\hline Iteração & Número de casos de teste & todos-nós & todas-arestas & todos-usos \\
\hline 1a & 10 & $74 \%$ & $56 \%$ & $56 \%$ \\
\hline 2a & 54 & $84 \%$ & $68 \%$ & $64 \%$ \\
\hline 3a & 104 & $84 \%$ & $75 \%$ & $71 \%$ \\
\hline
\end{tabular}

Na segunda iteração, para melhorar a cobertura de CustomerService, foram criados 50 novos casos de teste que foram executados juntamente com o conjunto de casos de teste original da composição. Na terceira iteração foram criados 100 novos casos de teste para serem executados com o conjunto de casos de teste original. A cobertura obtida nas duas iterações pode ser vista na Tabela 5.13.

Se a cobertura obtida pelos casos de teste criados pela abordagem BISTWS for comparada com a cobertura alcançada pelos casos de teste gerados randomicamente, percebe-se que a diferença não é muito grande. No melhor caso, a cobertura obtida pelos dados randômicos foi de $84 \%$, $75 \%$ e $71 \%$ para os critérios todos-nós, todas-arestas e todos-usos, respectivamente, enquanto que com a abordagem BISTWS foi de 90\%, 79\% e 78\%. Gerar casos de teste de forma randômica pode ser mais simples do que usar os metadados de teste, mas o custo é mais alto caso não seja possível executar muitos casos de teste para testar o serviço. A abordagem BISTWS conseguiu alcançar cobertura melhor com a criação de apenas seis novos casos de teste do que a abordagem randômica com a criação de 100 novos casos de teste.

No fator quantidade de casos de teste criados a abordagem BISTWS leva vantagem porque no teste de serviços quanto menor o número de invocações melhor. No teste de serviços fornecidos por terceiros, uma quantidade grande de requisições ao serviço pode sobrecarregar a infraestrutura do provedor do serviço e causar incômodo para outros usuários do serviço (Hou et al., 2008; Canfora e Penta, 2009). Além disso, existem serviços que impõem limite para o número máximo de requisições que podem ser feitas por certo período de tempo. Se o número de requisições supera o limite imposto pelo serviço, as requisições excedentes são ignoradas (Hou et al., 2008). Um exemplo de serviço que impõem esta limitação é um serviço cliente dos correios ${ }^{3}$. Ainda, é importante manter pequeno o número de requisições se o serviço sob teste cobrar seus clientes com base em cada requisição (Canfora e Penta, 2009).

\subsubsection{Resposta às questões de pesquisa}

As questões de pesquisa consideradas no início deste estudo foram respondidas pelos resultados obtidos:

- QP1: o integrador foi capaz de utilizar os metadados fornecidos por CustomerService para melhorar sua cobertura quando testado no contexto de RegisterService. Foi possível observar um aumento significativo na porcentagem de cobertura de todos os critérios

\footnotetext{
${ }^{3}$ http://www.autocep.com.br/cep-webservice.htm
} 
considerados. A criação dos casos de teste para a composição com base nos casos de teste do serviço testável pode exigir um esforço adicional do integrador, mas este conhece a implementação da composição e neste estudo esta tarefa foi executada sem grandes dificuldades.

- QP2: a cobertura calculada com base no perfil de uso do serviço testável mostrou-se mais adequada porque leva em consideração o contexto em que CustomerService estava sendo testado. Sem o perfil de uso a cobertura alcançada pelo integrador seria relativamente baixa e não saberia como e se seria possível aumentar a cobertura obtida.

\subsubsection{Ameaças à validade do estudo}

Neste estudo de caso foram utilizados serviços que são usados em ambientes reais para assegurar sua validade de construção. A forma com que o estudo foi conduzido também representa um cenário típico de teste de serviços no contexto de uma composição e no estudo são representados os conceitos e desafios para os quais a abordagem BISTWS foi criada.

Um fator de confusão para a validade interna dos resultados é o fato de que um dos autores da abordagem foi quem desempenhou o papel de integrador. Para tentar mitigar este fator, o integrador não explorou o código fonte de CustomerService durante a criação dos casos de teste para RegisterService. Além disso, procurou-se utilizar os casos de teste fornecidos pelos desenvolvedores do serviço como conjuntos de caso de teste iniciais. Apesar disto, não se pode excluir o impacto que este fator pode ter causado nos resultados do estudo.

A validade externa do estudo não pode ser garantida. Os objetos usados no estudo são reais, mas apenas um exemplo não pode ser usado para generalizar os resultados. É necessário que mais estudos sejam realizados para diferentes domínios de aplicação para assegurar a validade das conclusões.

\subsubsection{Análise de overhead de código instrumentado}

O overhead gerado pelas operações inseridas no código do serviço testável após a instrumentação foi analisado. Para isto, um conjunto de casos de teste foi executado 50 vezes para testar um serviço em três versões: a versão comum do serviço, a versão testável do serviço com as operações de rastreamento de execução desativadas e a versão testável do serviço com as operações de rastreamento de execução ativadas. Os tempos de execução dos casos de teste foram medidos e na Tabela 5.14 são apresentadas as médias de tempo de execução. O overhead de tempo gerado pelo código instrumentado é de $2.65 \%$ quando o serviço testável não está em uma sessão de teste e 5.26\% quando está em uma sessão de teste.

Durante a execução dos casos de teste foi possível perceber que o tempo de resposta dos serviços instrumentados era maior do que o tempo de resposta dos serviços não instrumentados, mas às vezes o contrário também acontecia. Por isso foi possível constatar que, além do overhead 
Tabela 5.14: Análise de overhead

\begin{tabular}{|c|c|c|}
\hline Versão & Tempo médio & Overhead \\
\hline \hline Regular (não testável) & 2070 & $0 \%$ \\
\hline Testável & 2125 & $2.65 \%$ \\
\hline Testável em uma sessão de teste & 2179 & $5.26 \%$ \\
\hline
\end{tabular}

introduzido pelo código instrumentado, o congestionamento da rede também é um fator que aumenta significativamente o tempo de resposta dos serviços. Com isso concluiu-se que o overhead introduzido pela instrumentação é pequeno.

\subsection{Um experimento realizado para avaliar a abordagem BISTWS}

Um experimento foi realizado para investigar se a interface de teste estrutural e os metadados fornecidos pelos serviço testáveis auxiliam os integradores a melhorar seus conjuntos de casos de teste e alcançar maior cobertura estrutural dos serviços testáveis utilizados em suas composições. Para isso foi realizada uma comparação entre o uso da abordagem BISTWS e de uma abordagem funcional no teste de uma aplicação que utiliza um serviço testável.

O experimento foi realizado da perspectiva dos integradores de serviços e em ambiente controlado. Estudantes de pós-graduação foram convidados a participar do experimento e desempenhar o papel de integradores. Metade dos sujeitos foi designada para utilizar a abordagem BISTWS e metade foi designada para utilizar uma abordagem funcional. O objetivo dos sujeitos era criar casos de teste para uma aplicação que utiliza um serviço testável. Os sujeitos foram avisados que, além de tentar revelar defeitos na aplicação testada, o objetivo era exercitar ao máximo a estrutura do serviço testável utilizado pela aplicação.

Os sujeitos que utilizaram a abordagem funcional podiam usar apenas os resultados dos casos de teste e os critérios de teste funcional para decidir se deveriam parar de testar ou criar mais casos de teste para a aplicação. Os sujeitos que utilizaram a abordagem BISTWS, entretanto, puderam usar a cobertura estrutural gerada pelo serviço testável e os metadados gerados sob demanda. Uma ilustração dos recursos utilizados pelos sujeitos utilizando as duas técnicas pode ser vista na Figura 5.7. Os objetos experimentais mostrados na figura serão apresentados com mais detalhes posteriormente.

As variáveis independentes consideradas neste experimento foram as seguintes:

- A abordagem BISTWS (tratamento).

- A abordagem Funcional (controle).

- Os objetos experimentais. 


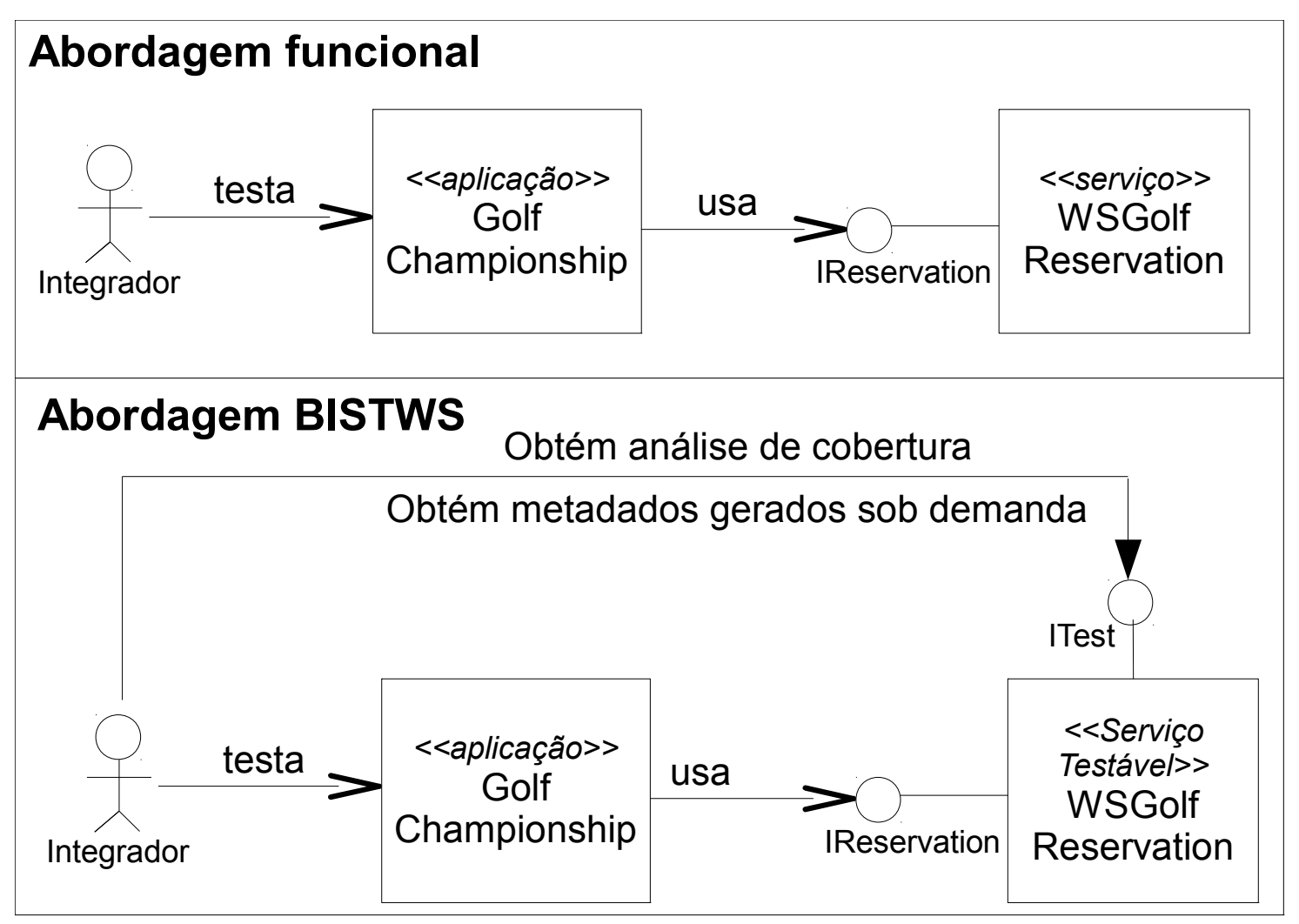

Figura 5.7: Diferenças entre os sujeitos que usam a abordagem funcional e os que usam a abordagem BISTWS

- A experiência dos sujeitos na área de teste de software.

As variáveis dependentes consideradas neste experimento foram as seguintes:

- A cobertura estrutural do serviço testável testado no contexto de uma aplicação.

- O número de falhas encontradas, tanto na aplicação quanto no serviço.

\subsubsection{Definição das hipóteses}

Duas hipóteses nulas e duas hipóteses alternativas foram definidas para este experimento.

- $\mathbf{H O}_{1}$ : a cobertura estrutural do serviço testável obtida pelos integradores utilizando a abordagem BISTWS é menor ou igual à cobertura obtida pelos integradores utilizando a abordagem Funcional, ou seja, $\mathrm{COB}_{B I S T W S}<=\mathrm{COB}_{F T}$.

- $\mathbf{H 1}_{1}$ : a cobertura estrutural do serviço testável obtida pelos integradores utilizando a abordagem BISTWS é maior do que a cobertura obtida pelos integradores utilizando a abordagem Funcional, ou seja, $\mathrm{COB}_{B I S T W S}>\mathrm{COB}_{F T}$. 
- $\mathbf{H 0}_{2}$ : o número de falhas encontradas pelos integradores utilizando a abordagem BISTWS é menor ou igual ao número de falhas encontradas pelos integradores utilizando a abordagem Funcional, ou seja, FALHA FISTWS $_{2}=$ FALHA $_{F T}$.

- $\mathbf{H 0}_{2}$ : o número de falhas encontradas pelos integradores utilizando a abordagem BISTWS é maior do que o número de falhas encontradas pelos integradores utilizando a abordagem Funcional, ou seja, FALHA $B I S T W S>$ FALHA $_{F T}$.

\subsubsection{Sujeitos e objetos experimentais}

Doze alunos de pós-graduação do Laboratório de Engenharia de Software (LabES) do ICMCUSP participaram do experimento. A seleção dos sujeitos foi feita por conveniência porque a maioria deles estava cursando uma disciplina de Engenharia de Software Experimental e já havia cursado uma disciplina de teste de software.

Dois objetos experimentais foram usados no experimento. O primeiro, WSGolfReservation, é um serviço extraído de uma aplicação-web de código aberto ${ }^{4}$ projetada para gerenciar reservas em clubes de golfe. O serviço tem 10 operações públicas e 571 linhas de código.

O segundo, GolfChampionship, é uma aplicação desenvolvida por um dos co-autores da abordagem BISTWS para gerenciar campeonatos de golfe. Para o experimento foi implementada somente a parte da aplicação responsável por gerenciar jogadores e partidas. A aplicação contém 9 operações e 230 linhas de código. GolfChampionship utiliza o serviço testável WSGolfReservation para fazer reservas de campos de golfe e alocar partidas do campeonato. O serviço testável foi publicado juntamente com metadados de teste capazes de alcançar 100\% de cobertura estrutural do serviço nos critérios todos-nós, todas-arestas e todos-usos.

\subsubsection{Preparação}

O nível de experiência de cada sujeito do experimento foi medido por meio de perguntas em formulários e uma classificação ordinal foi utilizada: 1-alta, 2-média e 3-baixa. Coincidentemente, o número de sujeitos para cada nível de experiência foi par. Com isso foi possível separar os sujeitos em dois grupos de experiências balanceadas. A escolha de qual sujeito faria parte do grupo de controle e qual faria parte do grupo do tratamento foi feita de forma aleatória. Todos os sujeitos testaram o mesmo objeto experimental e a diferença foi a abordagem de teste utilizada. $\mathrm{O}$ projeto do experimento pode ser visto na Tabela 5.15 .

\subsubsection{Operação}

Antes de executar as atividades do experimento, todos os sujeitos receberam uma hora de treinamento de acordo com a abordagem utilizada. Cada sujeito também recebeu uma descrição

\footnotetext{
${ }^{4}$ http://sourceforge.net/projects/golf-reserve/
} 
Tabela 5.15: Projeto do experimento

\begin{tabular}{|c|c|c|c|}
\hline \multicolumn{2}{|c|}{ BISTWS } & \multicolumn{2}{c|}{ Funcional } \\
\hline Sujeito & Experiência & Sujeito & Experiência \\
\hline Sujeito 2 & Alta & Sujeito 3 & Alta \\
\hline Sujeito 12 & Alta & Sujeito 9 & Alta \\
\hline Sujeito 4 & Média & Sujeito 1 & Média \\
\hline Sujeito 6 & Média & Sujeito 5 & Média \\
\hline Sujeito 10 & Média & Sujeito 7 & Média \\
\hline Sujeito 8 & Baixa & Sujeito 11 & Baixa \\
\hline
\end{tabular}

detalhada dos dois objetos experimentais (WSGolfReservation e GolfChampionship) e instruções sobre como executar cada tarefa requerida pelo experimento.

O experimento foi conduzido por duas semanas e os sujeitos executaram suas atividades em pares em ambientes controlados. Eles tinham de 1 a 4 horas para executar suas tarefas e todos seguiram corretamente as instruções recebidas. Com isso, nenhum resultado precisou ser desconsiderado. Após o experimento, os sujeitos preencheram um formulário para relatar os resultados obtidos. Os seguintes ítems deveriam estar contidos no relatório e resultados:

- Casos de teste criados.

- Número de falhas encontradas.

- Cobertura estrutural obtida (somente para sujeitos utilizando a abordagem BISTWS).

- As dificuldades em usar os metadados para criar novos casos de teste para a aplicação (somente para sujeitos utilizando a abordagem BISTWS).

- Observações e dificuldades encontradas.

A cobertura estrutural obtida pelos sujeitos utilizando a abordagem funcional foram coletadas pelo condutor do experimento assim que os sujeitos terminaram suas atividades. Para isto o condutor executou os casos de teste fornecidos pelos sujeitos e utilizou a interface de teste estrutural para obter a cobertura estrutural.

\subsubsection{Resultados}

Os formulários preenchidos pelos sujeitos foram validados pelos condutores e são apresentados resumidamente na Tabela 5.16. Para cada sujeito, a cobertura apresentada é uma média aritmética das coberturas alcançadas para os três critérios. O número de falhas é o número de diferentes falhas encontradas e não o número de casos de teste que encontraram uma falha, pois pode haver mais de um caso de teste usado para revelar a mesma falha. 
Tabela 5.16: Resultados do experimento

\begin{tabular}{|c|c|c|c|c|c|c|}
\hline & \multicolumn{3}{|c|}{ BISTWS } & \multicolumn{3}{c|}{ Funcional } \\
\hline Experiência & Sujeito & Cobertura & Falhas & Sujeito & Cobertura & Falhas \\
\hline Alta & 2 & $85 \%$ & 3 & 3 & $37 \%$ & 3 \\
\hline Alta & 12 & $83 \%$ & 7 & 9 & $72 \%$ & 2 \\
\hline Média & 4 & $82 \%$ & 3 & 1 & $74 \%$ & 5 \\
\hline Média & 6 & $85 \%$ & 5 & 5 & $75 \%$ & 2 \\
\hline Média & 10 & $85 \%$ & 6 & 7 & $81 \%$ & 5 \\
\hline Baixa & 8 & $85 \%$ & 3 & 11 & $56 \%$ & 2 \\
\hline
\end{tabular}

\subsubsection{Ameaças à validade do experimento}

Três fatores podem ameaçar a validade interna deste experimento: a experiência dos sujeitos, os objetos experimentais e a produtividade sob avaliação. A experiência dos estudantes pode impactar os resultados, mas este fator foi mitigado pelo treinamento específico que foi dado para cada sujeito de acordo com a experiência na área de teste. Além disso, os grupos de sujeitos estavam balanceados em relação à experiência.

Dois objetos experimentais foram utilizados no experimento: um serviço testável e uma aplicação. A aplicação foi desenvolvida por um dos co-autores da abordagem BISTWS. Este fator é uma ameaça porque o desenvolvedor, mesmo inconscientemente, poderia ter criado uma aplicação para dar vantagem aos resultados obtidos pela sua abordagem. Entretanto, após uma investigação detalhada dos resultados do experimento, observou-se que da forma como a aplicação foi implementada não era possível que algumas configurações de dados de entrada fossem utilizadas para invocar o serviço testável. Em várias situações os sujeitos utilizaram os metadados para criar casos de teste para a aplicação que não alteravam a cobertura obtida por esse motivo. Se não fosse isso, quase todos os sujeitos utilizando a abordagem BISTWS teriam alcançado quase $100 \%$ de cobertura. Isto mostra que o fato de a aplicação de campeonato de golfe ter sido implementada por um dos autores da abordagem não influenciou os resultados do experimento a favor da abordagem BISTWS.

Estudantes tendem a ser mais produtivos quando estão sob avaliação e isto poderia ter afetado os resultados. Neste caso, entretanto, o experimento não foi realizado no contexto de uma disciplina. Os estudantes não foram forçados a participar do experimento, mas a maioria participou para colaborar com as pesquisas e também para ganhar alguma experiência na realização de um experimento.

Existem dois fatores que ameaçam a validade externa deste experimento. A população de sujeitos não é estatisticamente significativa porque o grupo é homogêneo, uma vez que são estudantes de pós-graduação da área de Engenharia de Software. Além disso, o experimento não foi conduzido em um ambiente real, apesar de ter usado um objeto experimental reusado de uma aplicação real. Desta forma, as conclusões obtidas pelos testes de hipótese realizados neste experimento 
não podem ser generalizados para todos os casos. Para isso é necessário que seja realizada uma avaliação mais abrangente e em um ambiente de produção real.

\section{Análise descritiva}

Foi realizada uma análise descritiva dos resultados do experimento considerando a cobertura e o número de falhas, que são relacionados à primeira e à segunda hipótese, respectivamente. Os box-plots dos resultados do experimento são mostrados na Figura 6.6.
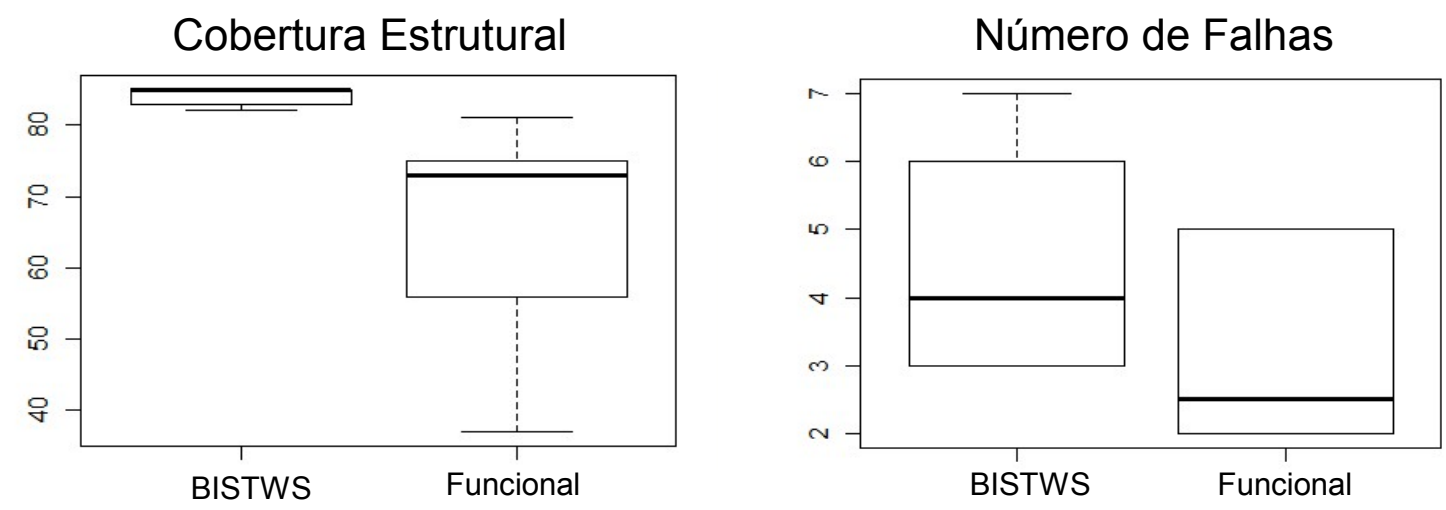

Figura 5.8: Boxplots feitos para os resultados do experimento

Em relação à cobertura, a abordagem BISTWS parece ter alcançado uma cobertura muito melhor do que a abordagem Funcional. É possível perceber que a maior cobertura alcançada por um sujeito utilizando a abordagem Funcional é menor do que a menor cobertura alcançada por um sujeito usando a abordagem BISTWS. Considerando o número de falhas, a abordagem BISTWS parece ser ligeiramente melhor.

Foi também realizada uma análise dos resultados considerando a experiência de cada sujeito, independentemente da abordagem utilizada. Esta análise é importante para verificar se o fator que determinou os resultados do experimento foi a experiência ou a abordagem utilizada. O box-plot com os resultados da cobertura para cada nível de experiência é apresentado na Figura 5.9. Aparentemente a experiência não influenciou os resultados uma vez que não existe grande diferença entre os resultados obtidos pelos sujeitos com diferentes experiências. Se a experiência fosse um fator determinante para afetar os resultados, os sujeitos com alta experiência teriam obtido as maiores coberturas enquanto os sujeitos com baixa experiência teriam obtido as menores coberturas, mas este não é o caso. Pelo contrário, um dos sujeitos com alta experiência foi o que obteve a menor cobertura do experimento, que foi de $36 \%$, enquanto a maioria dos sujeitos obteve cobertura superior a $56 \%$.

Na Figura 5.10 são apresentados os box plots dos resultados do experimento para os três níveis de experiência considerando o número de falhas encontradas. A experiência dos sujeitos parece ter tido uma leve influência nos resultados neste caso. O número de falhas encontradas pelos sujeitos com baixa experiência foi menor do que o número de falhas encontradas pelos sujeitos com 


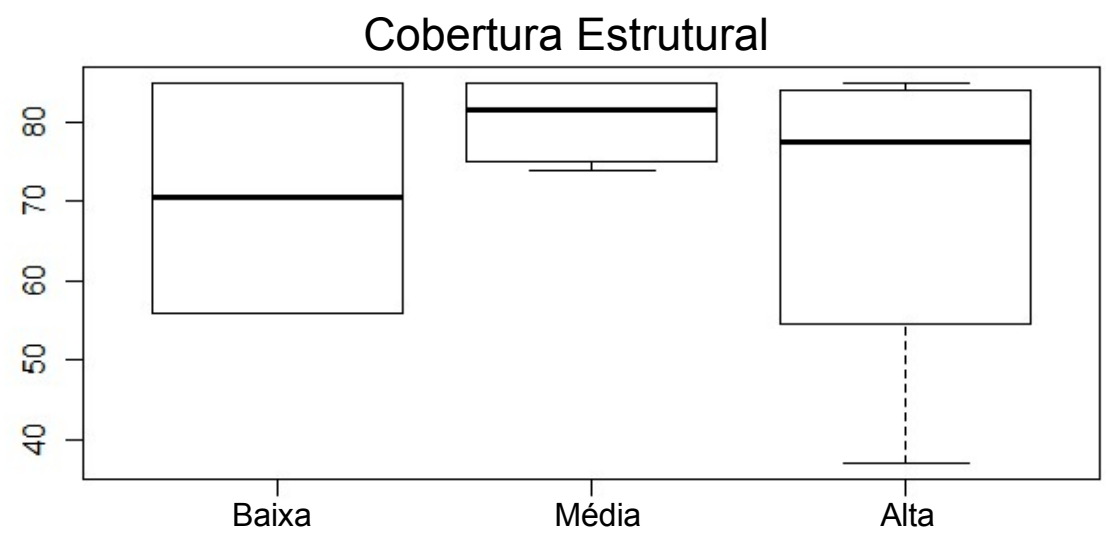

Figura 5.9: Boxplots da cobertura estrutural considerando cada nível de experiênciao dos sujeitos

experiência média que foram menores do que as falhas encontradas pelos sujeitos com experiência alta. Não se pode assegurar que a experiência foi o único fator determinante dos resultados porque existem apenas dois sujeitos com baixa experiência. Note que há sujeitos com experiência média e alta que encontraram apenas duas falhas, que foi o menor número de falhas encontradas por um sujeito neste experimento. Apesar disto, no geral, os sujeitos com experiência média e alta parecem ter sido os que encontraram mais falhas.

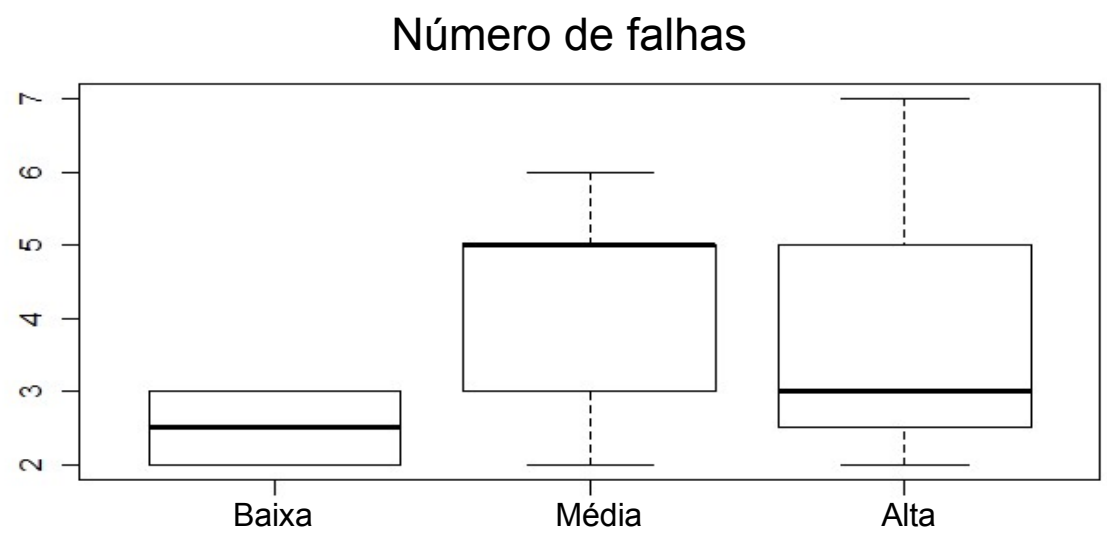

Figura 5.10: Boxplots do número de falhas encontradas considerando cada nível de experiênciao dos sujeitos

\section{Teste de hipótese}

As hipóteses deste experimento foram avaliadas por dois testes estatísticos diferentes, de acordo com o projeto e a distribuição das amostras coletadas. Antes de realizar os testes de hipótese o teste de Shapiro-Wilk foi aplicado para verificar a normalidade das amostras. Obteve-se, como resultado, que a distribuição das amostras relacionadas à cobertura estrutural não é normal enquanto a distribuição das amostras relacionadas às falhas encontradas é normal.

De acordo com sua distribuição e com as recomendações de Wohlin et al. (2000), para testar a primeira hipótese foi utilizado o teste de Mann-Whitney, que é um teste não paramétrico para 
amostras sem distribuição normal. O p-value obtido pelo teste de Mann-Whitney é de 0.002168 e com isso a hipótese nula $\mathrm{H} 0_{1}$ pode ser refutada e a hipótese alternativa $\mathrm{H} 1_{1}$ aceita. Além do p-value, obteve-se 0 como o valor de U (menor valor entre Ux e Uy, seguindo os passos para aplicação do teste (Nachar, 2008)). De acordo com a tabela de Mann-Whitney, com este valor de U é possível rejeitar a hipótese nula $\mathrm{H}_{1}$ e aceitar a hipótese alternativa $\mathrm{H} 1_{1}$ com $95 \%$ de confiança.

A segunda hipótese refere-se ao número de falhas encontradas em cada abordagem e seus resultados possuem distribuição normal. O Teste T não pareado foi usado para comparar as amostras da abordagem BISTWS com as amostras da abordagem Funcional. Existem seis amostras geradas pela abordagem BISTWS (m) e seis amostras geradas pela abordagem Funcional (n). De acordo com a distribuição do t-value, $t_{10}(m+n-2)$ é 1.812 considerando um intervalo de confiança de $95 \%$ e o one sided test. Além do p-value dado pelo Teste T, o valor de $t_{10}$ também foi utilizado para validar as hipóteses de acordo com as recomendações de Wohlin et al. (2000). O Teste T forneceu os seguintes resultados. $\mathrm{P}-\mathrm{v}$ alue é 0,09303 e $t$ é 1,4231. Estes resultados não permitem que a hipótese nula $\mathrm{H}_{2}$ seja rejeitada e a hipótese alternativa $\mathrm{H}_{2}$ seja aceita, pois $\mathrm{p}$-value $>0.05 \mathrm{e}$ $t<t_{10}$. A hipótese nula $\mathrm{H}_{2}$ só pode ser refutada e a hipótese alternativa $\mathrm{H}_{2}$ ser aceita usando um intervalo de confiança de $90 \%$ porque neste caso $t_{10}$ é 1.372 e $t>t_{10}$

\section{Análise descritiva considerando a experiência dos sujeitos}

Uma análise descritiva considerando os níveis de experiência e as abordagens separadamente também foi realizada. Os boxplots criados para a cobertura alcançada pelas abordagens BISTWS e Funcional de acordo com o nível de experiência dos sujeitos estão mostrados nas Figuras 5.11 e 5.12, respectivamente. Note que a experiência parece não ter influenciado os resultados. Aparentemente, a abordagem BISTWS ajudou os sujeitos com baixa experiência a alcançar a mesma cobertura obtida por sujeitos com alta experiência.

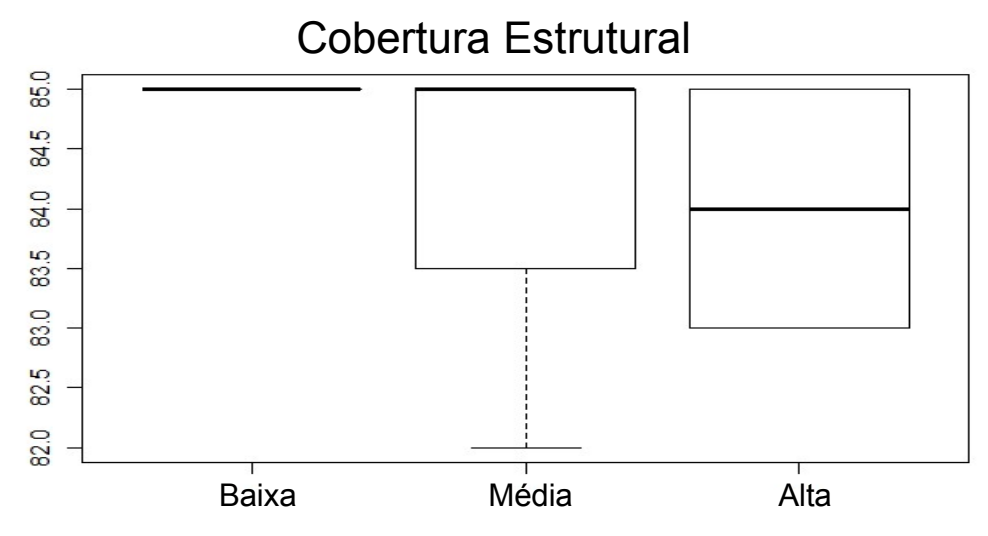

Figura 5.11: Boxplots da cobertura alcançada pelos sujeitos usando a abordagem BISTWS considerando cada nível de experiência

Os boxplots criados para o número de falhas encontradas pelos sujeitos do experimento considerando as abordaggens utilizadas e suas experiências são apresentados nas Figuras 5.13 e 5.14, 


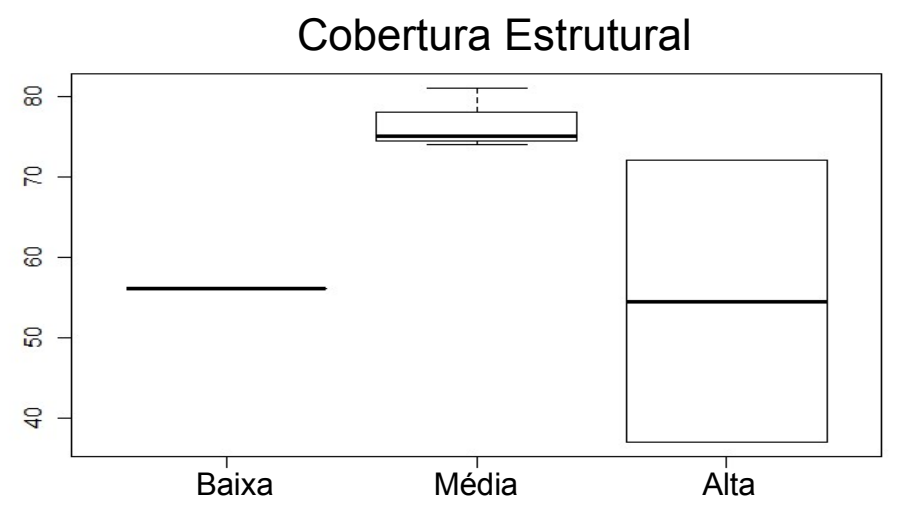

Figura 5.12: Boxplots da cobertura alcançada pelos sujeitos usando a abordagem Funcional considerando cada nível de experiência

respectivamente. Neste caso, a experiência dos sujeitos parece ter influenciado os resultados. O número de falhas encontradas pelos sujeitos com alta experiência parece ser maior do que o número de falhas encontradas pelos sujeitos com experiência média e baixa. Os sujeitos com experiência média também parecem ter encontrado mais falhas do que os sujeitos com baixa experiência. Para a abordagem Funcional, entretanto, a experiência de cada sujeito parece não ter afetado os resultados. O número de falhas encontradas pelos sujeitos com experiência média parece ser maior do que o número de falhas encontradas pelos sujeitos com experiência mais alta.

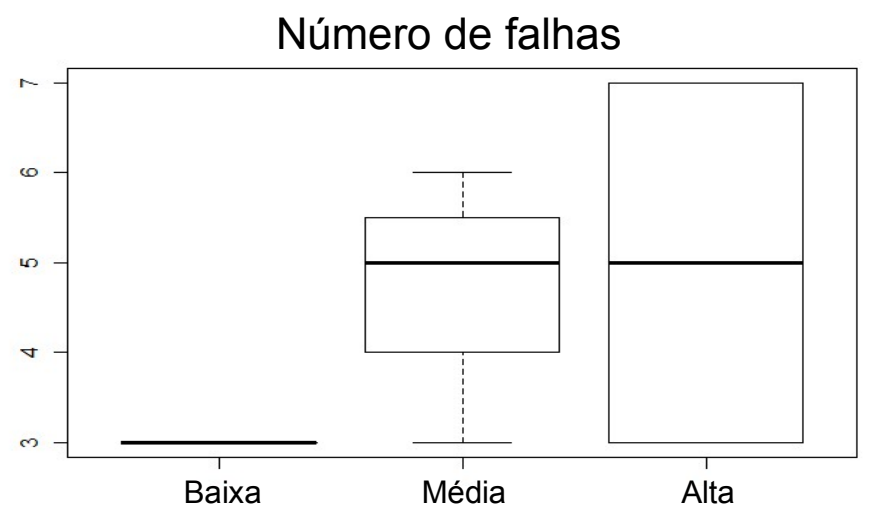

Figura 5.13: Boxplots do número de falhas encontradas com a abordagem BISTWS considerando a experiência dos sujeitos

\subsubsection{Discussão}

A análise descritiva e os testes de hipótese dos resultados do experimento mostraram que a abordagem BISTWS é capaz de ajudar integradores a melhorar seus conjuntos de casos de teste e alcançar maior cobertura estrutural nos serviços testáveis utilizados em suas composições. Entretanto, a abordagem não foi determinante para o aumento do número de falhas encontradas. $\mathrm{O}$ fato é que a abordagem não foi criada com o objetivo de maximizar o número de falhas encontradas e o experimento também não foi configurado para descobrir se a abordagem cumpre este propósito. 


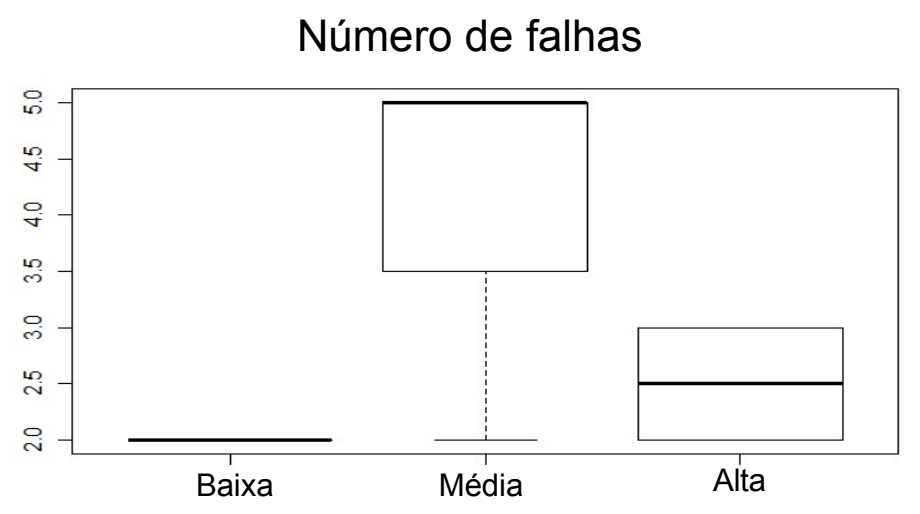

Figura 5.14: Boxplots do número de falhas encontradas com a abordagem funcional considerando a experiência dos sujeitos

Se este fosse o caso, falhas teriam sido semeadas no código. Ao invés disso, as falhas encontradas pelos sujeitos eram falhas causadas por defeitos que já estavam presentes nas aplicações.

Alguém pode argumentar que o propósito do teste de software é revelar falhas. Embora a abordagem BISTWS não tenha sido projetada para maximizar o número de falhas encontradas, ela é útil para auxiliar integradores a melhorar seus casos de teste e testar partes do código que ainda não foram testadas e, consequentemente, revelar falhas latentes que podem estar escondidas em partes do código que ainda não foram executadas.

\subsection{Considerações Finais}

A abordagem BISTWS foi criada com o objetivo de auxiliar desenvolvedores na criação de serviços testáveis que oferecem facilidades de teste estrutural. A abordagem é genérica e define os papéis e as responsabilidades de cada ator. Neste capítulo foi apresentada uma concretização da abordagem por meio da implementação e extensão de um Serviço de Teste chamado JaBUTiWS, que é uma versão orientada a serviços da ferramenta JaBUTi (Vincenzi et al., 2006). Essa implementação mostra a viabilidade da instanciação da abordagem e, de forma semelhante, ela poderia ser implementada para apoiar a geração de serviços testáveis criados em outras linguagens.

Para instanciar a abordagem para apoiar implementações de outras linguagens é necessário desenvolver um serviço que atenda a todas as funcionalidades do Serviço de Teste definido pela abordagem BISTWS. O Serviço de Teste deve ser capaz de instrumentar o código de um serviço recebido e inserir operações para apoiar o teste estrutural. É necessário que o serviço implemente critérios de teste estrutural para poder gerar os requisitos de teste e definir quais informações da execução dos serviços devem ser registradas durante sua execução. O serviço deve ser capaz de usar as informações de execução dos serviços instrumentados e gerar um relatório de cobertura com base nos requisitos de teste gerados durante a instrumentação.

Além disso, foram apresentados estudos de casos e experimentos configurados para mostrar a viabilidade da utilização da técnica de teste estrutural no contexto de serviços e as vantagens em 
poder combinar essa técnica com a técnica funcional em um cenário em que tipicamente usa-se apenas o teste caixa-preta dada a limitação imposta pelo encapsulamento dos serviços.

A estratégia de utilizar um Serviço de Teste para a geração de serviços testáveis impõe restrições à abordagem, pois a instrumentação, a interface de teste criada e a implementação de suas operações devem ser feitas para uma tecnologia específica. No caso da implementação utilizando o JaBUTiWS, somente é possível gerar serviços testáveis a partir de serviços escritos em Java.

Apesar das limitações, a instrumentação automatizada traz algumas vantagens. O esforço do desenvolvedor é pequeno pois sua tarefa principal, além de submeter o serviço ao JaBUTiWS e publicá-lo, é gerar os metadados de teste. Outra vantagem, no caso da implementação com o JaBUTiWS, é poder aproveitar as funcionalidades adicionais inseridas na ferramenta JaBUTi ao longo dos anos, como, por exemplo, a inclusão de critérios de teste de integração (de Oliveira Neves et al., 2009; Cafeo e Masiero, 2011).

Os conceitos introduzidos pela abordagem BISTWS e SOCT, juntamente com o trabalho realizado em conjunto para a especificação do modelo de metadados para serviços testáveis (Eler et al., 2011a), estão sendo considerados no projeto Choreos $^{5}$ (Large Scale Choreographies for the Future Internet) como uma possível solução para o fornecimento de uma infraestrutura de teste para coreografias de serviços (Bartolini et al., 2011b). O projeto é um consórcio realizado entre empresas, universidades e centros de pesquisas europeus e brasileiros.

\footnotetext{
${ }^{5}$ www.choreus.eu
} 



\section{Uma abordagem de monitoração de serviços testáveis}

\subsection{Considerações iniciais}

Serviços usados por integradores geralmente estão sob o controle de seus fornecedores e podem mudar sem notificação. As mudanças nos serviços podem trazer melhorias mas também é possível que defeitos sejam introduzidos e/ou que o serviço não funcione mais com a mesma qualidade que tinha antes de ser alterado (Bruno et al., 2005b). Para descobrir se algum serviço da aplicação sofreu alguma alteração os integradores usam técnicas de monitoração. Com isso podem verificar se as alterações sofridas pelo serviço prejudicam a qualidade da aplicação e então alguma atitude pode ser tomada, como, por exemplo, notificar o fornecedor ou substituir o serviço.

As técnicas de monitoração propostas na literatura em geral são de dois tipos: passivas e ativas. As técnicas passivas são aquelas que observam o tráfego de informações entre a aplicação e o serviço para descobrir se alguma mudança ocorreu, tanto em relação aos requisitos funcionais quanto aos requisitos não funcionais. As técnicas ativas são aquelas que invocam o serviço para analisar suas respostas e determinar se ocorreu alguma mudança. Em geral as técnicas ativas são baseadas na execução de casos de teste de um conjunto de regressão (Canfora e Di Penta, 2006).

O objetivo deste capítulo é apresentar uma abordagem de monitoração de serviços testáveis para mostrar como a abordagem BISTWS pode ser usada para a atividade de monitoração ativa, uma vez que ela é principalmente baseada na execução de casos de teste. A abordagem de monitoração apresentada utiliza as facilidades de teste oferecidas pelos serviços testáveis para criar mecanismos de detecção de mudanças mais precisos do que os mecanismos baseados apenas na 
observação dos resultados funcionais (Eler et al., 2011b). A abordagem apresentada só pode ser aplicada quando é possível usar as informações internas do serviço, como as informações fornecidas pelas interfaces de teste dos serviços testáveis.

Este capítulo está organizado da seguinte forma. Na Seção 6.2 a estratégia de monitoração de serviços testáveis usando as facilidades de teste estrutural é apresentada em detalhes. Três estudos de caso e um experimento formal são apresentados nas Seções 6.3 e 6.4, respectivamente. Por fim, na Seção 6.6, as considerações finais deste capítulo são apresentadas.

\subsection{Estratégia de monitoração}

A forma mais comum de realizar a monitoração ativa de serviços é executar um conjunto de casos de teste de regressão todas as vezes que se desejar saber se um serviço sofreu alguma alteração. Esta estratégia, entretanto, pode ser muito cara porque custos podem estar associados à execução de casos de teste. Além disso, pode haver serviços que permitam que seus clientes façam apenas uma quantidade limitada de invocações em um período determinado de tempo. Assim, o número de casos de teste usados para monitorar um serviço deve ser limitado, já que esta atividade pode ser executada várias vezes em um curto período de tempo (Canfora e Penta, 2009; Hou et al., 2008).

A estratégia de monitoração proposta para verificar mudanças em serviços testáveis usa as informações de teste estrutural oferecidas para selecionar um número limitado de casos de teste para descobrir mudanças nos serviços. Para que isto seja possível, é proposta uma extensão das operações da interface dos serviços testáveis para que mais informações estruturais sejam oferecidas aos clientes do serviço. Propõem-se a adição das seguintes operações na interface do serviço testável:

- getTestRequirements(): usada para obter os requisitos de teste do serviço e que devem ser cobertos pelos casos de teste para que uma cobertura alta seja alcançada.

- getCoveredRequirements () : usada para obter os requisitos de teste que foram cobertos em uma sessão de teste.

A estratégia de monitoração de serviços testáveis é dividida em duas etapas, Configuração e Monitoração, conforme é mostrado na Figura 6.1. A etapa de Configuração tem o objetivo de reunir as informações do serviço testável que serão usadas como referência para saber se o serviço sofreu alguma alteração. A etapa de Monitoração é utilizada para verificar se o serviço testável sofreu alguma alteração no decorrer do tempo. As duas etapas são apresentadas a seguir.

\subsubsection{Configuração}

Esta etapa requer que as seguintes atividades sejam executadas: 


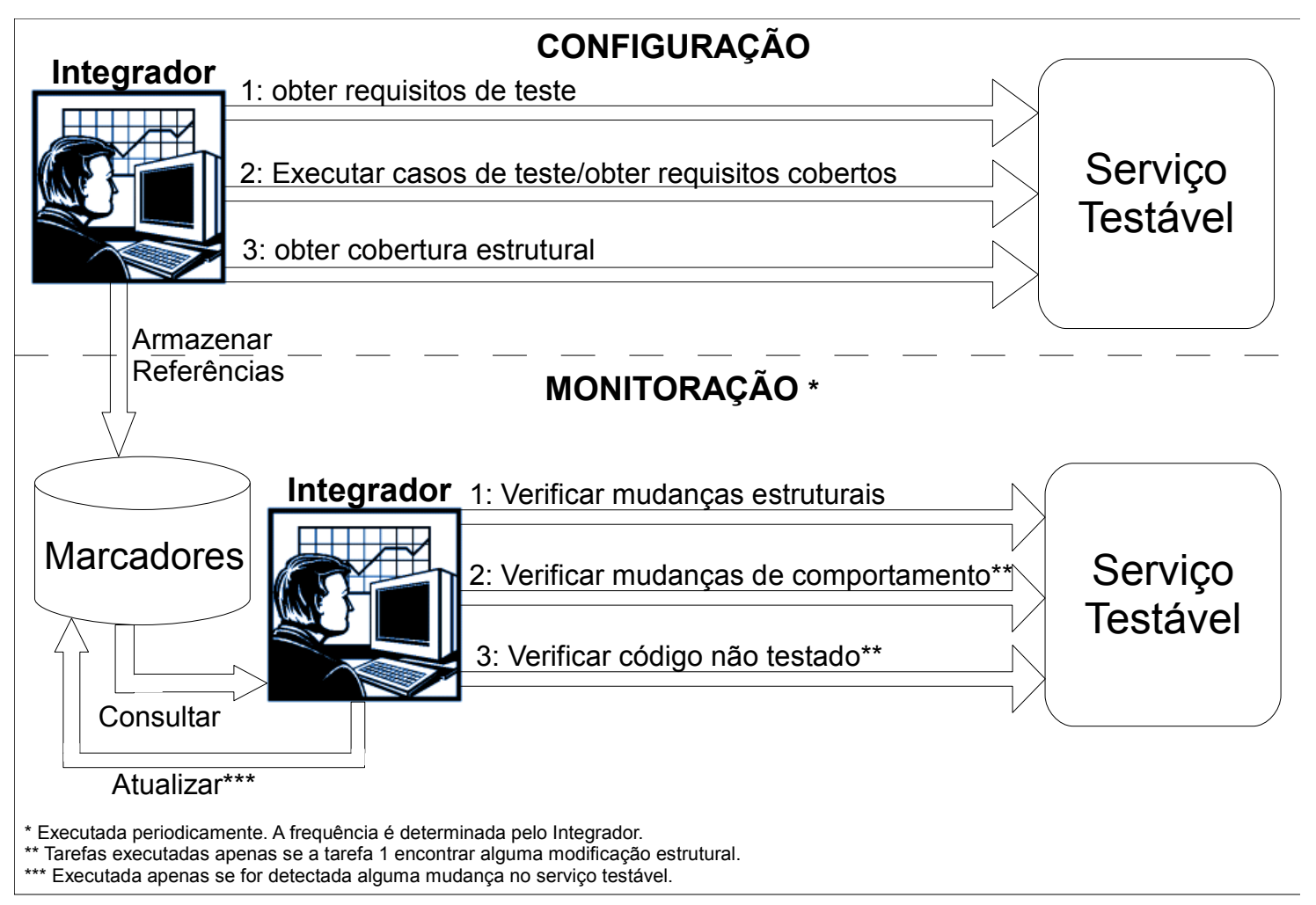

Figura 6.1: Ilustração de uma estratégia de monitoração de um serviço testável

1. Obter os requisitos de teste do serviço testável usando a operação get Test Requi rements ( ) .

2. Executar cada caso de teste do conjunto de regressão do serviço testável e identificar, usando a operação getCoveredRequirements, quais requisitos de teste foram cobertos pelos casos de teste individualmente.

3. Obter a cobertura estrutural alcançada com a execução do conjunto de regressão.

Esta etapa é executada apenas uma vez e as informações obtidas são usadas como marcadores de referência (baseline) para comparar com as informações obtidas durante a atividade de monitoração para detectar mudanças no serviço testável.

\subsubsection{Monitoração}

Esta etapa é responsável por detectar as mudanças nos serviços monitorados. Para isto as seguintes atividades devem ser executadas periodicamente:

1. Verificar mudanças estruturais: esta atividade tem o objetivo de verificar se a estrutura do serviço monitorado continua a mesma. Cada vez que esta atividade é realizada deve-se obter os requisitos de teste do serviço testável e compará-los aos requisitos obtidos na etapa de Configuração. O propósito da comparação é identificar as diferenças entre os requisitos de teste considerando os nós, as arestas e os usos das variáveis do serviço porque eles refletem 
sua implementação. Com os requisitos de teste é possível criar um grafo de fluxo de controle da estrutura de cada operação do serviço testável. Independentemente das várias maneiras em que o código de um serviço pode ser alterado, as mudanças geralmente são as mesmas:

- Mudança no fluxo de controle: isto significa que instruções que desviam o controle do programa (while, if, switch) foram adicionadas ou removidas do código. Consequentemente, nós e arestas serão adicionados ou removidos da estrutura e dos requisitos de teste.

- Mudança no fluxo de dados: isto significa que variáveis passaram a ser usadas em diferentes nós ou arestas ou que variáveis não estão sendo mais usadas em nós e arestas onde estavam sendo usadas anteriormente. O critério todos-usos geralmente define um requisito de teste como um par definição-uso. A definição refere-se ao nó onde a variável é definida e o uso refere-se ao nó ou aresta onde a variável é usada. Esta abordagem de monitoração está preocupada apenas em identificar mudanças referentes ao uso das variáveis.

- Nenhuma mudança no fluxo de controle ou de dados: isto significa que instruções foram adicionadas ou alteradas sem afetar a estrutura do código considerando os nós, as arestas e os usos. Um exemplo deste tipo de modificação é quando um operador relacional ou matemático é trocado por outro. Esses tipos de mudanças não mudam os requisitos de teste. Uma das soluções para identificar este tipo de mudança é comparar o código hash dos blocos de instruções que compõem os nós do grafo de fluxo de controle Ruth et al. (2007).

O resultado desta atividade é uma lista de requisitos de teste (nós e arestas) que foram alterados porque a estrutura do serviço mudou.

2. Verificar mudanças de comportamento: esta atividade é usada para verificar se o comportamento do serviço monitorado mudou com base na execução de casos de teste de um conjunto de regressão. Nesta abordagem, ao invés de executar todos os casos de teste do conjunto de regressão, são executados apenas os casos de teste que cobrem pelo menos um dos requisitos de teste da lista criada na atividade anterior. Esta estratégia permite que o teste de regressão seja usado da maneira tradicional em que casos de teste são executados após uma mudança conhecida.

Os resultados da execução dos casos de teste selecionados são comparados aos resultados da execução dos casos de teste na etapa de Configuração. Qualquer mudança nos resultados indicará que o comportamento do serviço está diferente, considerando serviços com resultados determinísticos.

Esta atividade é executada apenas se alguma mudança estrutural foi identificada. Esta estratégia é uma vantagem porque as atividades de monitoração podem ser executadas periodicamente e se nenhuma mudança for percebida nenhum caso de teste será executado. Mesmo 
quando uma mudança estrutural é identificada, o número de casos de teste executados pela abordagem é reduzido, uma vez que somente são executados casos de teste criteriosamente selecionados.

3. Verificar código não testado: esta atividade é usada para verificar se existem partes do código do serviço monitorado que ainda não foram executadas. A cobertura estrutural obtida após a execução dos casos de teste na atividade anterior é comparada com a cobertura obtida com a execução dos casos de teste na etapa de Configuração. Diferenças entre as duas coberturas indicam que alguma coisa mudou dentro do código, mesmo quando nenhuma mudança foi identificada no comportamento do serviço.

Essa última situação pode ocorrer por diversos motivos:

- Novos trechos de código que não foram exercitados pelos casos de teste.

- Trechos de código foram removidos do serviço.

- Os caminhos percorridos dentro do código pelos casos de teste mudaram porque houve alguma alteração nas instruções do serviço.

Os integradores podem utilizar as informações de cobertura para decidir se as mudanças de cobertura identificadas requerem alguma ação para evitar algum problema. Novos trechos de código que ainda não foram testados, por exemplo, podem esconder defeitos e por isso devem ser testados.

4. Reagir: As alterações sofridas por um serviço não são necessariamente ruins. Uma mudança ruim é quando defeitos são introduzidos no serviço ou quando o serviço para de apresentar o nível de qualidade esperado. Outro exemplo de mudança ruim é quando as regras de negócio de um serviço mudam e a aplicação no qual ele está integrado passa a ficar inconsistente. As boas mudanças de um serviço ocorrem quando as funcionalidades de um serviço são aprimoradas e ele passa a desempenhar sua função com maior qualidade.

Identificar qual tipo de alteração o serviço sofreu, e se é uma alteração boa ou ruim, é essencial para que alguma atitude seja tomada quando alguma mudança é detectada. Na Tabela 6.1 são apresentadas algumas possíveis mudanças sofridas pelos serviços combinando os elementos utilizados por esta abordagem para detectar tais mudanças. Em seguida são apresentadas reações possíveis para cada uma das alterações apresentadas.

Tabela 6.1: Tipos de mudanças sofridas por um serviço e as reações sugeridas

\begin{tabular}{|l|c|c|}
\hline & Todos caso de teste passaram & Pelo menos 1 caso de teste falhou \\
\hline A cobertura não mudou & 1 & 2 \\
\hline A cobertura está maior & 1 & 2 \\
\hline A cobertura está menor & 3 & 2 \\
\hline
\end{tabular}


- Mudança tipo 1: Esta é uma mudança boa, considerando os elementos observados para identificar as mudanças. Todos os casos de teste passaram e a cobertura é igual ou maior à cobertura obtida anteriormente. Significa que a mudança não alterou o comportamento e possivelmente existem menos trechos de código que ainda não foram testados. Nesta situação não se deve tomar nenhuma atitude para adequar a aplicação às mudanças sofridas pelo serviço.

- Mudança tipo 2: Esta á uma alteração ruim, pois foram encontradas falhas no serviço após ele ter sido modificado. Neste caso deve-se substituir o serviço defeituoso por um que desempenhe a mesma função. Na falta de um serviço substituto o provedor do serviço deve ser notificado. Se o serviço estiver falhando porque o serviço usado possui novas regras de negócio, deve-se adaptar a aplicação para ela se adequar ao serviço se este for o caso.

- Mudança tipo 3: Esta é uma mudança que pode ser considerada neutra porque não traz nenhum prejuízo imediato. O comportamento não mudou de acordo com os casos de teste executados, mas a cobertura está menor. É possível que haja mais trechos de código que não foram executados ainda e que podem vir a apresentar uma falha futuramente. Neste caso pode-se criar mais casos de teste para tentar cobrir as partes do código que ainda não foram cobertas e aumentar a confiança para a aplicação que usa o serviço.

Os tipos de mudanças e as ações que podem ser tomadas de acordo com cada uma delas são apenas exemplos do que pode ser feito quando mudanças são detectadas nos serviços monitorados. Definir estratégias de reação não está nos objetivos da abordagem de monitoração de serviços testáveis apresentada.

\subsubsection{Implementação}

Realizar a monitoração de serviços testáveis manualmente é uma tarefa difícil e propensa a erros. Para validar a estratégia de monitoração apresentada foi desenvolvido um framework para automatizar tanto as atividades da etapa de Configuração quanto da etapa de Monitoração. A implementação do framework foi feita para monitorar serviços testáveis gerados pela implementação JaBUTiWS da abordagem BISTWS. O framework foi escrito na linguagem Java e as classes que o compõem podem ser vistas na Figura 6.2.

A instanciação do framework é feita por meio da extensão da classe BaseTest, que é uma classe de teste JUnit abstrata. Na instanciação deve-se criar os casos de teste de regressão e concretizar os seguintes métodos abstratos:

- getEndpointAddress: para retornar o endereço do serviço que será invocado pelos casos de teste. Pode ser o endereço do serviço monitorado ou então da aplicação na qual 


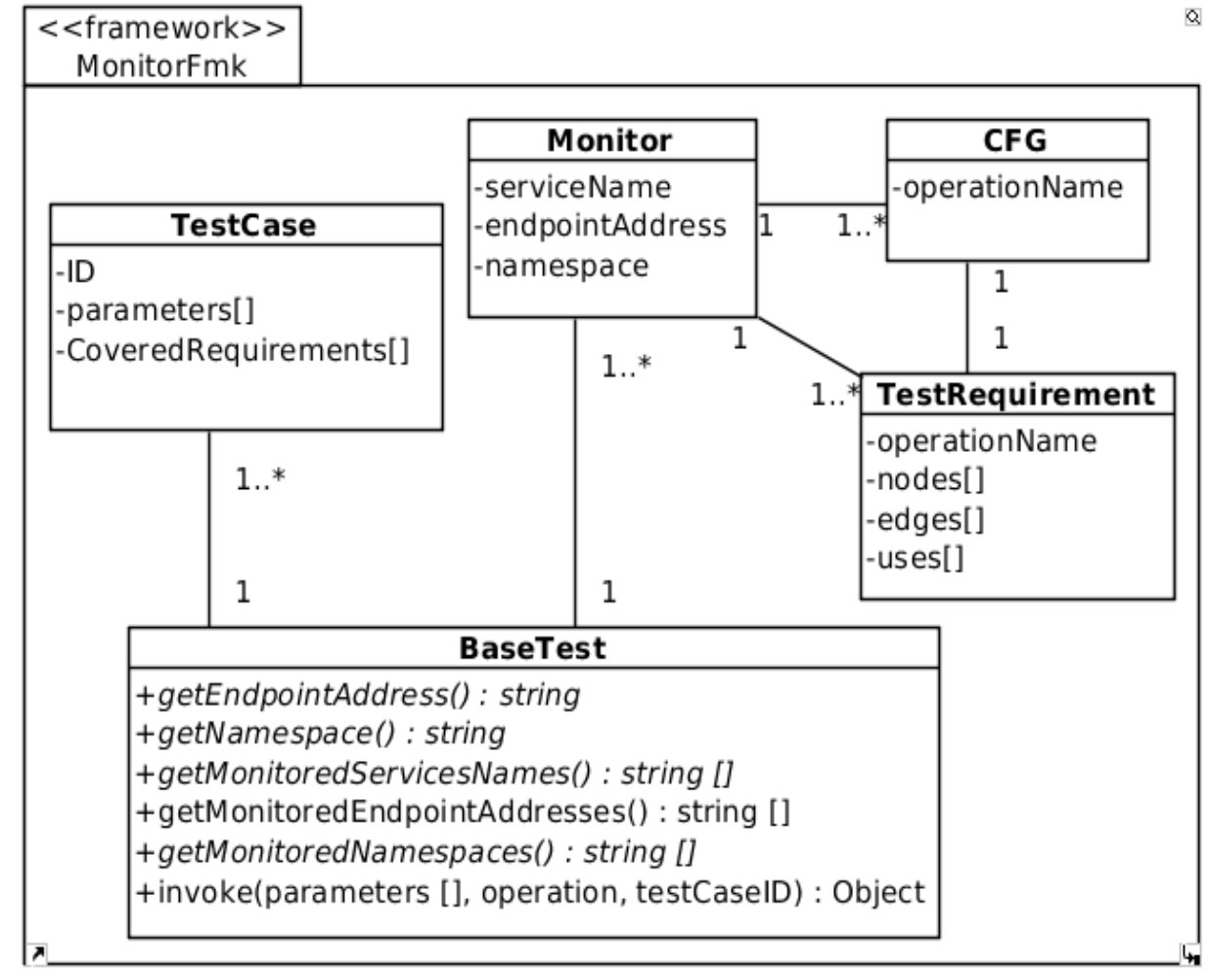

Figura 6.2: Diagrama de classes do framework de monitoração

o serviço está integrado. A monitoração de um serviço também pode ser feita para ele isoladamente ou no contexto de uma aplicação.

- getNamespace: para retornar o namespace no serviço que será invocado pelos casos de teste.

- getMonitoredServiceNames: para retornar o nome dos serviços que serão monitorados. Quando os casos de teste executados têm o objetivo de testar uma aplicação, é possível monitorar vários serviços utilizando o mesmo conjunto de regressão. Quando o serviço testado é o serviço monitorado, então é possível monitorar apenas um serviço por vez.

- getMonitoredEndpointAddress: para retornar o endereço dos serviços que serão monitorados.

- getMonitoredNamespaces: para retornar os namespaces dos serviços monitorados.

Um exemplo de uma instanciação do framework para monitorar três serviços usados por uma aplicação pode ser visto na Listagem 6.1. Nessa instanciação os casos de teste são omitidos para economizar espaço.

$\mathrm{Na}$ etapa de Configuração, o framework executa os casos de teste criados na subclasse de BaseTest e para cada caso de teste são armazenados os requisitos de teste do(s) serviço(s) monitorado(s) (classe TestCase). Para cada serviço monitorado um monitor é criado (classe 
Monitor). O Monitor cria um grafo de fluxo de controle para cada operação do(s) serviço(s) monitorado(s) (classe CFG) com base em seus requisitos (classe TestRequirement).

Durante a estapa de Monitoração, o framework obtém os requisitos de teste do(s) serviço(s) monitorado(s) e cria um novo monitor para cada um deles, juntamente com o grafo de fluxo de controle de cada operação. Os grafos são então comprados com os grafos criados na etapa anterior e os casos de teste afetados pelas mudanças identificadas são executados. Os resultados são comparados com os resultados obtidos na etapa de Configuração e um relatório de mudanças é apresentado, incluindo as diferenças na análise de cobertura. Sempre que uma mudança é identificada todas as informações dos marcadores de referência (baseline) são atualizadas automaticamente pelo framework.

O JaBUTiWS foi modificado para permitir a utilização da estratégia de monitoração apresentada, que requer que os integradores vejam os requisitos de teste dos serviços testáveis e os requisitos de teste cobertos durante uma sesão de teste. A partir desse momento os serviços testáveis gerados pelo JaBUTiWS passaram a ter as operações get TestRequirements e getCoveredRequirements incluídas em suas interfaces de teste geradas durante a instrumentação. A operação get TestRequirements, além dos requisitos de teste para os critérios implementados pelo JaBUTiWS, também retorna um código has h para cada nó do grafo de fluxo de controle gerado para as operações do serviço instrumentado.

\subsection{Estudos de caso}

Três estudos exploratórios foram realizados para avaliar a abordagem de monitoração de serviços testáveis proposta. Para todos os estudos de caso, as seguintes questões de pesquisa foram consideradas:

QP1 A abordagem de monitoração é capaz de identificar todas as mudanças sofridas pelo serviço?

QP2 O número de casos de teste selecionados para verificar o comportamento do serviço é menor do que o número total de casos de teste do conjunto de regressão?

QP3 Os casos de teste selecionados para verificar o comportamento do serviço monitorado são adequados para revelar mudanças no serviço? Para responder a esta questão é preciso identificar:

QP3.1 O número de casos de teste que revelam alguma mudança no serviço monitorado.

QP3.2 O número de casos de teste que não foram executados mas que revelariam alguma mudança se fossem selecionados para serem executados.

A primeira questão de pesquisa é relacionada à eficácia da abordagem em verificar se um serviço mudou. A segunda questão indica se a abordagem é capaz de detectar mudanças de comportamento executando um número reduzido de casos de teste. A terceira questão é usada para 
identificar se a abordagem é capaz de selecionar apenas os casos de teste que são adequados para revelar algum tipo de mudança do serviço.

\subsubsection{Estudo exploratório 1: monitoração de um serviço simples}

No primeiro estudo foi utilizado um serviço simples que calcula o fatorial de um número. $\mathrm{O}$ código da única operação do serviço e o grafo de fluxo de controle equivalente podem ser vistos na Figura 6.3. Os requisitos de teste do serviço apresentado podem ser vistos na Tabela 6.2. O requisito $(\mathrm{x}, 4,(3,5))$ significa que a variável $\mathrm{x}$ é definida no nó 4 e é usada em uma decisão que leva o controle do nó 3 para o nó 5 . O requisito $(x, 1,4)$ significa que a variável x é definida no nó 1 e é usada em uma computação no nó 4.

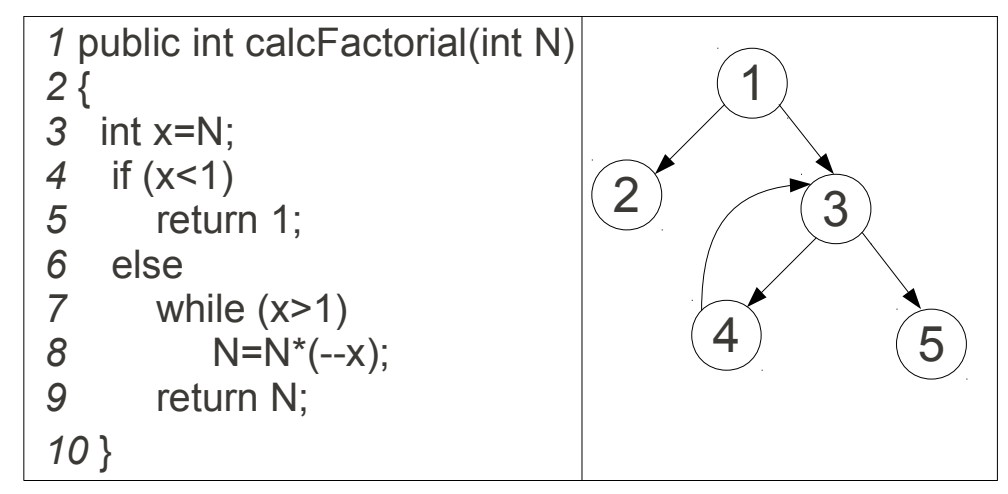

Figura 6.3: Código fonte e grafo de fluxo de controle da operação calcFactorial

Tabela 6.2: Requisitos de teste de calcFactorial

\begin{tabular}{|l|l|}
\hline Critério & Requisitos de teste \\
\hline Todos-nós & $1,2,3,4,5$ \\
\hline Todas-arestas & $(1,2),(1,3),(3,4),(3,5),(4,3)$ \\
\hline Todos-usos & $\begin{array}{l}(\mathrm{N}, 1,5),(\mathrm{N}, 1,4),(\mathrm{N}, 4,5),(\mathrm{x}, 4,(3,5)),(\mathrm{x}, 4,(3,4)),(\mathrm{x}, 1,4), \\
(\mathrm{x}, 1,(3,4)),(\mathrm{x}, 1,(3,5)),(\mathrm{x}, 1,(1,2)),(\mathrm{x}, 1,(1,3))\end{array}$ \\
\hline
\end{tabular}

Foi criada uma instância do framework de monitoração para monitorar o serviço WSF actorial. Na primeira vez que o framework foi ativado as atividades da etapa de configuração foram executadas. Assim foram obtidos os requisitos de teste de WSFactorial (Tabela 6.2), os resultados da execução do conjunto de regressão (Tabela 6.3) e a cobertura estrutural (Tabela 6.5).

Tabela 6.3: Conjunto de regressão para monitorar WSFactorial

\begin{tabular}{|c|c|c|l|c|}
\hline TC-ID & Entrada & Saída esperada & Caminho percorrido & Situação \\
\hline TC-01 & 0 & 1 & $1-2$ & Passou \\
\hline TC-02 & 1 & 1 & $1-3-5$ & Passou \\
\hline TC-03 & 4 & 24 & $1-3-4-3-5$ & Passou \\
\hline
\end{tabular}

Após a execução da etapa de Configuração, as atividades da etapa de Monitoração passaram a ser executadas periodicamente. A estratégia de monitoração apoiada pelas informações estruturais 
implementadas no framework foram capazes de detectar as quatro vezes em que WSFactorial foi atualizado. As alterações às quais WSFactorial foi submetido e que foram identificadas pelo framework podem ser vistas na Figura 6.4. Na figura são apresentados tanto o código fonte quanto o grafo de fluxo de controle das versões do serviço.

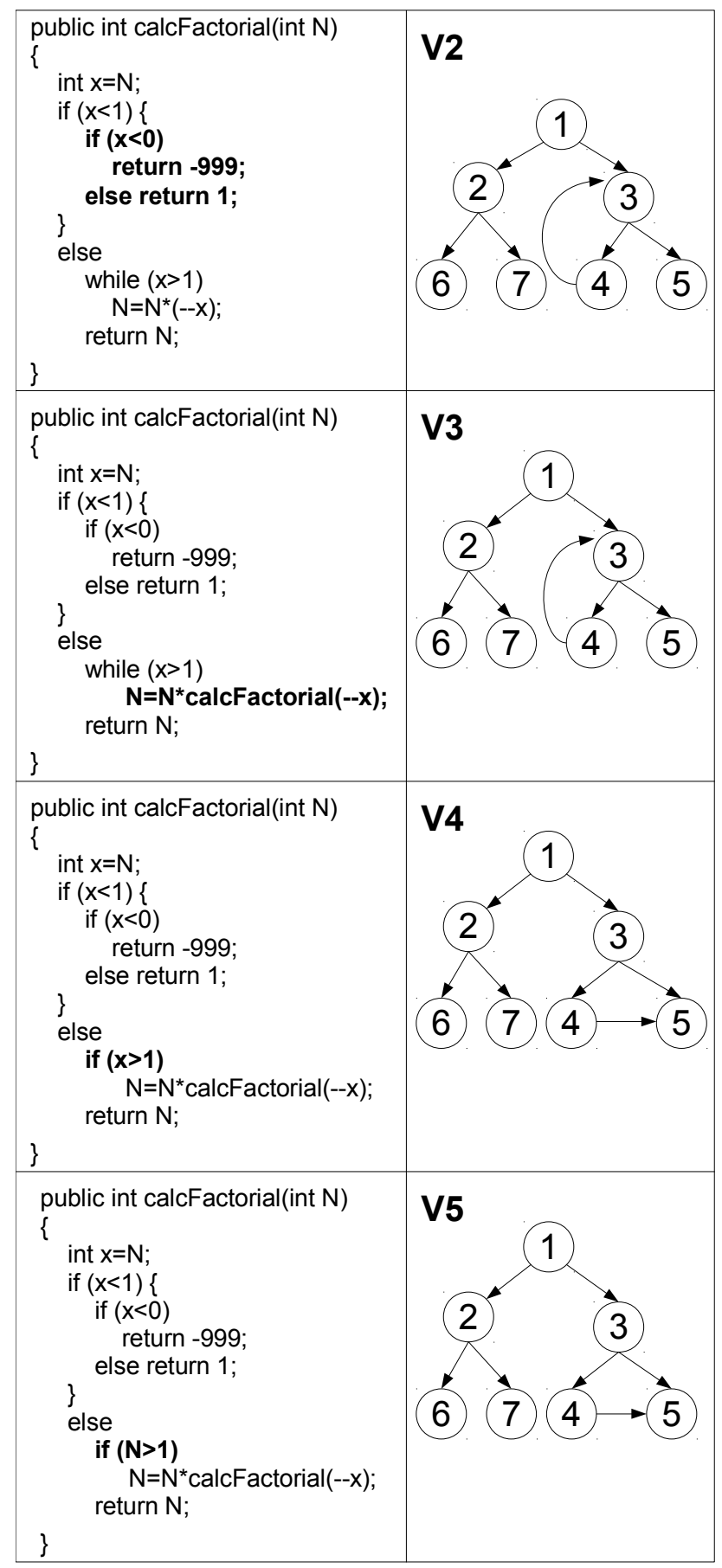

Figura 6.4: As quatro alterações sofridas por WSFactorial

As mudanças estruturais identificadas pelo framework de monitoração bem como os casos de teste selecionados para verificar o comportamento do serviço alterado estão resumidos na Tabela 
6.4. A seguir são apresentados os detalhes de cada alteração realizada e de como o framework detectou as mudanças usando a abordagem de monitoração proposta.

Tabela 6.4: Mudanças sofridas por WSFactorial detectadas pelo framework de monitoração

\begin{tabular}{|c|c|c|c|c|}
\cline { 2 - 5 } \multicolumn{1}{c|}{} & \multicolumn{3}{c|}{ Principais mudanças } & Uasos de teste executados \\
\hline Transição & Nós & Arestas & Usos & TC-01 \\
\hline V1 to V2 & $+6,+7$ & $+(2,6),+(2,7)$ & $+(\mathrm{x}, 1,(2,6)),+(\mathrm{x}, 1,(2,7))$ & TC-03 \\
\hline V2 to V3 & & & $+($ return,1,4) & TC-02, TC-03 \\
\hline V3 to V4 & & $-(4,3),+(4,5)$ & & TC-02, TC-03 \\
\hline V4 to V5 & & & $-(\mathrm{x}, 1,(3,4)),-(\mathrm{x}, 1,(3,5))$ \\
& & & $+(\mathrm{N}, 1,(3,4)),+(\mathrm{N}, 1,(3,5))$ & \\
\hline
\end{tabular}

Quando o serviço mudou da versão V1 para V2, o framework detectou que dois novos nós e duas novas arestas foram criadas. O caso de teste TC-01 é o único caso de teste que cobre o nó 2 (veja Tabela 6.3) e foi o único caso de teste executado para verificar se o comportamento de WSFactorial havia mudado. Após executar o TC-01 foi possível constatar que o comportamento do serviço não mudou, pelo menos considerando a execução de TC-01. Na análise de cobertura, entretanto, foi possível perceber que a cobertura está mais baixa porque os novos nós, arestas e usos introduzidos não foram testados por nenhum caso de teste (ver Tabela 6.5). De fato, é possível verificar que o código fonte do serviço foi alterado para tratar entradas inválidas (números negativos), mas no conjunto de regressão não existe nenhum caso de teste para exercitar este tipo de situação.

Tabela 6.5: Cobertura estrutural obtida para cada versão de WSFactorial

\begin{tabular}{|l|c|c|c|}
\hline Version & all-nodes & all-edges & all-uses \\
\hline V1 & $100 \%$ & $100 \%$ & $100 \%$ \\
\hline V2 & $85 \%$ & $85 \%$ & $92 \%$ \\
\hline V3 & $85 \%$ & $85 \%$ & $93 \%$ \\
\hline V4 & $85 \%$ & $85 \%$ & $92 \%$ \\
\hline V5 & $85 \%$ & $85 \%$ & $92 \%$ \\
\hline
\end{tabular}

Sempre que o framework detecta alguma mudança, os requisitos de teste, os resultados da execução dos casos de teste de regressão e a cobertura obtida passam a ser as informações usadas como referência para as novas comparações, pois é como se a etapa de Configuração tivesse acabado de ser executada e a nova versão do serviço passasse a ser a versão inicial.

A transição da versão V2 para a versão V3 adicionou um novo uso no nó 4: o retorno da chamada recursiva que é declarada implicitamente ( $\mathrm{N}=\mathrm{N} * \mathrm{Cal} C \mathrm{CF}$ actorial $(-\mathrm{x})$; ). TC-03 foi executado porque é o único caso de teste do conjunto de regressão que foi afetado pela modificação, uma vez que somente ele cobre o nó 4 (veja o caminho percorrido por TC-03 na Tabela 6.3). O caso de teste falhou quando foi executado, indicando que o comportamento do serviço mudou. Apesar da falha detectada, manteve-se o serviço da forma como estava para que as mudanças seguintes fossem detectadas pelo framework de monitoração. 
Da versão V3 para V4 o serviço de monitoração detectou que uma aresta foi criada enquanto uma aresta desapareceu. Os casos de teste TC-02 e TC-03 foram executados e passaram. Isto significa que a alteração sofrida por $V 3$ foi uma correção do defeito que havia sido introduzido anteriormente. Quando o serviço mudou da versão V4 para V5, dois novos usos foram criados e outros dois usos desapareceram. Em V4, a variável $x$ é usada na sentença if $(x>1)$, mas em V5 a variável N é usada no lugar (if $(\mathrm{N}>1)$ ). TC-02 e TC-03 foram executados e passaram. A análise de cobertura para os três critérios é a mesma (veja Tabela 6.5).

Como resultado deste estudo pode-se perceber que o framework implementando a estratégia de monitoração proposta pôde identificar todas as mudanças sofridas por WSFactorial, o que responde a QP1. Para detectar mudanças de comportamento em WSFactorial, o framework de monitoração executou 1 de 3 casos de teste na primeira e na segunda mudança e 2 de 3 na terceira e na quarta alteração. Assim, apenas 6 casos de teste de 12 possíveis foram executados (50\%), o que responde a QP2. Em relação à QP3, foi possível observar que 3 dos 6 casos de teste executados revelaram uma mudança. Para verificar se nenhum caso de teste que deveria ter sido selecionado deixou de sê-lo, os casos de teste não selecionados foram executados para avaliar se algum deles revelaria alguma mudança no serviço, o que não aconteceu neste caso.

\subsubsection{Estudo exploratório 2: monitoração de um serviço testável no contexto de uma aplicação}

No segundo estudo foi realizada a monitoração de três serviços usados por uma aplicação chamada ShoppingService. As alterações realizadas em ShippingService foram feitas por meio de operadores de mutação. Uma ilustração da aplicação ShoppingService e os serviços utilizados por ela é apresentada na Figura 6.5.

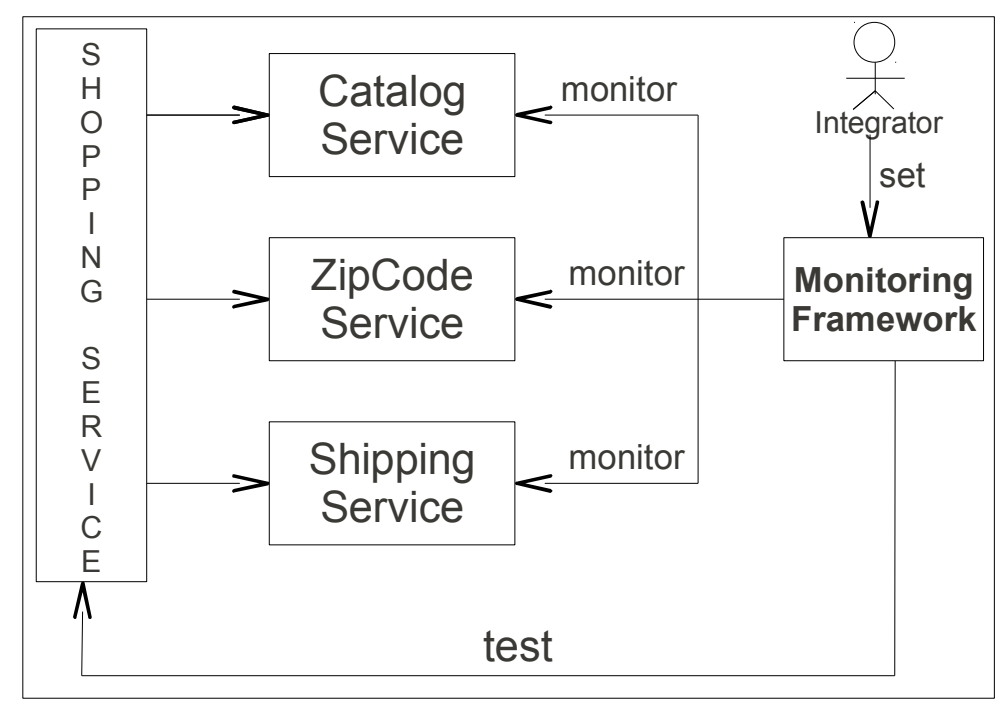

Figura 6.5: Ilustração da aplicação ShoppingService 
ShoppingService é uma aplicação escrita na linguagem Java e que utiliza três serviços testáveis: CatalogService, ZipCodeService e ShippingService. A aplicação é também um serviço e oferece a seus clientes a operação buyItems, que recebe como parâmetros de entrada uma lista de identificadores de produtos (IDs) e um CEP (zip code). Para realizar sua função, a aplicação (i) utiliza Cata logServi ce para obter o preço e o peso de cada produto recebido pela lista de identificadores; (ii) obtém o endereço para o qual serão entregues os produtos usando ZipCodeService; (iii) e obtém o custo de entrega dos produtos usando ShippingService. O retorno da operação buy Items é o preço total da compra, incluindo o preço dos produtos e o frete.

O framework de monitoração foi instanciado para monitorar os três serviços e executar casos de teste para testar a aplicação ShoppingService. Um trecho do código da subclasse usada para instanciar o framework de monitoração pode ser visto na Listagem 6.1. Na instanciação foi informado o endereço do serviço que deve ser testado e os endereços dos serviços que devem ser monitorados. Os casos de teste de regressão foram omitidos no código, mas podem ser vistos na Tabela 6.6.

Listagem 6.1: Trecho de código usado para instanciar o framework de monitoração

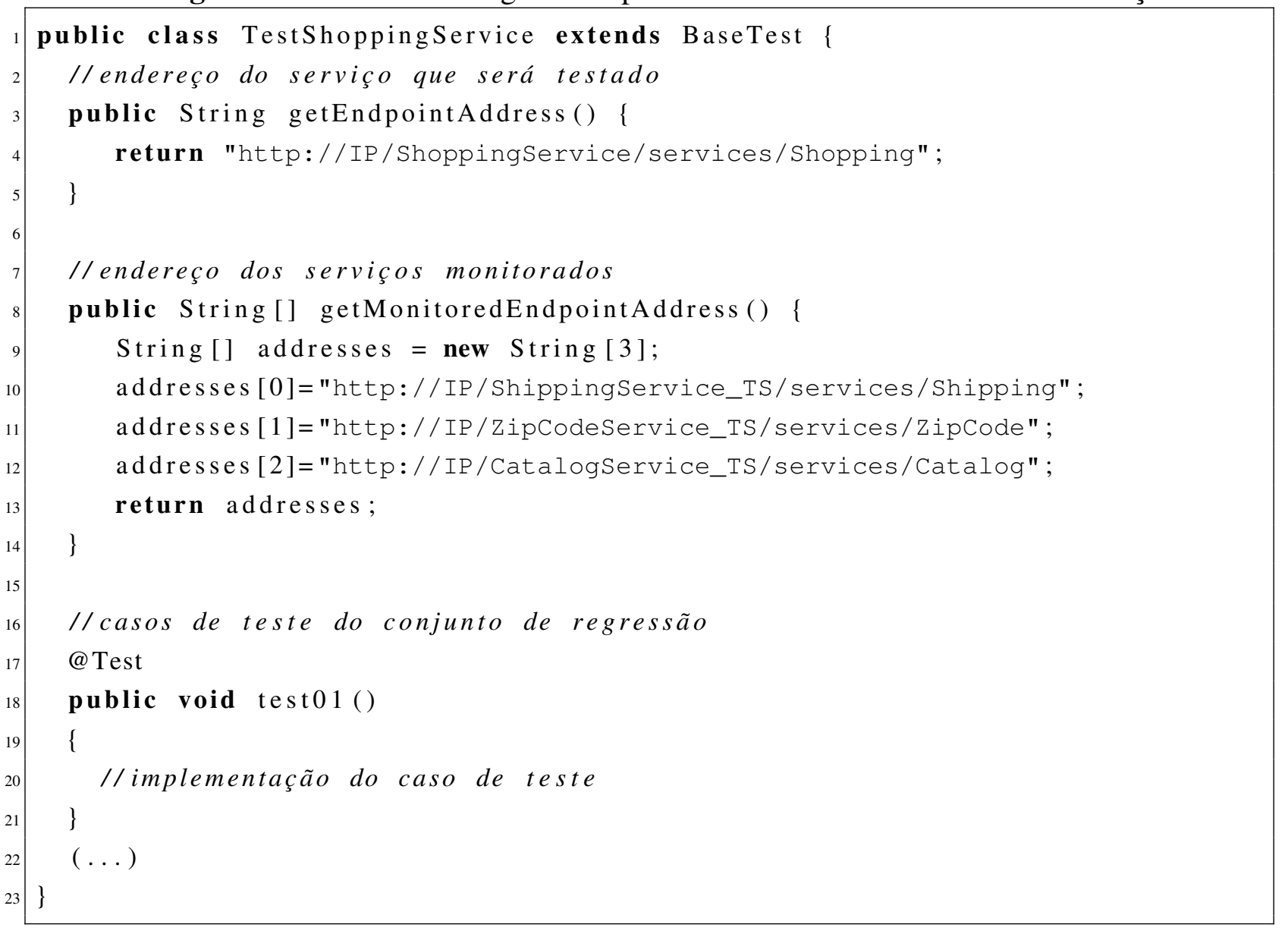

Assim que começou a ser executado, o framework de monitoração obteve as informações da etapa de Configuração e começou a executar a atividade de Monitoração periodicamente. Para este estudo foram selecionados apenas os resultados obtidos com a monitoração do serviço testá- 
Tabela 6.6: Casos de teste criados para ShoppingService

\begin{tabular}{|l|l|l|c|c|}
\hline TC-ID & Items & Zip code & Exp.Result & Description \\
\hline TC-01 & 01,02 & $13564-390$ & 285.0 & $1 \mathrm{~kg}<$ wght $<5 \mathrm{~kg}$, reg=1 \\
\hline TC-02 & 01 & $13564-390$ & 265.0 & wght $<=1 \mathrm{~kg}, \mathrm{reg}=1$ \\
\hline TC-03 & 03,04 & $13564-390$ & 4035 & wght $>5 \mathrm{~kg}, \mathrm{reg}=1$ \\
\hline TC-04 & 01,02 & $81130-210$ & 285.0 & $\mathrm{reg}=2 ; 1 \mathrm{~kg}<\mathrm{wght}<5 \mathrm{~kg}$ \\
\hline TC-05 & 01 & $74023-010$ & 270.0 & $\mathrm{reg}=3 ; \mathrm{wght}<=1 \mathrm{~kg}$ \\
\hline TC-06 & 04 & $51020-021$ & 2540.0 & $\mathrm{reg}=4 ;$ wght $>5 \mathrm{~kg}$ \\
\hline TC-07 & 02 & $69010-010$ & 35.0 & reg=5; wght $<=1 \mathrm{~kg}$ \\
\hline TC-08 & 02 & $04620-000$ & 20.0 & sao paulo, wght $<=1 \mathrm{~kg}$ \\
\hline TC-09 & - & $04620-000$ & -1.0 & invalid items \\
\hline TC-10 & 999 & $04620-000$ & -2.0 & item not found \\
\hline TC-11 & 03 & - & -3.0 & invalid zip code \\
\hline TC-12 & 01,04 & $04620-999$ & -3.0 & invalid zip code \\
\hline
\end{tabular}

vel ShippingService. Para gerar novas versões do serviço a ferramenta de apoio ao teste de mutação MuJava ${ }^{1}$ foi utilizada. Foram gerados vários mutantes utilizando os operadores de mutação disponíveis na ferramenta e foram selecionados aleatoriamente apenas dois mutantes de cada operador. Cada mutante gerado foi publicado como uma nova versão de ShippingService. É importante destacar que neste estudo os dados utilizados para a comparação foram sempre os dados obtidos na etapa de Configuração. A cada nova versão (mutante) de ShippingServi ce publicada a comparação das mudanças voltava a ser feita com base na versão inicial do serviço.

Os resultados da monitoração podem ser vistos na Tabela 6.7. A primeira coluna mostra o nome do mutante de acordo com o operador utilizado. A segunda coluna indica se o framework detectou ou não a mudança ocorrida. A terceira coluna mostra o número de casos de teste selecionados para verificar se o comportamento do serviço havia mudado (\#CT-Sel). A quarta coluna representa o número de casos de teste que falharam (\#CT-Sel-F), indicando assim que alguma mudança havia ocorrido. A quinta coluna mostra o número de casos de teste que não foram selecionados e que falhariam caso tivessem sido executados (\#CT-NSel-F). Para obter esta informação foi preciso executar os casos de teste que não foram selecionados.

Os resultados deste estudo de caso responderam satisfatoriamente todas as questões de pesquisa. Todas as alterações foram detectadas (QP1). O número de casos de teste executado para verificar as alterações é menor do que o número de casos de teste do conjunto de regressão (QP2). Uma abordagem que usasse todos os casos de teste do conjunto de regressão para verificar as mudanças teria executado pelo menos 168 casos de teste (considerando apenas uma execução da atividade de monitoração), enquanto a abordagem para a monitoração de serviços testáveis executou 72 casos de teste ( $43 \%$ do total). Os casos de teste selecionados também foram adequados para indicar as mudanças uma vez que 52 de 72 casos de teste falharam quando foram executados. Além disso, nenhum caso de teste que não foi selecionado falhou quando foi executado para ve-

\footnotetext{
${ }^{1}$ http://www.cs.gmu.edu/ offutt/mujava/
} 
Tabela 6.7: Resultados da monitoração dos mutantes de ShippingService

\begin{tabular}{|l|c|c|c|c|}
\hline Mutante & Mudou? & \#CT-Sel & \#CT-Sel-F & \#CT-NSel-F \\
\hline M-AOIS05 & $\operatorname{sim}$ & 4 & 2 & 0 \\
\hline M-AOIS26 & $\operatorname{sim}$ & 8 & 8 & 0 \\
\hline M-AOIU01 & $\operatorname{sim}$ & 8 & 8 & 0 \\
\hline M-AOIU02 & $\operatorname{sim}$ & 8 & 8 & 0 \\
\hline M-ASRS01 & $\operatorname{sim}$ & 2 & 2 & 0 \\
\hline M-ASRS06 & $\operatorname{sim}$ & 2 & 1 & 0 \\
\hline M-COI01 & $\operatorname{sim}$ & 7 & 6 & 0 \\
\hline M-COI08 & $\operatorname{sim}$ & 4 & 4 & 0 \\
\hline M-COR02 & $\operatorname{sim}$ & 7 & 0 & 0 \\
\hline M-COR08 & $\operatorname{sim}$ & 3 & 2 & 0 \\
\hline M-LOI02 & $\operatorname{sim}$ & 4 & 1 & 0 \\
\hline M-LOI06 & $\operatorname{sim}$ & 4 & 2 & 0 \\
\hline M-ROR14 & $\operatorname{sim}$ & 3 & 0 & 0 \\
\hline M-ROR23 & $\operatorname{sim}$ & 8 & 8 & 0 \\
\hline Total & 14 & 72 & 52 & 0 \\
\hline
\end{tabular}

rificar se eles deveriam ter sido executados. Em duas situações nenhum caso de teste selecionado falhou. Isto ocorreu na monitoração de M-COR02 e M-ROR14, pois eram mutantes equivalentes.

Se for considerado que a atividade de monitoração é executada várias vezes, mesmo que o serviço não tenha sido alterado, os benefícios de usar uma abordagem baseada em informações estruturais para selecionar um número mínimo de casos de teste ficam ainda mais evidentes. Suponha que as modificações realizadas neste estudo de caso tenham sido feitas diariamente e que a atividade de monitoração seja executada três vezes por dia. Em uma abordagem que não fizesse a seleção de casos de teste para testar apenas a parte do código que foi alterada seriam executados 504 casos de teste diariamente. Neste caso, o número de casos de teste executados pela abordagem baseada nas informações dos serviços testáveis representaria apenas $14 \%$ dos casos de teste executados pela outra abordagem, pois se nenhuma alteração estrutural é detectada nenhum caso de teste é executado.

\subsubsection{Estudo exploratório 3: monitoração em um contexto mais re- alístico}

A vantagem de usar mutação para fazer alterações em ShippingService é que é possível mudar o serviço exaustivamente. A desvantagem, entretanto, é que cada operador de mutação faz apenas uma pequena alteração no código e isto pode não ser muito realístico se for comparada com as alterações que poderiam ser realizadas pelos fornecedores dos serviços, como, por exemplo, a adição ou alteração das regras de negócio. As alterações realizadas por mutação são pontuais e representam os principais erros cometidos pelos programadores (DeMillo et al., 1978) e, portanto, são úteis para avaliar se a abordagem é capaz de detectar as pequenas alterações realizadas no 
código e que podem introduzir defeitos. É possível que a utilização de mutação de segunda ou terceira ordem permita que os resultados obtidos sejam mais satisfatórios, mas ainda assim as alterações não seriam totalmente realísticas. A mutação de segunda ordem é quando um operador de mutação é aplicado sobre um mutante gerado a partir do código fonte original. Um mutante de terceira ordem é um mutante gerado a partir do mutante de segunda ordem.

Neste terceiro estudo foram convidados três alunos de pós-graduação para realizar as alterações em ShippingService enquanto o framework realizava a monitoração do serviço no contexto da aplicação ShoppingService. Cada estudante criou apenas uma única nova versão de ShippingService com base na versão original. Assim, o primeiro estudante criou novas regras de negócio; o segundo fez uma refatoração do código; e o terceiro introduziu um defeito no código do serviço.

O framework de monitoração também detectou as três mudanças (QP1). O número de casos de teste executados foi 39\% do total possível (QP2) e 78\% dos casos de teste executados falharam e indicaram mudança no comportamento (QP3). Os casos de teste não selecionados foram executados e nenhum deles falhou, garantindo assim que de fato não deveriam ter sido selecionados para execução.

\subsection{Comparação da abordagem de monitoração de ser- viços testáveis com uma abordagem funcional}

Um experimento controlado para investigar e avaliar o uso de informações estruturais fornecidas por serviços testáveis para a realização das atividades de monitoração foi realizado. Esse experimento foi realizado antes da definição completa da abordagem de monitoração como está apresentada neste capítulo. Quando o experimento foi realizado a abordagem não havia sido projetada para usar os requisitos de teste para selecionar um número reduzido de casos de teste. Ao invés disto, todos os casos de teste eram executados a cada vez que se tentava identificar mudanças nos serviços monitorados. Apesar de não refletir a abordagem definida atualmente, este experimento foi importante porque foi a partir de seus resultados e também de comentários de revisores de artigos submetidos a conferências que a abordagem foi refinada até chegar à versão como foi apresentada.

Geralmente, as abordagens de monitoração baseadas na execução de casos de teste de regressão utilizam apenas os resultados da execução dos casos de teste para verificar se houve alguma mudança no serviço monitorado (teste funcional). O objetivo geral deste experimento foi verificar se existem vantagens em utilizar, além dos resultados funcionais, informações de teste estrutural fornecidas por serviços testáveis. Essa verificação foi realizada por meio de uma comparação entre os resultados obtidos por monitoradores que utilizaram apenas os resultados funcionais da execução dos casos de teste com os resultados obtidos por monitoradores que utilizaram os resultados funcionais e estruturais da execução dos casos de teste. 
Esse experimento foi realizado na perspectiva dos monitoradores de serviços e em ambiente controlado. Dos sujeitos que participaram do experimento, dois deles desempenharam o papel dos fornecedores de serviços e os demais foram divididos em dois grupos de monitoradores. Cada grupo utilizou uma das abordagens consideradas no experimento. Os sujeitos que utilizaram a abordagem de serviços testáveis puderam utilizar os requisitos de teste para detectar mudanças estruturais, executar os casos de teste de regressão para verificar o comportamento do serviço e observar a análise de cobertura para identificar mudanças. Os monitoradores que usaram a abordagem funcional puderam utilizar apenas os casos de teste de regressão e os resultados para poder identificar mudanças no serviço monitorado.

O foco quantitativo do experimento foi medir quantas mudanças cada abordagem consegue identificar e quais operações foram alteradas. O foco qualitativo foi medir a confiança dos monitoradores das duas abordagens sobre os resultados da monitoração. As variáveis independentes deste experimento são as seguintes: a abordagem de monitoração de serviços testáveis; a abordagem Funcional; os objetos experimentais; e a experiência dos sujeitos. As variáveis dependentes são as seguintes: o número de mudanças identificado durante o período do experimento; o número de identificações corretas das operações modificadas; e o grau de confiança de que as modificações foram devidamente identificadas.

\subsubsection{Definição das hipóteses}

As seguintes hipóteses nulas e alternativas foram definidas:

- $\mathrm{HO}_{1}$ : a quantidade de mudanças corretamente identificadas pela abordagem de monitoração de serviços testáveis é menor ou igual à quantidade de mudanças corretamente identificadas pela abordagem funcional.

- $\mathrm{H}_{1}$ : a quantidade de mudanças corretamente identificadas pela abordagem de monitoração de serviços testáveis é maior do que a quantidade de mudanças corretamente identificadas pela abordagem funcional.

- $\mathrm{H}_{2}$ : a precisão com que a abordagem de monitoração de serviços testáveis consegue identificar quais operações foram alteradas é menor ou igual à precisão da abordagem funcional.

- $\mathrm{H}_{2}$ : a precisão com que a abordagem de monitoração de serviços testáveis consegue identificar quais operações foram alteradas é maior do que precisão da abordagem funcional.

- $\mathrm{HO}_{3}$ : a confiança dos monitoradores que utilizam a abordagem de monitoração de serviços testáveis de que as alterações foram identificadas corretamente é menor ou igual à confiança dos monitoradores que utilizam a abordagem funcional.

- $\mathrm{H}_{3}$ : a confiança dos monitoradores que utilizam a abordagem de monitoração de serviços testáveis de que as alterações foram identificadas corretamente é maior do que confiança dos monitoradores que utilizam a abordagem funcional. 


\subsubsection{Sujeitos e objetos experimentais}

Os sujeitos deste experimento foram 11 alunos de pós-graduação na área de Engenharia de Software do ICMC-USP selecionados por conveniência. Dois sujeitos desempenharam o papel de fornecedores e eram responsáveis por realizar alterações nos serviços monitorados pelos demais sujeitos. Os objetos de estudo deste experimento são dois serviços que haviam sido desenvolvidos anteriormente pelos autores da abordagem para outros estudos de caso: BankWS e IRWS. O primeiro oferece funcionalidades de empréstimos bancários e o segundo oferece funcionalidades de cálculos de Imposto de Renda segundo as regras definidas pela Receita Federal para o ano de exercício 2010 e ano base 2009. O projeto deste experimento pode ser visto na Tabela 6.8.

Tabela 6.8: Projeto do experimento
\begin{tabular}{|c|c|c|}
\hline Sujeitos & Funcional & Estrutural \\
\hline 1 & $\mathrm{X}$ & \\
\hline 2 & $\mathrm{X}$ & \\
\hline 3 & & $\mathrm{X}$ \\
\hline 4 & & $\mathrm{X}$ \\
\hline 5 & $\mathrm{X}$ & \\
\hline 6 & $\mathrm{X}$ & \\
\hline 7 & & $\mathrm{X}$ \\
\hline 8 & & $\mathrm{X}$ \\
\hline 9 & & $\mathrm{X}$ \\
\hline
\end{tabular}

A determinação de qual abordagem seria atribuída a cada sujeito foi feita de forma aleatória. Nota-se que, como o total de monitoradores é ímpar, a distribuição dos sujeitos para o uso das duas abordagens ficou desbalanceada. Esse cenário foi alterado durante a execução do experimento porque o sujeito número 4 não executou adequadamente as atividades de monitoração para a abordagem estrutural e seus resultados foram descartados da análise, o que deixou a distribuição balanceada.

\subsubsection{Operação do experimento}

O experimento foi realizado durante duas semanas, sendo que na primeira semana foi realizada a monitoração de BankWS enquanto que na segunda semana foi realizada a monitoração de IRWS. A distribuição dos sujeitos para cada abordagem de monitoração apresentada na Tabela 6.8 foi seguida em ambas as semanas. Foram utilizados dois objetos experimentais distintos para garantir que os resultados do experimento não são dependentes de apenas um tipo de objeto.

Os sujeitos que fizeram o papel de fornecedor receberam treinamento adequado para alterar o serviço monitorado pelos outros sujeitos e para transformá-los em serviços testáveis e publicá-los em um servidor. Os fornecedores estavam livres para fazer o tipo de alteração que desejassem. As mudanças seguiram basicamente a seguinte classificação: introdução e correção de defeitos, otimização, alteração de regras de negócio e refatoração. 
Os monitoradores receberam treinamento adequado para o tipo de abordagem utilizado e seguiram os passos recomendados para executar as atividades de monitoração dos serviços. Os monitoradores deveriam identificar, para cada dia, se o serviço havia sido modificado, quais operações haviam sido modificadas e o quanto estavam confiantes nos resultados obtidos. Durante a execução do experimento, os monitoradores não tiveram problemas em seguir as recomendações da abordagem utilizada, com exceção do sujeito número 4, que teve disponível informações estruturais mas não as utilizou para identificar as mudanças nos serviços. Por esse motivo os resultados desse sujeito foram excluídos da análise dos dados e do teste de hipótese.

\subsubsection{Ameaças à validade do experimento}

Existem algumas ameaças à validade interna deste experimento: a experiência dos alunos (sujeitos) e a produtividade sob avaliação. O primeiro fator não influenciou o experimento porque os sujeitos possuíam experiências semelhantes. O segundo fator não pode ser considerado porque o experimento, apesar de ter sido realizado no contexto de uma disciplina, não fazia parte da disciplina e os alunos não receberam nota pela participação. Todos os alunos que participaram foram voluntários.

Uma das ameaças à validade de construção deste experimento são os objetos experimentais utilizados. Ambos os serviços foram construídos pelo autor da abordagem avaliada, o que poderia, mesmo que inconscientemente produzir objetos construídos para se adequar melhor à abordagem de monitoração de serviços testáveis. Para mitigar este fator foram utilizados serviços que haviam sido usados em outros estudos de caso não relacionados à monitoração e criados antes mesmo da abordagem de monitoração ser elaborada, o que significa que não foram construídos especificamente para este experimento.

Alguns fatores ameaçam a validade externa do experimento. A população de participantes não é representativa, pois são alunos e não profissionais da área. Além disso, a instrumentação pode não ser adequada à prática industrial e o período de aplicação do experimento pode não corresponder ao tempo em que os serviços sofrem alteração em sistemas reais. Portanto, os resultados inferidos pela análise descritiva e as conclusões dadas pelos testes das hipóteses não podem ser generalizados. Os resultados são apenas indícios de que neste contexto as informações estruturais agregam informações à atividade de monitoração e têm potencial de trazer benefícios para as atividades de monitoração.

\subsubsection{Análise dos dados do experimento}

Uma escala ordinal foi definida para pontuar os resultados dos monitoradores a partir dos resultados do experimento: 
- Para a primeira hipótese: o monitorador ganha um (1) ponto quando identifica corretamente que um serviço mudou ou que não mudou e nenhum ponto (0) quando detecta que o serviço não mudou quando de fato ele sofreu alteração e vice versa.

- Para a segunda hipótese: o monitorador ganha dois (2) pontos quando identifica corretamente que uma operação mudou, um (1) ponto quando identifica corretamente que uma operação não mudou nenhum ponto (0) quando identifica incorretamente que uma operação mudou e perde um ponto (-1) quando identifica incorretamente que uma operação não mudou.

- Para a terceira hipótese: o monitorador ganha três (3) pontos quando sua confiança nos resultados é alta, dois (2) pontos quando sua confiança é média e um (1) ponto quando sua confiança é baixa.

Os formulários preenchidos pelos monitoradores foram validados pelos condutores do experimento e em seguida foram comparados com as anotações dos fornecedores sobre as modificações realizadas. Uma pontuação foi atribuída a cada monitorador de acordo com a escala de pontos definida para cada hipótese e os resultados são apresentados na Tabela 6.9. Os resultados consideram o somatório de pontos obtidos durante uma semana. A primeira ocorrência de um sujeito na tabela indica quais são os resultados da primeira semana. A segunda ocorrência do mesmo sujeito indica os resultados da segunda semana.

Tabela 6.9: Pontuação de cada monitorador com base nos resultados do experimento

\begin{tabular}{|l|c|c|c|}
\cline { 2 - 4 } \multicolumn{1}{c|}{} & \multicolumn{3}{c|}{ Abordagem Funcional } \\
\hline Sujeitos & mudanças & Operações & Confiança \\
\hline 1 & 2 & 6 & 8 \\
\hline 2 & 2 & 6 & 8 \\
\hline 5 & 3 & 9 & 5 \\
\hline 6 & 2 & 6 & 10 \\
\hline 1 & 3 & 4 & 10 \\
\hline 2 & 3 & 4 & 8 \\
\hline 5 & 3 & 4 & 10 \\
\hline 6 & 4 & 4 & 6 \\
\hline & Abordagem de monitoração serviços testáveis \\
\hline 3 & 4 & 12 & Confiança \\
\hline 7 & 4 & 12 & 11 \\
\hline 8 & 3 & 12 & 12 \\
\hline 9 & 2 & 6 & 10 \\
\hline 3 & 3 & 11 & 12 \\
\hline 7 & 3 & 11 & 12 \\
\hline 8 & 4 & 14 & 9 \\
\hline 9 & 4 & 13 & Operações \\
\hline
\end{tabular}

A Figura 6.6 mostra os boxplots criados para a comparação dos resultados referentes a cada hipótese formulada. Em relação às modificações corretamente identificadas, aparentemente a abor- 
dagem de monitoração de serviços testáveis é mais precisa do que a abordagem Funcional. Em relação à identificação das operações que foram modificadas, o boxplot parece indicar que a abordagem de monitoração de serviços testáveis tem uma precisão muito maior do que a abordagem Funcional. Em relação à confiança nos resultados, aparentemente os monitoradores que utilizaram os serviços testáveis têm mais confiança nos resultados obtidos do que os monitoradores que utilizaram a abordagem funcional.

Mudanças identificadas

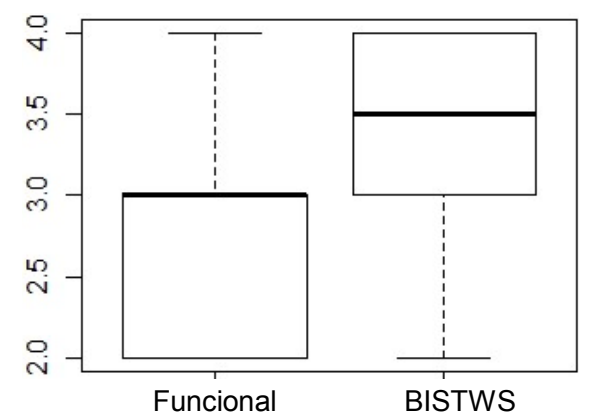

Operações modificadas

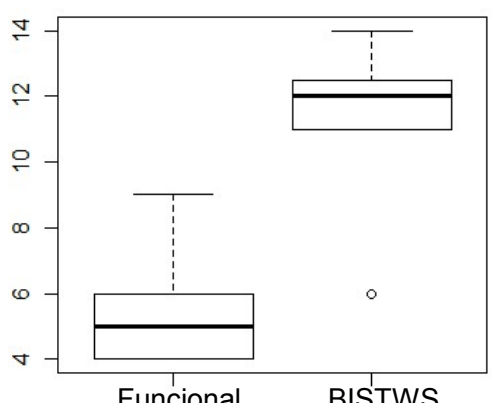

Funcional BISTWS

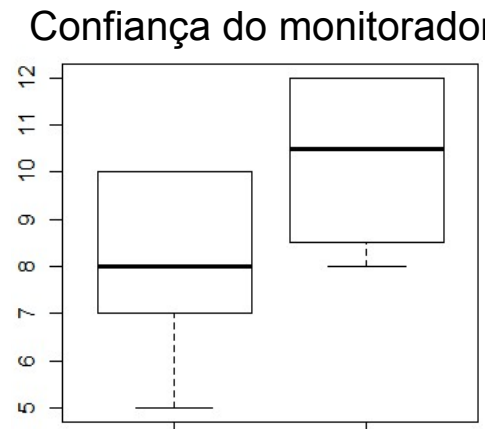

Funcional

Figura 6.6: Boxplots dos resultados do experimento

Também foi realizada uma análise descritiva considerando cada objeto experimental separadamente. O boxplot desta análise para os resultados obtidos na monitoração de BankWS é apresentado na Figura 6.7. Aparentemente a abordagem de monitoração de serviços testáveis apresenta melhores resultados do que a abordagem Funcional em todas as hipóteses definidas.

Mudanças identifidadas

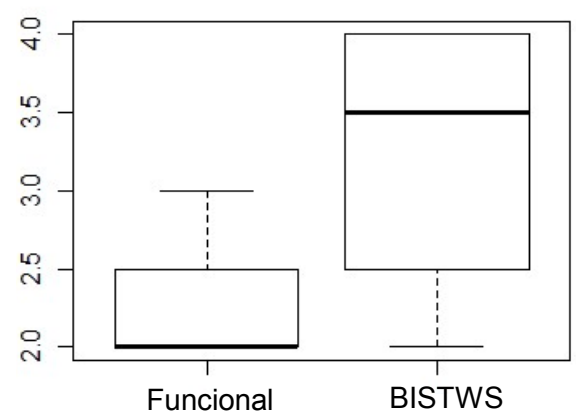

Operações modificadas

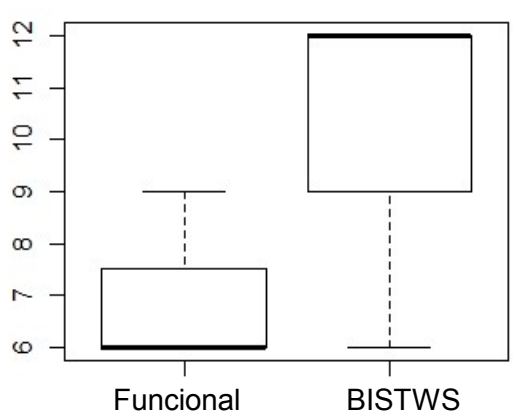

Confiança do monitorador

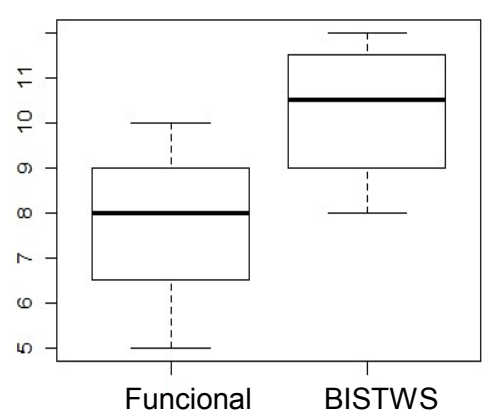

Figura 6.7: Boxplot dos resultados do experimento considerando a monitoração de BankWS

O boxplot dos resultados obtidas com a monitoração de IRWS é apresentado na Figura 6.8. Parece que, desta vez, a abordagem de monitoração de serviços testáveis apresentou resultados apenas ligeiramente melhores do que a abordagem Funcional. Os resultados para a primeira hipótese parecem ser os mesmos para ambas as abordagens. A confiança dos monitoradores é também similar para as duas abordagens. A única exceção neste caso são os resultados considerando a segunda hipótese. A abordagem de serviços testáveis pode identificar mais precisamente quais operações dos serviços monitorados mudaram e quais operações não mudaram. 

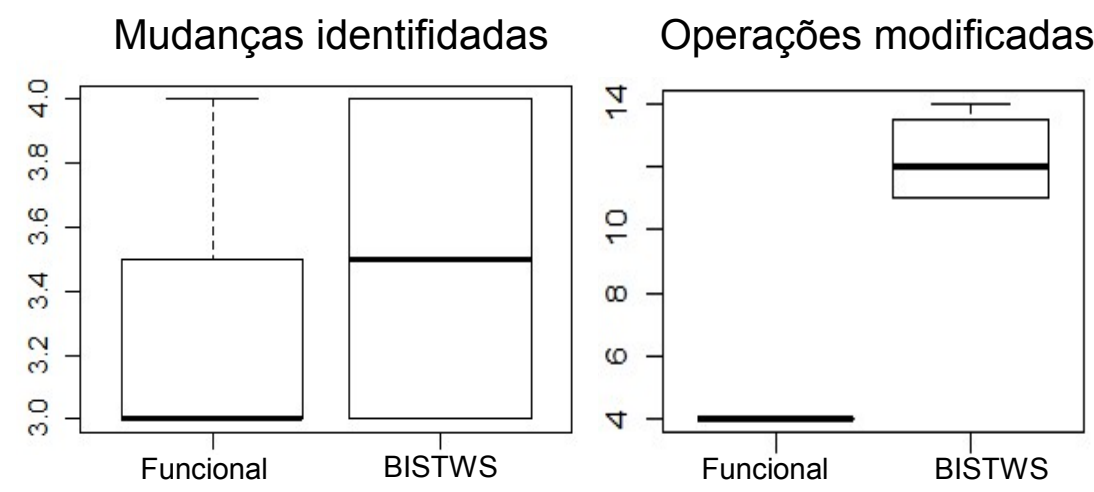

Confiança do monitorador

Figura 6.8: Boxplot dos resultados do experimento considerando a monitoração de BankWS IRWS

Os dados do experimento foram analisados para descobrir os motivos destas diferenças entre os resultados considerando os objetos separadamente. Foi constatado que a diferença nos resultados não ocorreu por causa da natureza do serviço, mas pelos tipos de modificações realizadas pelos fornecedores. A maioria das mudanças feitas em BankWS não afetaram o comportamento do serviço, ficando assim mais difícil para os monitoradores da abordagem Funcional identificar qualquer mudança. Já para o serviço IRWS, a maioria das mudanças afetou o seu comportamento e por isso foi mais fácil detectar as mudanças usando apenas os casos de teste de regressão. Como os casos de teste apresentaram resultados diferentes, naturalmente os monitoradores da abordagem Funcional também ficaram mais confiantes com os resultados obtidos.

\subsubsection{Teste de hipóteses}

As hipóteses deste experimento foram avaliadas por dois testes estatísticos diferentes, de acordo com o projeto e a distribuição das amostras coletadas. Antes de realizar os testes de hipótese o teste de Shapiro-Wilk foi aplicado para verificar a normalidade das amostras. Obteve-se, como resultado, que a distribuição das amostras relacionadas às hipóteses 1 e 2 é normal e a distribuição das amostras relacionadas à hipótese 3 não é normal. Com isso, aplicou-se o Teste T não pareado para as hipóteses 1 e 2 e o teste de Mann-Whitney para a hipótese 3.

Usando o Teste $\mathrm{T}$ não pareado, para a primeira hipótese o $\mathrm{p}$-value foi de 0.05355 e $\mathrm{t}_{0}$ foi de 1.7222. Segundo a tabela de distribuição dos valores $\mathrm{t}, \mathrm{t}_{14}$ é equivalente a 1.761 considerando um intervalo de confiança de $95 \%$. Estes resultados permitem refutar a hipótese nula $\mathrm{HO}_{1}$, pois $\mathrm{t}_{0}>\mathrm{t}_{14}$. Portanto, pode-se afirmar que o uso de informações estruturais permite que os monitoradores identifiquem mais corretamente que os serviços monitorados foram alterados.

No teste da segunda hipótese o p-value foi de 0.00003667 e $\mathrm{t}_{0}$ foi de 5.7138 . Utilizando um intervalo de confiança de $99.95 \%, \mathrm{t}_{14}$ é equivalente a 4.14 , o que permite refutar a hipótese nula $\mathrm{HO}_{2}$ pois $\mathrm{t}_{0}>\mathrm{t}_{14}$ e p-value é ínfimo. Portanto, pode-se concluir que os monitoradores que usam a abordagem de monitoração de serviços testáveis identificam com mais precisão quais operações dos serviços foram alteradas. 
O teste de Mann-Whitney foi usado para testar a terceira hipótese. O p-value foi de 0.02622 e U foi de 13.5 (menor valor entre Ux e Uy). O p-value e a comparação de U com os valores da tabela de Mann-Whitney permite refutar a hipótese nula $\mathrm{H}_{3}$ e aceitar a hipótese alternativa $\mathrm{H} 1_{3}$. Portanto, é possível afirmar que os monitoradores que usam informações estruturais fornecidas pelos serviços testáveis têm mais confiança nos resultados obtidos do que os monitoradores que usam apenas informações funcionais para identificar mudanças nos serviços.

Portanto, os testes de hipóteses confirmam os resultados intuitivos mostrados pelo boxplots, de que o uso de informações estruturais facilita a identificação mais precisa de mudanças nos serviços monitorados e fornece informações suficientes para que os monitoradores tenham mais confiança nos resultados obtidos.

\subsection{Trabalhos relacionados}

Diversos trabalhos têm sido propostos na literatura para a monitoração ativa de serviços (Bruno et al., 2005a; Lin et al., 2006; Ruth et al., 2007; Liu et al., 2007; Denaro et al., 2007; Baresi et al., 2007; Wang et al., 2008; Li et al., 2010; Nguyen et al., 2011; Bartolini et al., 2011a). Todas essas abordagens estão relacionadas à abordagem proposta no que se refere à tentativa de identificar mudanças nos serviços monitorados por meio da instanciação de monitores para os serviços e da execução de casos de teste para comparar os resultados com execuções anteriores. A maioria delas, entretanto, trata o serviço como uma caixa preta e as mudanças são identificadas com base na execução periódica de um conjunto de casos de teste de regressão. Os indícios de mudanças ocorridas nos serviços são as mudanças nos resultados dos casos de teste.

Parte dos trabalhos encontrados são relacionados a abordagens de monitoração baseadas em teste estrutural (Lin et al., 2006; Ruth et al., 2007). Esses dois trabalhos, à semalhança da abordagem de monitoração apresentada, basearam-se na proposta de Rothermel e Harrold (1997) e Harrold et al. (2000) para selecionar e minimizar o número de casos de teste usados no teste de regressão de programas monolíticos e de componentes, respectivamente. Eles usam um grafo de fluxo de controle para identificar partes do código que mudaram e selecionar os casos de teste afetados. Lin et al. (2006) e Ruth et al. (2007) utilizaram esses conceitos e os aplicaram no contexto de serviços, sem, contudo, fornecer uma solução para usar código fonte do serviço para a criação do grafo de fluxo de controle.

Lin et al. (2006) supõem a utilização de esqueletos e stubs gerados por bibliotecas Java para obter um grafo de fluxo da simulação do serviço invocado, ao passo que Ruth et al. (2007) supõem que o código seja fornecido pelo próprio desenvolvedor. Uma das diferenças dessas abordagens para a estratégia de monitoração proposta e apresentada neste capítulo é que os serviços testáveis de BISTWS fornecem informações estruturais que podem ser utilizadas para a criação do grafo de fluxo de controle e para o rastreamento de quais requisitos são cobertos por quais casos de teste. 
Integradores que usarem serviços testáveis têm a certeza de que as informações estruturais estarão disponíveis, o que não depende de uma tecnologia de implementação, como é o caso do trabalho de Lin et al. (2006) ou da disponibilização do código pelo desenvolvedor, como ocorre no trabalho de Ruth et al. (2007). Segundo Bozkurt et al. (2012), as abordagens deles só podem ser aplicadas do ponto de vista do desenvolvedor, ao passo que a abordagem de monitoração de serviços testáveis pode ser aplicada pela perspectiva do integrador dos serviços.

Lin et al. (2006) e Ruth et al. (2007) baseiam-se principalmente em critérios de fluxo de controle e código hash para identificar as mudanças no serviço, ao passo que a abordagem de monitoração proposta neste trabalho, além desses critérios, se baseia também em critérios de fluxo de dados. Os critérios de fluxo de dados são mais sensíveis porque pequenas mudanças, como, por exemplo, a substituição de uma variável em um cálculo, geram diferentes requisitos de teste que podem ser usados como indícios de mudanças.

Apesar de ser o critério de mudança mais sensível, o código hash não permite saber mais detalhes sobre o tipo de mudança que ocorreu. O critério de fluxo de dados, por exemplo, permite saber que um nó foi alterado porque existe uma nova definição ou um novo uso de uma variável, por exemplo. Com base nos critérios de fluxo de dados é possível escolher, por exemplo, marcar apenas os nós cujas alterações referem-se ao uso de variáveis, e não às definições, o que pode ser útil para evitar a execução de casos de teste para partes do código cujas alterações não afetam o comportamento.

Considere o seguinte exemplo. Uma nova variável foi declarada no início de uma operação e usada em um de seus nós. Para a abordagem que identifica mudanças com base no código hash, tanto o primeiro nó do grafo quanto o nó em que a variável é usada foram alterados. Nesse caso, como o primeiro nó mudou, todos os casos de teste da operação são selecionados para verificar se houve mudanças de comportamento. Em uma abordagem que utiliza os critérios de fluxo de dados a situação é diferente. Com ela são apenas selecionados os casos de teste cujos caminhos de execução incluem o nó em que a variável é utilizada.

Além disso, em alguns testes realizados com serviços testáveis gerados por JaBUTiWS, percebeuse que, quando a modificação realizada refere-se à inclusão de uma chamada a uma operação, o compilador automaticamente gera uma declaração de uma variável para armazenar o resultado do retorno da função. Esta variável declarada é definida no primeiro nó da operação. Em um teste realizado apenas com o hash todos os casos de teste da operação foram selecionados, ao passo que quando foram utilizados os critérios de fluxo de dados combinados com o hash foram executados apenas os casos de teste relacionados aos nós e arestas em que a chamada de função foi acrescentada.

Por esses motivos optou-se, na abordagem de monitoração proposta, por usar a combinação dos critérios de fluxo de controle e de dados com o código hash dos nós do grafo. Nesse caso, o código hash é usado apenas se nenhum outro critério conseguiu identificar alguma mudança em um determinado nó ou aresta. 
Além disso, em algumas implementações, as declarações implícitas feitas pelo compilador podem alterar os resultados. Na implementação de serviços testáveis usando o JaBUTiWS, por exemplo, uma variável é declarada pelo próprio compilador para armazenar o valor do retorno de uma função externa invocada dentro de uma operação. A definição da variável é feita no primeiro bloco de instruções da operação (primeiro nó), o que afeta o resultado do código hash gerado para aquele nó. Em alguns testes realizados somente com o código hash, todos os casos de teste da operação foram selecionados para execução porque todos passam pelo primeiro nó, mas, naquele caso, somente uma invocação a uma operação externa havia sido acrescentada. Com os requisitos de fluxo de dados, foi possível perceber que deveriam ser executados somente os casos de teste que exercitavam a parte do código em que a chamada à operação externa foi incluída.

Além das diferenças apontadas com os trabalhos de Lin et al. (2006) e Ruth et al. (2007) no que diz respeito ao uso das informações estruturais e aos critérios de identificação de mudanças utilizados, a abordagem de monitoração apresentada também usa a cobertura estrutural obtida pela execução dos casos de teste de regressão. Nesse quesito a semelhança é com o trabalho de Bartolini et al. (2011a), que também utiliza informações de cobertura estrutural para identificar mudanças nos serviços, mas eles não consideram o uso de outras informações estruturais para reduzir o número de casos de teste executados durante a atividade.

\subsection{Considerações finais}

Neste capítulo foi apresentada uma abordagem para mostrar como as facilidades de teste estrutural fornecidas pelos serviços testáveis podem apoiar a atividade de monitoração de serviços. A monitoração ativa de serviços é baseada na execução de casos de teste e, portanto, a utilização de serviços testáveis possibilita a combinação das técnicas de teste funcional e estrutural para a obtenção de melhores resultados, à semelhança do que acontece com a combinação dessas técnicas na atividade de teste (Myers, 1979).

A estratégia de monitoração apresentada utiliza os requisitos de teste fornecidos pelos serviços testáveis para identificar mudanças estruturais. A partir das mudanças estruturais identificadas um número reduzido de casos de teste é selecionado para verificar se houve alguma mudança no comportamento do serviço monitorado. Além disso, a cobertura estrutural obtida pela execução dos casos de teste também é usada para verificar se existem trechos de código que não foram executados.

Foram apresentados três estudos de caso e um experimento controlado que mostraram a viabilidade da aplicação da abordagem. Os resultados indicaram que o uso das informações estruturais permitiu identificar mais precisamente as alterações do serviço e reduzir os casos de teste executados do conjunto de regressão. Além disso, os estudos mostraram que é viável utilizar técnicas de seleção e redução de casos de teste sem possuir o código do serviço. 
Apesar de apoiar e aumentar as possibilidades de teste possíveis nas atividades de monitoração, a abordagem apresentada também possui limitações. Só é possível aplicar a abordagem para serviços que forneçam informações de teste estrutural tais como os requisitos de teste e os requisitos cobertos em uma sessão de teste. Os serviços fornecidos pela abordagem SOCT (Bartolini et al., 2011a), por exemplo, não fornecem esse tipo de informação. Além disso, não é possível afirmar que a identificação das mudanças estruturais para a seleção dos casos de teste de regressão é $100 \%$ precisa. É preciso que sejam realizados estudos exploratórios para descobrir se existem tipos de mudanças que não podem ser percebidas pela combinação da análise da estrutura, do comportamento e da cobertura do serviço monitorado. Acredita-se, entretanto, que a maioria das mudanças ocorridas nos serviços altera de alguma forma os requisitos de teste e possibilitam a identificação das mudanças estruturais e da seleção de um reduzido número de casos de teste para avaliar se houve mudanças no comportamento do serviço. 


\subsection{Considerações Finais}

Neste trabalho foi apresentada uma abordagem que possibilita a utilização da técnica de teste estrutural no contexto de aplicações baseadas em serviços sem, contudo, expor o código fonte dos serviços para os clientes externos. A abordagem proposta apoia os desenvolvedores na criação de serviços que possuem alta testabilidade por oferecer uma interface de teste cujas operações implementam funcionalidades para facilitar a aplicação do teste estrutural. Esses serviços são chamados de serviços testáveis e são instrumentados para rastrear as informações de sua própria execução e emitir um relatório de cobertura estrutural após a realização de uma sessão de teste. Além do relatório de cobertura estrutural, os serviços testáveis também fornecem metadados de teste para apoiar os testadores na criação de casos de teste para a obtenção de uma cobertura estrutural satisfatória.

A abordagem proposta também apoia integradores que desejam utilizar a técnica de teste estrutural para testar um serviço isoladamente ou no contexto de sua aplicação. A abordagem mostra como os integradores podem utilizar as funcionalidades de teste oferecidas pelos serviços testáveis para iniciar e finalizar uma sessão de teste e obter uma análise de cobertura estrutural. A abordagem também mostra como os integradores podem utilizar os metadados de teste fornecidos pelos serviços testáveis para aumentar seu conjunto de casos de teste e aumentar a cobertura estrutural. Além disso, os integradores podem criar um perfil de utilização do serviço testável para que o cálculo de cobertura estrutural seja personalizado, isto é, com base nas operações e funcionalidades que são realmente utilizadas. 
A abordagem é genérica e pode ser aplicada a qualquer tecnologia de implementação de serviços. Para mostrar a viabilidade da proposta foi apresentada uma instanciação da abordagem utilizando um serviço de teste estrutural chamado JaBUTiWS para a geração de serviços testáveis implementados em Java. Os serviços testáveis gerados com essa instanciação permitem a geração do cálculo de cobertura estrutural com báse nos critérios estruturais todos-nós, todas-arestas e todos-usos.

As facilidades de teste oferecidas pelos serviços testáveis beneficiam não só a atividade de teste das aplicações baseadas em serviços mas também atividades que se baseiam na execução de casos de teste. Dessa forma, foi apresentada uma abordagem de monitoração de serviços testáveis para mostrar como as informações estruturais disponibilizadas por esse tipo de serviço podem ser usadas para apoiar a monitoração ativa. As informações estruturais são utilizadas para a identificação de mudanças estruturais nos serviços. A partir das mudanças estruturais identificadas, um número reduzido de casos de teste é selecionado para verificar se o comportamento do serviço monitorado mudou após a alteração ralizada. Além disso, o relatório de cobertura estrutural também é utilizado para verificar se existem partes do código que ainda não foram testadas. Uma implementação da abordagem de serviços é apresentada com base nos serviços testáveis escritos em Java gerados pelo serviço de teste JaBUTiWS e em um framework que implementa a estratégia de identificação de mudanças e de seleção/execução de casos de teste de regressão.

Para validar as propostas de criação e utilização de serviços testáveis, tanto na atividade de teste quanto na atividade de monitoração, foram realizados quatro estudos de caso e dois experimentos formais. Os resultados dos estudos de caso e do experimento mostraram que é possível utilizar a técnica de teste estrutural para testar e monitorar serviços mesmo sem possuir o código fonte. Além disso, os resultados forneceram indícios promissores dos benefícios de usar a técnica de teste estrutural em combinação com a técnica de teste funcional, como ocorre tradicionalmente na atividade de teste de software (Myers, 1979).

\subsection{Contribuições}

A principal contribuição desta tese é uma abordagem de teste de serviços que possibilita o uso da técnica de teste estrutural em um contexto em que, geralmente, usa-se somente técnicas de teste baseadas em especificação e/ou interface (teste caixa preta) porque o código fonte dos serviços não está disponível. Em particular, destacam-se as seguintes contribuições deste trabalho:

1. Uma abordagem de serviços testáveis: foram definidas as características principais de um serviço testável que, apesar de não expor sua implementação, possui alta testabilidade por possuir facilidades de teste que apoiam o uso da técnica de teste estrutural. Para isso foi especificado um conjunto mínimo de operações e informações que um serviço testável precisa oferecer por meio de sua interface de teste. Juntamente com a abordagem foi definido um modelo de metadados para serviços testáveis, incluindo os metadados calculados em tempo 
de execução, e um perfil de utilização que soluciona os problemas relacionados à cobertura relativa, pois a cobertura calculada é personalizada para cada contexto.

2. Uma abordagem de monitoração: foi proposta uma estratégia de monitoração ativa em que as informações estruturais disponibilizadas por serviços testáveis são utilizadas para detectar mudanças estruturais e selecionar um número reduzido de casos de teste para verificar se o comportamento do serviço mudou. Nessa estratégia são consideradas tanto as informações dadas pelos requisitos gerados pelos critérios de fluxo de controle quanto pelos requisitos gerados pelos critérios de fluxo de dados e a cobertura estrutural do serviço. A estratégia definida permite a diminuição do número de casos de teste executados quando ela é comparada com as estratégias que optam pela execução de todo o conjunto de caso de teste de regressão para identificar alguma mudança.

3. Um serviço de teste estrutural: foi implementado o serviço JaBUTiWS em colaboração com pesquisadores do projeto Qualipso. O serviço apoia o teste estrutural de programas escritos em Java e a geração de serviços testáveis de acordo com as especificações da abordagem BISTWS. O serviço é uma versão e uma extensão da ferramenta JaBUTi (Vincenzi et al., 2006). O serviço tem sido usado, desde sua primeira implementação, como o fornecedor das funcionalidades de instrumentação e avaliação de cobertura estrutural da ferramenta ProgTest (de Souza et al., 2011). Além disso, o JaBUTiWS também tem sido utilizado no repositório (factory) de serviços do projeto Qualipso (QUALIPSO, 2012) para a criação de sistemas integrados de ferramentas de teste, métricas e de monitoração de qualidade de software.

4. Realização de experimentos e estudos de caso: os resultados mostraram que é possível aplicar a técnica de teste estrutural mesmo em um contexto em que o código fonte dos serviços não está disponível. Os desenvolvedores foram capazes de usar a abordagem para gerar serviços testáveis e os integradores foram capazes de usar as informações estruturais e os metadados para criar casos de teste e alcançar coberturas estruturais satisfatórias. Além disso, observou-se que as informações de teste estrutural são sensíveis o suficiente para detectar mudanças que afetam a estrutura, o fluxo de controle e de dados dos serviços monitorados.

Os conceitos de serviços testáveis, o modelos de metadados e o perfil de utilização introduzidos tanto pela abordagem BISTWS quanto pela abordagem SOCT (Bartolini et al., 2011a), estão sendo considerados para a criação de estratégias de teste de grandes coreografias de serviços no contexto do projeto Choreos (Bartolini et al., 2011b).

Acredita-se, portanto, que as contribuições trazidas por esta tese de doutorado contribuem para o avanço da área de teste de aplicações orientadas a serviços. Em especial, a abordagem contribui com as perspectiva do desenvolvedor e do integrador. O desenvolvedor é capaz de utilizar as técnicas propostas para gerar um serviço com alta testabilidade e possivelmente agregar mais qualidade nos serviços desenvolvidos (Tsai et al., 2006; O’Brien et al., 2007; Canfora e Penta, 
2009). O integrador é beneficiado porque pode utilizar as facilidades de teste estrutural oferecidas pelos serviços testáveis e com isso pode aplicar técnicas de teste além da técnica funcional e testar os serviços mais extensivamente, tanto isoladamente quanto no contexto de sua integração com a aplicação.

\subsection{Trabalhos Futuros}

Como trabalhos futuros desta tese destacam-se os seguintes. Em princípio é necessária a realização de experimentos e estudos de caso mais realísticos para melhor avaliar a abordagem proposta. Os experimentos realizados utilizaram objetos experimentais simples e alunos como sujeitos. Além disso, eles foram realizados em ambiente controlado que não representava necessariamente um ambiente real de desenvolvimento de aplicações baseadas em serviços. É necessária a realização de experimentos em que os objetos experimentais sejam mais complexos e reais, e os sujeitos sejam desenvolvedores, integradores e monitoradores de serviços que atuam nessa área profissionalmente.

É desejável realizar a instanciação da abordagem BISTWS para apoiar a geração de serviços testáveis escritos em outras linguagens de programação. Uma ideia interessante seria a implementação de um serviço de teste para instrumentar serviços gerados para a plataforma .NET. Em princípio, todos os programas escritos para esta plataforma, independentemente da linguagem utilizada, são compilados para uma linguagem intermediária chamada de CLR (Common Language Runtime). Um serviço de teste criado para gerar serviços testáveis a partir de código CLR atenderia a um grande número de desenvolvedores de serviços porque há uma grande quantidade de linguagens apoiadas pela plataforma .NET.

As facilidades de teste oferecidas pelos serviços testáveis podem apoiar outras perspectivas de teste além dos desenvolvedores e integradores. Seria importante realizar uma investigação sobre como as facilidades de teste oferecidas pelos serviços testáveis podem apoiar o trabalho dos certificadores. As facilidades de teste oferecidas podem ser utilizadas pelos certificadores assim como são usadas pelos integradores, mas os certificadores testam os serviços apenas em contextos genéricos, o que pode não ser muito realístico. Uma possível solução é a utilização de metadados para a simulação de contextos. Os desenvolvedores devem fornecer, como metadados, sequências de operações necessárias para que todas as funcionalidades do serviço sejam utilizadas e todos os requisitos de teste sejam cobertos. As sequências de operações não precisam ser únicas. $\mathrm{O}$ desenvolvedor pode fornecer várias sequências para simular diferentes contextos, pois o desenvolvedor do serviço consegue imaginar mais contextos reais para a utilização do serviço do que o certificador, uma vez que o desenvolvedor cria o serviço após certa experiência em um domínio de aplicação.

Os serviços testáveis podem ser usados por diversos integradores ao mesmo tempo. Por isso é desejável que seja definido um modelo de controle de concorrência que use estratégias para 
garantir que as informações de teste provenientes das invocações de diferentes integradores sejam adequada e corretamente registradas para cada cliente específico, sem haver contaminação dos dados. No modelo apresentado já são utilizados os identificadores de sessão de teste e de usuário, mas é preciso investigar se essa solução é suficiente.

Em relação à instanciação da abordagem realizada, seria interessante utilizar mecanismos para facilitar o uso do JaBUTiWS pelos desenvolvedores. Uma opção é o desenvolvimento de plugins para os ambientes de desenvolvimento como o Eclipse e o Netbeans, por exemplo. Outra solução viável seria instrumentar o servidor Web Tomcat para que, ao publicar um serviço comum, o servidor invoque o JaBUTiWS, obtenha o serviço instrumentado e publique a versão testável, de acordo com a solicitação do desenvolvedor ao fazer a publicação.

Por fim, deve-se realizar uma investigação sobre como utilizar critérios de teste de integração para apoiar o teste de interação entre serviços testáveis. Para isso é necessário criar um mecanismo de geração de um grafo de fluxo de controle contendo a integração dos grafos dos diversos serviços integrados em uma aplicação. 

Referências Bibliográficas

Almeida, L. F. J.; Vergilio, S. R. Exploring perturbation based testing for web services. In: Proceedings of the IEEE International Conference on Web Services, Washington, DC, USA: IEEE Computer Society, 2006, p. 717-726.

Andrés, C.; Cambronero, M. E.; Núñez, M. Passive testing of web services. In: Proceedings of the 7th International Conference on Web Services and Formal Methods, Berlin, Heidelberg: Springer-Verlag, 2011, p. 56-70.

Angelis, F. D.; Polini, A.; Angelis, G. D. A counter-example testing approach for orchestrated services. In: Proceedings of the Third International Conference on Software Testing, Verification and Validation, Washington, DC, USA: IEEE Computer Society, 2010, p. 373-382.

Bai, X.; Dong, W.; Tsai, W.-T.; Chen, Y. WSDL-based automatic test case generation for web services testing. In: Proceedings of the IEEE International Workshop on Service Oriented System Engineering, Washington, DC, USA: IEEE Computer Society, 2005, p. 215-220.

BaI, X.; LeE, S.; Tsai, W.-T.; Chen, Y. Ontology-based test modeling and partition testing of web services. In: Proceedings of the IEEE International Conference on Web Services, Washington, DC, USA: IEEE Computer Society, 2008, p. 465-472.

BARBier, F.; Belloir, N.; Bruel, J. M. Chapter: Incorporation of test functionality into software componentes. in book: Cots-based software systems. Springer, 2003.

Barbosa, E.; Silva, M.; Corte, C.; Maldonado, J. Integrated teaching of programming foundations and software testing. In: 38th Annual Frontiers in Education Conference, 2008, p. S1H-5-S1H-10.

Baresi, L.; GhezzI, C.; Guinea, S. Smart monitors for composed services. In: Proceedings of the 2nd International Conference On Service Oriented Computing, New York, NY, USA: ACM, 2004, p. 193-202. 
BARESI, L.; GuINEA, S. Dynamo: Dynamic monitoring of WS-BPEL processes. In: International Conference on Service Oriented Computing, Springer, 2005, p. 478-483 (Lecture Notes in Computer Science, v.3826).

BARESi, L.; NitTo, E. D.; GHEzZI, C. Toward open-world software: issue and challenges. IEEE Computer, v. 39, n. 10, p. 36-43, 2006.

BAResi, L.; Nitto, E. D.; Ghezzi, C.; GuineA, S. A framework for the deployment of adaptable web service compositions. Service Oriented Computing and Applications, v. 1, n. 1, p. 75-91, 2007.

Bartolini, C.; Bertolino, A.; Elbaum, S.; Marchetti, E. Whitening SOA testing. In: Proceedings of the the 7th joint meeting of the European software engineering conference and the ACM SIGSOFT symposium on The foundations of software engineering, New York, NY, USA: ACM, 2009a, p. 161-170.

Bartolini, C.; Bertolino, A.; Elbaum, S.; Marchetti, E. Bringing white-box testing to service oriented architectures through a service oriented approach. Journal of Systems and Software, v. 84, p. 655-668, 2011a.

Bartolini, C.; Bertolino, A.; Marchetti, E.; Polini, A. WS-TAXI: A WSDl-based testing tool for web services. In: International Conference on Software Testing Verification and Validation, 2009b, p. $326-335$.

Bartolini, C.; Hamida, A. B.; Bertolino, A.; Besson, F.; Calabro, A.; Corradini, F.; Angelis, F. D.; Angelis, G. D.; Fusani, M.; Kon, F.; Leal, P.; Lonetti, F.; Mulas, D.; Polini, A.; ZRIBI, S. D4.1 - Governance V\&V policies and rules, 2011b.

Disponível em: http://www.choreos.eu/bin/download/Download/ Deliverables/CHOReOSWP 0 4D 4 . 1GovernanceVVpoliciesandrulesVA.pdf

BeanUtils Apache Common BeanUtils, 2012.

Disponível em: http: / / commons.apache.org/beanutils/

Beck, K.; Gamma, E. JUnit Test Infected: Programmers Love Writing Tests - Java Report, July 1998, Volume 3, Number 7., 1998.

Disponível em: http://JUnit.sourceforge.net/doc/testinfected/ testing.htm

Belli, F.; Endo, A. T.; Linschulte, M.; Simao, A. Model-based testing of web service compositions. In: Proceedings of the 6th IEEE Symposium on Service-Oriented System Engineering, Irvine, CA, USA: IEEE Computer Society, 2011, p. 182-192. 
Bertolino, A.; Frantzen, L.; Polini, A.; Tretmans, J. Audition of web services for testing conformance to open specified protocols. In: Architecting Systems with Trustworthy Components, London, UK: Springer-Verlag, 2006, p. 336-347.

Bertolino, A.; Gao, J.; Marchetti, E.; Polini, A. Automatic test data generation for XML schema-based partition testing. In: Proceedings of the Second International Workshop on Automation of Software Test, Washington, DC, USA: IEEE Computer Society, 2007, p. 4-10.

Bertolino, A.; Polini, A. SOA test governance: Enabling service integration testing across organization and technology borders. In: Proceedings of the IEEE International Conference on Software Testing, Verification and Validation, Washington, DC, USA: IEEE Computer Society, 2009, p. 277-286.

Beydeda, S.; Gruhn, V. State of the art in testing components. In: Proceedings of the Third International Conference on Quality Software, 2003, p. 146 - 153.

BINDER, R. V. Modal testing strategies for OO software. IEEE Computer, v. 29, n. 11, p. 97-99, 1996.

BozKurT, M.; HARMAn, M. Automatically generating realistic test input from web services. In: Proceedings of the 6th IEEE Symposium on Service-Oriented System Engineering, Irvine, CA, USA: IEEE Computer Society, 2011, p. 13-24.

Bozkurt, M.; Harman, M.; Hassoun, Y. Testing \& verification in service-oriented architecture: A survey. Software Testing, Verification and Reliability (STVR), 2012.

Brenner, D.; Atkinson, C.; Hummel, O.; Stoll, D. Strategies for the run-time testing of third party web services. In: Proceedings of the IEEE International Conference on ServiceOriented Computing and Applications, Washington, DC, USA: IEEE Computer Society, 2007, p. 114-121.

Brenner, D.; Atkinson, C.; Paech, B.; Malaka, R.; Merdes, M.; Suliman, D. Reducing verification effort in component-based software engineering through built-in testing. In: Proceedings of the 10th IEEE International Enterprise Distributed Object Computing Conference, Washington, DC, USA: IEEE Computer Society, 2006, p. 175-184.

Briand, L. C.; LABiche, Y.; SówKA, M. M. Automated, contract-based user testing of commercial-off-the-shelf components. In: Proceeding of the 28th international conference on Software engineering, New York, NY, USA: ACM, 2006, p. 92-101.

BRITTENHAM, P. Understanding the WS-I Test Tools, 2003.

Disponível em: http://www.ibm.com/developerworks/webservices/ library/ws-wsitest/ 
Brown, A. W.; Wallnau, K. C. The current state of CBSE. IEEE Software, v. 15, n. 5, p. 37-46, 1998.

Bruel, J.-M.; AraúJo, J.; Moreira, A.; Royer, A. Using aspects to develop built-in tests for components. In: The 4th AOSD Modeling With UML Workshop, 2003.

Bruno, M.; Canfora, G.; Penta, M. D.; Esposito, G.; Mazza, V. Using test cases as contract to ensure service compliance across releases. In: Proceedings of the $3 r d$ International Conference on Service Oriented Computing, 2005a, p. 87-100.

Bruno, M.; Canfora, G.; Penta, M. D.; Esposito, G.; Mazza, V. Using test cases as contract to ensure service compliance across releases. In: Third International Conference on Service-Oriented Computing, 2005b, p. 87-100.

Bundell, G. A.; Lee, G.; Morris, J.; PARK, K. A software component verification tool. In: Proceedings of the International Conference on software Methods and Tools, Washington, DC, USA: IEEE Computer Society, 2000, p. 137-148.

Disponível em: http://dl.acm.org/citation.cfm?id=555920.830373

C. M. Toyota, E. M. Construção de classes auto-testáveis. In: Simpósio de Computação Tolerante a Falhas, 1999, p. 196-209.

Cafeo, B. B.; Masiero, P. C. Contextual integration testing of object-oriented and aspectoriented programs: A structural approach for Java and AspectJ. In: Proceedings of the 25th Brazilian Symposium on Software Engineering, Washington, DC, USA: IEEE Computer Society, 2011, p. 214-223.

CAfeO, B. B. P.; MASIERO, P. C. Teste estrutural de integração contextual de programas orientados a objetos e a aspectos. In: IV Latin American Workshop on Aspect-Oriented Software Development, 2010.

CAnfora, G.; Di Penta, M. SOA: Testing and self-checking. Proceedings of International Workshop on Web Services Modeling and Testing, p. 3-12, 2006.

CANFORA, G.; Penta, M. International summer school on software engineering. cáp. ServiceOriented Architectures Testing: A Survey, Berlin, Heidelberg: Springer-Verlag, p. 78-105, 2009.

CAnfora, G.; Penta, M. D. Testing services and service-centric systems: Challenges and opportunities. IT Professional, v. 8, n. 2, p. 10-17, 2006.

CheESMAN, J.; DANIELS, J. UML components: A simple process for specifying componentbased software. Addison-Wesley, 2000. 
Chen, L.; WANG, Z.; XU, L.; LU, H.; XU, B. Test case prioritization for web service regression testing. In: Fifth IEEE International Symposium on Service Oriented System Engineering, 2010, p. $173-178$.

Councill, B.; Heineman, G. T. Definition of a software component and its elements. Component-based software engineering: putting the pieces together, p. 5-19, 2001.

Delamaro, M. E.; Maldonado, J. C.; Mathur, A. P. Interface mutation: An approach for integration testing. IEEE Transactions on Software Engineering, v. 27, n. 3, p. 228-247, 2001.

DeMillo, R. A.; Lipton, R. J.; SAyward, F. G. Hints on test data selection: Help for the practicing programmer. Computer, v. 11, p. 34-41, 1978.

Denaro, G.; Pezze, M.; Tosi, D. SHIWS: A self-healing integrator for web services. In: International Conference on Software Engineering Companion, Washington, DC, USA: IEEE Computer Society, 2007, p. 55-56.

Dong, W.-L.; YU, H. Web service testing method based on fault-coverage. In: Proceedings of the 10th IEEE International Enterprise Distributed Object Computing Conference Workshops, Washington, DC, USA: IEEE Computer Society, 2006, p. 43-.

EDWARDS, S. H. Toward reflective metadata wrappers for formally specified software components. In: OOPSLA Workshop Specification and Verification of Component-Based Systems, London, UK: Springer-Verlag, 2001, p. 129-144.

Eler, M.; Bertolino, A.; Masiero, P. More testable service compositions by test metadata. In: 6th IEEE International Symposium on Service Oriented System Engineering, Washington, DC, USA: IEEE Computer Society, 2011a, p. 204 -213.

Eler, M.; Delamaro, M.; Masiero, P. Using structural testing information to support monitoring activities. In: 6th IEEE International Symposium on Service Oriented System Engineering, Washington, DC, USA: IEEE Computer Society, 2011b, p. 25 -30.

Eler, M. M.; Delamaro, M. E.; Maldonado, J. C.; Masiero, P. C. Built-in structural testing of web services. In: Proceedings of the 24th Brazilian Symposium on Software Engineering, Washington, DC, USA: IEEE Computer Society, 2010, p. 70-79.

Eler, M. M.; Endo, A. T.; Masiero, P. C.; Delamaro, M. E.; Maldonado, J. C.; VinCEnZI, A. M. R.; CHAIM, M. L.; BEDER, D. M. JaBUTiService: A web service for structural testing of java programs. In: Proceedings of the 33rd Annual IEEE Software Engineering Workshop, Washington, DC, USA: IEEE Computer Society, 2009, p. 69-76.

Endo, A. T.; Simao, A. Model-based testing of service-oriented applications via state models. In: Proceedings of the IEEE International Conference on Services Computing, Washington, DC, USA: IEEE Computer Society, 2011, p. 432-439. 
Endo, A. T.; Simão, A. S.; SouzA, S. R. S.; SouzA, P. S. L. Web services composition testing: a strategy based on structural testing of parallel programs. In: Proceedings of the Testing: Academic and Industrial Conference - Pratice and Research Techniques, Windsor, United Kingdom, 2008, p. 3-12.

ENGINEERING GROUP Spago4Q, 2012.

Disponível em: http://www.spagoworld.org/xwiki/bin/view/Spago4Q/

Franchin, I. G.; Lemos, O. A. L.; MASiero, P. C. Pairwise structural testing of object and aspect-oriented java programs. In: Proceedings of the 21th Software Engineering Brazilian Symposium, Joao Pessoa, PB, Brazil, 2007.

Fuentes, L.; Troya, J. M. Towards an open multimedia service framework. ACM Computing Surveys, v. 32, 2000.

Ghosh, S.; Mathur, A. P. Inferface mutation. In: Mutation Symposium - A Symposium on Mutation Testing, San Jose, USA: Kluwer Academic Publishers, 2000, p. 227-247.

Gross, H.-G. Component-based software testing with UML. Springer, 316 p., 2005.

Harrold, M. J.; Orso, A.; Rosenblum, D.; Rothermel, G.; Soffa, M. L. Using component metadata to support the regression testing of component-based software. Relatório Técnico GIT-CC-00-38, 2000.

Harrold, M. J.; Rothermel, G. Performing dataflow testing on classes. In: Proceedings of the ACM Symposium on the Foundations of Software Engineering, 1994, p. 154-163.

Heckel, R.; Mariani, L. Automatic conformance testing of web services. In: Fundamental Approaches to Software Engineering, 2005, p. 34-48.

Hornstein, J.; EdLER, H. Test reuse in cbse using built-in tests. 2002.

Hou, S.-S.; ZHANG, L.; XIE, T.; Sun, J. Quota-constrained test-case prioritization for regression testing of service-centric systems. In: Proceedings of the IEEE International Conference on Software Maintenance, 2008, p. 257-266.

Huang, H.; Tsai, W.-T.; Paul, R.; Chen, Y. Automated model checking and testing for composite web services. In: Proceedings of the Eighth IEEE International Symposium on Object-Oriented Real-Time Distributed Computing, Washington, DC, USA: IEEE Computer Society, 2005, p. 300-307.

IEEE Ieee standard glossary of software engineering terminology, ieee std 610. 1990.

Illeva, S.; PAVlov, V.; Manova, I. A composable framework for test automation of servicebased applications. In: Proceedings of the 7th International Conference on the Quality of 
Information and Communications Technology, Washington, DC, USA: IEEE Computer Society, 2010, p. 286-291.

Karam, M.; SAFA, H.; Artail, H. An abstract workflow-based framework for testing composed web services. In: Proceedings of the ACS/IEEE International Conference on Computer Systems and Applications, IEEE, 2007, p. 901-908.

KeUm, C.; KAnG, S.; Ko, I.-Y.; BAIK, J.; CHOI, Y.-I. Generating test cases for web services using extended finite state machine. In: Proceedings of 18th International Conference on Testing of Communicating Systems, Springer, 2006, p. 103-117.

KIM, S.; ClARK, J. A.; MCDERMID, J. A. The rigorous generation of java mutation operators using HAZOP. In: 12TH International Conference On Software \& Systems Engineering and Their Applications, 1999.

KIM, S.; Clark, J. A.; MCDERmid, J. A. Class mutation: Mutation testing for object-oriented programs. In: Proceedings of the NET OBJECTDAYS, 2000, p. 9-12.

KrafZIG, D.; BAnKe, K.; Slama, D. Enterprise SOA : Service-oriented architecture best practices (the coad series). Prentice Hall PTR, 2004.

Kunda, D.; Brooks, L. Component-Based Software Engineering for Developing Countries: Promises and Possibilities. 2000.

L. Baresi, D. Bianculli, C. G. S. G.; Spoletini, P. Validation of web service compositions. IET Software, v. 1, p. 219-232, 2007.

Lemos, O. A. L.; Vincenzi, A. M. R.; Maldonado, J. C.; Masiero, P. C. Control and data flow structural testing criteria for aspect-oriented programs. Journal of Systems and Software, v. 80, n. 6, p. 862-882, 2007.

LI, B.; QIU, D.; JI, S.; WANG, D. Automatic test case selection and generation for regression testing of composite service based on extensible BPEL flow graph. In: Proceedings of the IEEE International Conference on Software Maintenance, Washington, DC, USA: IEEE Computer Society, 2010, p. 1-10.

LI, Z. J.; SUN, W. BPEL-unit: JUnit for BPEL processes. In: International Conference on Service Oriented Computing, Springer, 2006, p. 415-426 (Lecture Notes in Computer Science, v.4294).

Li, Z. J.; ZhU, J.; ZhAng, L.-J.; Mitsumori, N. Towards a practical and effective method for web services test case generation. In: Workshop on Automation of Software Test, 2009, p. $106-114$. 
Lin, F.; RUTH, M.; TU, S. Applying safe regression test selection techniques to Java web services. In: Proceedings of the International Conference on Next Generation Web Services Practices, Washington, DC, USA: IEEE C.S., 2006, p. 133-142.

LIONS, J. L. ARIANE 5 - Flight 501 Failure: Report by the Inquiry Board, 1996.

Disponível em: http://www.ima.umn. edu/ arnold/disasters/ariane5rep. html

LIU, H.; LI, Z.; ZHU, J.; TAN, H. Business process regression testing. In: International Conference on Service Oriented Computing, Lecture Notes in Computer Science, Springer, 2007, p. 157-168 (Lecture Notes in Computer Science, ).

MeI, H.; ZhANG, L. A framework for testing web services and its supporting tool. In: Proceedings of the IEEE International Workshop on Service-Oriented System Engineering, Washington, DC, USA: IEEE Computer Society, 2005, p. 207-214.

MeI, L.; Chan, W.; Tse, T. Data flow testing of service-oriented workflow applications. In: Proceedings of the 30th international conference on Software engineering, New York, NY, USA: ACM, 2008, p. 371-380.

Meijler, T. D.; Nierstrasz, O. Beyond objects: Components. In: Papazoglou, M. P.; Schlageter, G., eds. Cooperative Information Systems: Current Trends and Directions, Academic Press, p. 49-78, 1997.

Moreira, A.; Bruel, J.-M.; Araújo, J. Adding behavior description support to cots components through the use of aspects. In: Proceedings of the 2 nd International Workshop on Models for Non-functional Aspects of Component-Based Software, 2005, p. 9-19.

Myers, G. J. The art of software testing. New York: Wiley, 1979.

NACHAR, N. The mann - whitney u : A test for assessing whether two independent samples come from the same distribution. Tutorials in Quantitative Methods for Psychology, v. 4, n. 1, p. 13-20, 2008.

Disponível em: http://www.tqmp.org/Content/vol 04-1/p013/p013.pdf

Neves, V. O.; Masiero, P. C. Extensão da ferramenta JaBUTi/Aj para teste de integração de programas orientados a objetos e a aspectos. In: XVIII Sessão de Ferramentas - II Congresso Brasileiro de Software: Teoria e Prática, 2011.

Nguyen, C.; Marchetto, A.; Tonella, P. Test case prioritization for audit testing of evolving web services using information retrieval techniques. In: IEEE International Conference on Web Services, Washington, DC, USA: IEEE Computer Society, 2011, p. 636 -643. 
O'BRIEN, L.; MERSON, P.; BASS, L. Quality attributes for service-oriented architectures. In: Proceedings of the International Workshop on Systems Development in SOA Environments, Washington, DC, USA: IEEE Computer Society, 2007, p. 3.

OfFUT, A. J.; IRVINE., A. Testing object oriented software using the category-partition method. In: International Conference on Technology of Object-Oriented Languages and Systems, 17., 1995, p. 293-304.

Offutt, J.; XU, W. Generating test cases for web services using data perturbation. SIGSOFT Software Engineering Notes, v. 29, n. 5, p. 1-10, 2004.

Oliveira Neves, V.; Lemos, O.; Masiero, P. C. Teste estrutural de integração nível 1 de programas orientados a objetos e a aspectos. In: III Latin American Workshop on AspectOriented Software Development, 2009.

Orso, A.; Harrold, M. J.; Rosenblum, D. Component metadata for software engineering tasks. In: 2nd International Workshop on Engineering Distributed Objects, Springer, 2000a, p. 129-144.

Orso, A.; Harrold, M. J.; Rosenblum, D. S. Component metadata for software engineering tasks. In: Revised Papers from the Second International Workshop on Engineering Distributed Objects, London, UK: Springer-Verlag, 2000b, p. 129-144.

Ossher, H.; TARR, P. Multi-dimensional separation of concerns and the hyperspace approach. In: Proceedings of the Symposium on Software Architectures and Component Technology: The State of the Art in Software Development, Kluwer, 2000.

Palomo-Duarte, M.; García-Domínguez, A.; Medina-Bulo, I.; Alvarez-Ayllón, A.; SANTACRUZ, J. Takuan: a tool for WS-BPEL composition testing using dynamic invariant generation. In: Proceedings of the 10th international conference on Web engineering, Berlin, Heidelberg: Springer-Verlag, 2010, p. 531-534.

Papazoglou, M. P. Service -oriented computing: Concepts, characteristics and directions. In: Proceedings of the Fourth International Conference on Web Information Systems Engineering, Washington, DC, USA: IEEE Computer Society, 2003, p. 3.

Papazoglou, M. P.; Heuvel, W.-J. Service oriented architectures: approaches, technologies and research issues. The Very Large DataBases Journal, v. 16, n. 3, p. 389-415, 2007.

Papazoglou, M. P.; Traverso, P.; Dustdar, S.; Leymann, F. Service-oriented computing: a research roadmap. International Journal of Cooperative Information Systems, v. 17, n. 2, p. 223-255, 2008.

PARNAS, D. L. On the criteria to be used in decomposing systems into modules. Communications of the ACM, v. 15, n. 12, p. 1053-1058, 1972. 
Pressman, R. S. Engenharia de software. Rio de Janeiro: McGraw-Hill, 2002.

Pulier, E.; TAYlor, H. Understanding enterprise SOA. Greenwich, CT, USA: Manning Publications Co., 2005.

QUALIPSO Qualipso - Quality Plataform for Open Source Software, 2012.

Disponível em: http: //www.qualipso.org/

RAmsokul, P.; Sowmya, A.; RAmesh, S. A test bed for web services protocols. In: International Conference on Internet and Web Applications and Services, IEEE Computer Society, 2007, p. 16.

Rothermel, G.; HARrold, M. J. A safe, efficient regression test selection technique. ACM Transactions Software Engineering and Methodology, v. 6, p. 173-210, 1997.

Ruth, M.; Oh, S.; Loup, A.; Horton, B.; Gallet, O.; MAtA, M.; Tu, S. Towards automatic regression test selection for web services. In: Proceedings of the 31st Annual International Computer Software and Applications Conference, Washington, DC, USA: IEEE Computer Society, 2007, p. 729-736.

Siblini, R.; MAnsour, N. Testing web services. In: The 3rd ACS/IEEE International Conference on Computer Systems and Applications, 2005, p. 135.

SinHA, A.; PARADKAR, A. Model-based functional conformance testing of web services operating on persistent data. In: Proceedings of the Workshop on Testing, Analysis, and Verification of Web Services and Applications, New York, NY, USA: ACM, 2006a, p. 17-22.

SinHA, A.; PARADKAR, A. Model-based functional conformance testing of web services operating on persistent data. In: Proceedings of the Workshop on Testing, Analysis, and Verification of Web Wervices and Applications, New York, NY, USA: ACM, 2006b, p. 17-22.

SNEED, H. M.; HuAng, S. WSDLTest - a tool for testing web services. In: Proceedings of the Eighth IEEE International Symposium on Web Site Evolution, Washington, DC, USA: IEEE Computer Society, 2006, p. 14-21.

Souza, D. M.; Maldonado, J. C.; Barbosa, E. F. Progtest: An environment for the submission and evaluation of programming assignments based on testing activities. In: 24th IEEE Conference on Software Engineering Education and Training, Washington, DC, USA: IEEE Computer Society, 2011, p. 1-10.

SZYPERSKI, C. Component software: Beyond object-oriented programming. ACM Press/Addison- Wesley Publishing Co., 1998.

SzYPers KI, C. Component Software, Beyond Object-Oriented Programming. Component Software. Addison-Wesley, 2002. 
TARr, P. L.; OSShER, H.; HARrison, W. H.; JR., S. M. S. N degrees of separation: Multidimensional separation of concerns. In: International Conference on Software Engineering, 1999, p. 107-119.

Teixeira, V. S.; Delamaro, M. E.; Vincenzi, A. M. R. Uma estratégia para o teste de componentes utilizando a técnica de teste estrutural. In: 1st Brazilian Workshop on Systematic and Automated Software Testing, New York, NY, USA: ACM Press, 2007a, p. 7-12.

Teixeira, V. S.; Delamaro, M. E.; Vincenzi, A. M. R. Fatesc - uma ferramenta de apoio ao teste estrutural de componentes. In: Sessão de ferramentas - XXI SIMPÓSIO BRASILEIRO DE ENGENHARIA DE SOFTWARE, New York, NY, USA: ACM Press, 2007b, p. 7-12.

TSAI, W. T. Service-oriented system engineering: A new paradigm. IEEE Symposium on Service Oriented System Engineering, v. 0, p. 3-8, 2005.

Tsai, W.-T.; Chen, Y.; PAul, R. A. Specification-based verification and validation of web services and service-oriented operating systems. In: Workshop on Object-Oriented Real-Time Dependable Systems, IEEE Computer Society, 2005, p. 139-147.

TsAi, W. T.; GAO, J.; WeI, X.; ChEn, Y. Testability of software in service-oriented architecture. In: Proceedings of the 30th Annual International Computer Software and Applications Conference, Washington, DC, USA: IEEE Computer Society, 2006, p. 163-170.

Tsai, W. T.; Paul, R.; Song, W.; CAO, Z. Coyote: An XML-based framework for web services testing. hase, v. 00, p. 173, 2002a.

Tsai, W. T.; PAul, R.; WAnG, Y.; FAn, C.; WAnG, D. Extending WSDL to facilitate web services testing. In: Proceedings of the 7th IEEE International Symposium on High Assurance Systems Engineering, Washington, DC, USA: IEEE Computer Society, 2002b, p. 171.

VALLE, J. D. Faltam profissionais e sobram oportunidades em TI. Reportagem da revista VEJA DIGITAL., 2011.

Disponível em: http://veja.abril.com.br/noticia/vida-digital/ faltam-profissionais-e-sobram-oportunidades-em-ti

Vincenzi, A. M. R.; Delamaro, M. E.; Maldonado, J. C.; Wong, W. E. Establishing structural testing criteria for java bytecode. Software Practice \& Experience, v. 36, n. 14, p. $1513-1541,2006$.

Vincenzi, A. M. R.; Maldonado, J. C.; Delamaro, M. E.; Spoto, E. S.; Wong, W. E. Component-based software: An overview of testing. In: Component-Based Software Quality, 2003, p. 99-127. 
WANG, D.; LI, B.; CAI, J. Regression testing of composite service: An xbfg-based approach. In: Proceedings of the IEEE Congress on Services Part II, Washington, DC, USA: IEEE Computer Society, 2008, p. 112-119.

WANG, Y.; KING, G. A european COTS architecture with built-in tests. In: Proceedings of the 8th International Conference Object-Oriented Information Systems, London, UK: SpringerVerlag, 2002, p. 336-347.

WAnG, Y.; King, G.; Court, I.; Ross, M.; StaPles, G. On built-in tests in object-oriented reengineering. 1997.

Disponível em: citeseer.ist.psu.edu/wang97built.html

WANG, Y.; KING, G.; WiCKBURG, H. A method for built-in tests in component-based software maintenance. In: Proceedings of the Third European Conference on Software Maintenance and Reengineering, Washington, DC, USA: IEEE Computer Society, 1999, p. 186.

WeyUKer, E. J. Testing component-based software: A cautionary tale. IEEE Software, v. 15, n. 5, p. 54-59, 1998.

Wohlin, C.; Runeson, P.; Höst, M.; Ohlsson, M. C.; Regnell, B.; Wesslén, A. Experimentation in software engineering: an introduction. Norwell, MA, USA: Kluwer Academic Publishers, 2000.

Xu, W.; Offutt, J.; LuO, J. Testing web services by XML perturbation. In: Proceedings of the 16th IEEE International Symposium on Software Reliability Engineering, Washington, DC, USA: IEEE Computer Society, 2005, p. 257-266.

YAN, J.; LI, Z.; YUAN, Y.; SUn, W.; ZHANG, J. BPEL4WS unit testing: Test case generation using a concurrent path analysis approach. In: Proceedings of the 17th International Symposium on Software Reliability Engineering, Washington, DC, USA: IEEE Computer Society, 2006, p. 75-84.

Ye, K.; HuAng, J.; Gong, Y.; YANG, X. A static analysis method of WSDL related defect pattern in BPEL. In: Computer Engineering and Technology (ICCET), 2010 2nd International Conference on, 2010, p. 472-475.

YUAN, Y.; LI, Z.; SUN, W. A graph-search based approach to BPEL4WS test generation. In: Proceedings of the International Conference on Software Engineering Advances, Washington, DC, USA: IEEE Computer Society, 2006, p. 1-14. 